GLOBAL

ALLIANCE FOR THE

FUTURE OF FOOD

\title{
THE POLITICS OF KNOWLEDGE
}

Understanding the Evidence for Agroecology, Regenerative Approaches, and Indigenous Foodways

GLOBAL ALLIANCE FOR THE FUTURE OF FOOD 


\section{DISCLAIMER}

This document was commissioned by the Global Alliance for the Future of Food, for use by Global Alliance members and partners to stimulate discussion about critical issues related to food systems transformation and to help guide collective action. The Global Alliance has chosen to make it available to the broader community to contribute to the discussion about sustainable food systems transformation. It constitutes the work of independent authors; any views expressed in this document do not necessarily represent the views of the Global Alliance and any of its members nor the views or policies of the FAO.

Copyright @ 2021 Global Alliance for the Future of Food This work is licensed under a Creative Commons Attribution-NonCommercial 4.0 International License.

Suggestion for referencing: Global Alliance for the Future of Food, The Politics of Knowledge: Understanding the Evidence for Agroecology, Regenerative Approaches, and Indigenous Foodways. n.p.: Global Alliance for the Future of Food, 2021. 


\section{CONTENTS}

CONTRIBUTING TEAMS AND AUTHORS

FOREWORD 3

INTRODUCTION

KEY MESSAGES

SECTION 1: THE POLITICS OF KNOWLEDGE 10

Indigenous foodways 11

Agroecology 13

Regenerative approaches $\quad 15$

Historical context: The colonial legacy of industrial agriculture $\quad 16$

Embracing different ways of knowing: Today's opportunity 18

SECTION 2: THE QUESTIONS THAT HOLD BACK

FOOD SYSTEMS TRANSFORMATION 33

Question 1: Can these approaches feed the world? 34

Question 2: Can these approaches be scaled? 40

Question 3: Can these approaches provide meaningful livelihoods? 46

Question 4: Can these approaches solve the climate, biodiversity,

Question 5: Can these approaches accelerate transformation? 62

Ascendant narratives $\quad 67$

SECTION 3: MOBILIZING KNOWLEDGE AND EVIDENCE FOR

FOOD SYSTEMS TRANSFORMATION 29

The difference between intrinsic and extrinsic strategies $\quad 70$

The role of relationships in strategy $\quad 73$

$\begin{array}{ll}\text { Creative mobilization } & 75\end{array}$

SECTION 4: TOWARD A TRANSFORMATIVE RESEARCH
AND ACTION AGENDA: FIVE PRIORITIES

$\begin{array}{ll}\text { Priority 1: Support comparative and systems performance research } & 78\end{array}$

Priority 2: Explore questions of scale, time, and space 81

Priority 3: Build capacity for transdisciplinary and participatory research and training 82

Priority 4: Support knowledge and evidence mobilization and communication 83

Priority 5: Accelerate transformational pathways 84

CONCLUDING REFLECTIONS 90

APPENDIX: GUIDING QUESTIONS FOR THE CONTRIBUTORS 91

ENDNOTES

$\begin{array}{lc}\text { ACKNOWLEDGEMENTS } & 98\end{array}$

ABOUT THE GLOBAL ALLIANCE FOR THE FUTURE OF FOOD 99 


\section{CONTRIBUTING TEAMS AND AUTHORS}

Andhra Pradesh Community-managed Natural Farming (APCNF). Agroecology Evidence. Vijay Kumar, Swati Renduchintala, G. Muralidhar, Zakir Hussain. India.

Agroecology Research-Action Collective (ARC). Maywa Montenegro de Wit, Antonio Roman-Alcalá, Hannah Wittman, Molly D. Anderson, Alastair Iles, Vivian Wauters. North America.

The Christensen Fund. Hassan Roba. Multiple regions globally.

Ecdysis Foundation and Blue Dasher Farm (Ecdysis). Jonathan Lundgren. USA.

ENDA Pronat. Mariam Sow, Emile Frison. Senegal.

EnviroStrat. Cerasela Stancu, Brendan Hoare, Hugh Jellie, Jessica Hutchings, Nick Roskruge. New Zealand.

Agroecology Europe. Evidence on Agroecology. Alexander Wezel (INREA: French National Institute for Agriculture, Food and Environment), Elena Ambuhl, Stéphane Bellon (ISARA: Agro School for Life). Europe.

AgroEcology Fund (AEF). Evidence on Agroecology: For Whom and For What? Multiple regions globally.

Food and Agriculture Organization - Tool for Agroecology Performance Evaluation (FAO TAPE). From Narratives to Evidence Using and Testing a Comprehensive Tool Measuring Agroecology Transitions and Performance. FAO TAPE team and collaborating organizations): Louvain Cooperation, The University of Hong Kong, Food and Agriculture Organization of the United Nations, Dan Church Aid, Agroecology and Safe Food Systems Transitions in Southeast Asia Project, Farmers and Nature Net, Institut de Recherche et de Promotion des Alternatives en Développement. Cambodia and Mali: Amaury Peeters, Simon Croccel, Thida Kim, Dario Lucantoni, Abram Bicksler, Anne Mottet, with contributions from Celia Del Campo Aragonés, Rada Kong, Sokchhoin Kong, Mamadou Goïta. Multiple regions globally.

Groundswell International. Steve Brescia, Peter Gubbels, Christopher Sacco, Tsuamba Bourgou, Edwin Escoto, Gopal Kumar Nakarmi. Multiple regions globally.

The Indigenous Partnership for Agrobiodiversity and Food Sovereignty (TIP). Indigenous Responses to Food Production During COVID-19 Pandemic: Learnings from Yucatec Maya and NE India for the Design and Management of Sustainable Food Systems. Francisco J. Rosado-May, Bhogtoram Mawroh, Phrang Roy. India, Mexico.

Centro Latinoamericano de Investigaciones Agroecológicas (CELIA). Clara I. Nicholls, Miguel A. Altieri, Luis Vazquez, Marta Astier, Agustin Infante. Mexico, Colombia, Cuba, Chile.

McKnight Foundation Collaborative Crop Research Program (CCRP) Farmer Research Networks. Jane Maland Cady, Rebecca Nelson, Mary Richardson, Phoebe Larson. Multiple regions globally.

Palestinian Heirloom Seed Library (PHSL). Vivien Sansour. Palestine. 
Centre for Agroecology, Water and Resilience; Agroecology Now!; and University of Vermont Agroecology and Livelihoods Collaborative (CAWR-ALC). Seeing, Knowing and Mobilizing Agroecology for Food Systems' Transformations. Colin Anderson, Martha Caswell, Georges Felix, V. Ernesto Méndez, Nina Moeller, Michel Pimbert, Barbara Van Dyck. Multiple regions globally.

Institute of Rural Reconstruction of China (IRR-China). Socialized Ecological Agriculture and Alternative Food System in China: Understanding Agroecology in Agriculture Development. Southwest University Chongqing, Sources for Action Southeast Exchange Program China, and Food Think: Lanying Zhang, Ma Xiaochao. China.

Soils, Food and Healthy Communities (SFHC). Rachel Bezner Kerr, Laifolo Dakishoni, Daniel Kpienbaareh, Esther Lupafya, Lizzie Shumba. Malawi.

Lead Authors: Faris Ahmed, Margarita Fernandez, Lauren Baker, Samara Brock, and Amanda Jekums. 


\section{FOREWORD}

Profound changes in the way food has been grown, processed, distributed, consumed, and wasted over the last century have led to increasing threats to our food and ecosystems. The science is clear: Planetary boundaries have been surpassed or are being breached. The reality of climate change, species extinction, increasing globalization, demographic changes, shifting global economics, and growing corporate power make it apparent that threats to sustainability, equity, and security are escalating.

At this critical moment - with the planet increasingly on the edge of crisis, and the world's food systems highly imperilled - key debates about the future of food remain steeped in controversy. Indeed, the vast potential for agroecology, regenerative approaches, and Indigenous foodways to contribute to transformational change remains highly contested despite the vast body of evidence exposing the cracks in and failures of the industrialized food system. Many critical stakeholders - donors, scientists, and policymakers in particular — still choose to distance themselves from agroecology, voicing skepticism about its viability, profitability, and scalability; its ability to feed the world; as well as its perceived "ideological" nature.*

For almost a decade, the Global Alliance for the Future of Food has been committed to upholding agroecology, regenerative approaches, and Indigenous foodways, and advocating for their adoption, enablement, and implementation in global policy processes and many other forums. During this time, we have been asked repeatedly to defend the transformative potential of these approaches: "Show us the evidence." "We need more data." "We need science-based decision-making." We therefore seek to get to the root of this uncertainty and to deepen our collective understanding of what counts as evidence — for whom and to what end.

All too often claims about evidence - that it is clear or lacking, that the data is statistically valid or not — are used to undermine transformative action and create the mirage that solutions lie just ahead of us if we remain on our current path. This is because, beyond the surface of the commonly agreed refrain that food systems are not fit for purpose and that humanity cannot continue on its destructive path, there are powerful interests that continue to move the signposts that orient us toward the radical paradigm shift we urgently need and, instead, keep us locked in the status quo. This undermines the ability of the global community to advance solutions based on diverse ways of knowing and solid evidence.

The continued questioning about what evidence matters is, of course, intrinsically connected to power, with legacies of establishment thinking and colonial mindsets entrenching hierarchies of knowledge. The growing global efforts to advance agroecology, regenerative approaches, and Indigenous foodways therefore have much to do with social and political change and the ability to capture the imagination and attention of a wider concerned public.

\footnotetext{
*Based on five interviews conducted with donors/staff who fund agricultural programs and research to gauge their perspectives on agroecological and regenerative approaches and Indigenous foodways.
} 
The growing global efforts to advance agroecology, regenerative approaches, and Indigenous foodways therefore have much to do with social and political change and the ability to capture the imagination and attention of a wider concerned public.

In 2020, we set out to understand these dynamics and tensions. We asked 17 diverse contributor teams from around the world how they understand, document, and communicate evidence about agroecology, regenerative approaches, and Indigenous foodways. The result is this compendium - an effort to assess and showcase the wide range of evidence that already exists in abundance. In doing so, it supports the efficacy of agroecology and Indigenous and regenerative agricultural approaches. It also challenges the key issues related to the politics of knowledge that all too often keep these approaches from being understood, taken up, and acted upon - even when we need them most.

A salient takeaway from the synthesis of the Contributors' rich participation is that to mobilize the evidence for systems transformation, we must counter the dominant narratives holding back change but do so without "getting into the ring" defined by the forces that shape public discourse. The concerns and skepticism of some actors must be addressed while acting on the evidence that exists. Sadly, today's narrow focus on solely scientific evidence of food systems impacts, at the expense of insights from a diversity of actors and disciplines, also obscures systems interconnections and jeopardizes even the most well-intentioned actions.

So, for those of us working to transform food systems, our task then is to use our platforms and our means to amplify and validate other ways of knowing to overturn prevailing narratives, change how we act, and offer well-reasoned and compelling paths forward that can shift the needle of public concern toward political action. For a network of funders like the Global Alliance for the Future of Food, it means reasserting research as a public good and identifying pathways to enable agroecology, regenerative approaches, and Indigenous foodways to flourish. This process uncovered five priorities for a transformative research and action agenda where philanthropy, multilateral donors, researchers, and policymakers can play a uniquely impactful role when working in partnership with farmer and Indigenous People's organizations, civil society, the private sector, and others.

Ultimately, however - for all of us - the type of transformation we need to create a future of food that is sustainable, inclusive, equitable, and resilient involves reawakening the senses, and rekindling our relationships with our communities and with nature. We must channel the everyday acts of courage, imagination, ingenuity, and perseverance that farmers, food providers, women, youth, and Indigenous Peoples do, and turn them into forces for change.

We know from the evidence that it can be done.
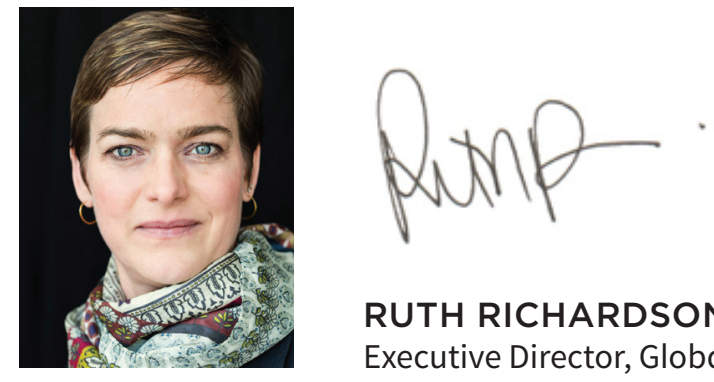

RUTH RICHARDSON Executive Director, Global Alliance for the Future of Food 


\section{INTRODUCTION}

For thousands of years, traditional Indigenous foodways have reflected a worldview grounded in principles of reciprocity that actively nourish health, culture, and nature. More recently, the modern science, practice, and movements of agroecology have drawn from and built upon Indigenous wisdom and expertise. Over the past decade, we've also seen elements of these traditional practices emerge in regenerative agriculture movements. Together, these approaches offer significant opportunities to advance healthy, equitable, renewable, resilient, inclusive, diverse, and interconnected food systems that are shaped by people, communities, and their institutions.

Many of the 30+ Global Alliance members actively support agroecology science, practice, and movementbuilding. Others, however, have valid questions about whether sufficient evidence exists to back up the claims made about agroecology and regenerative approaches. In January 2020, Global Alliance members met in San Francisco. The perennial questions over the existing evidence for agroecology, regenerative approaches, and Indigenous foodways were discussed. In the process, key tensions surfaced regarding how Indigenous foodways relate to agroecology and regenerative approaches, and how agricultural science, practice, and food movements co-opt or marginalize Indigenous histories.

To deepen our collective understanding, the Global Alliance looked across and beyond its networks and reached out to diverse experts to help us understand these complex issues. The result is this compendium, where accomplished Contributors join us to shed light on the robust and diverse body of evidence and knowledge that speaks to the ability of agroecology, regenerative approaches, and Indigenous foodways to transform food systems into more sustainable, secure, and equitable ways of living.

While evidence can motivate transformational change, it is not the only factor. Structural barriers, such as short-term thinking, cheap food, export orientation, and narrow measures of success, keep industrial food systems cemented in place. Breaking these structural barriers requires decolonizing and democratizing knowledge systems within education, research, and innovation. Narratives, communications, and mobilization strategies also play an important role in both catalyzing change and/or maintaining the status quo. Narratives and communications, however, are not always rooted in evidence, and there is often a tenuous connection between the evidence and decisions made. To understand these dynamics and tensions, we asked the Contributors to answer the following questions, among others (see the Appendix on page 91 for the complete list of questions):

1. How do you understand and document evidence?

2. What narratives, evidence, and audiences are the most important and compelling to you?

3. How do you communicate and mobilize evidence?

This compendium synthesizes the key insights shared by all of the Contributors.

Section 1 discusses the broader meaning of evidence, the power and politics that shape and infuse our understanding of evidence, what counts as evidence, the broad range of ways evidence is documented, and 
the historical, epistemological roots that shape our understanding of agroecology, regenerative approaches, and Indigenous foodways.

Section $\mathbf{2}$ is shaped by five dominant questions identified by the Contributors as contested ground in agroecology, regenerative approaches, and Indigenous foodways. In each we share evidence from their experiences and perspectives, whether academic, practical, farmer, Indigenous, scientific, social movement, or a combination. The five questions identified are:

1. Can these approaches feed the world?

2. Can these approaches be scaled?

3. Can these approaches provide meaningful livelihoods?

4. Can these approaches solve the climate, biodiversity, and soils crises?

5. Can these approaches accelerate transformation?

Section 3 provides insights into how evidence is mobilized across different constituencies — who is asking for evidence, for whom, and in what form? Two key findings are that: 1) different food systems actors (farmers, policymakers, and donors, for example) require different evidence; and 2) relationship-building with these different actors is a key strategy for mobilization.

Section 4 outlines five priority areas to catalyze a transformative research and action agenda that is transdisciplinary; is focused on political and social justice and the right to food and food sovereignty; and challenges entrenched power, vested interests, and structural lock-ins. These five priority areas are:

1. Support comparative and systems performance research;

2. Explore questions of scale, time, and space;

3. Build capacity for transdisciplinary and participatory research and training;

4. Support knowledge and evidence mobilization as well as communication; and

5. Accelerate transformational pathways.

There is no time to wait. Our Contributors shine a light on the deep reservoirs of knowledge and evidence in support of agroecology, regenerative approaches, and Indigenous foodways. There is also ample evidence about the negative impacts and escalating costs of industrial agriculture. Remaining questions should be addressed through a robust transformative research agenda that supports action, research, as well as evidence-building and mobilization in service of people and the planet. 


\section{ABOUT THIS COMPENDIUM AND ITS METHODOLOGY}

The Global Alliance for the Future of Food commissioned this compendium to gather and uplift the knowledge and evidence on agroecological and regenerative approaches and Indigenous foodways, recognizing that different forms of evidence, knowledge, and expertise are fundamental to shifting mindsets and the basis for action. It brings together the commonly held perspectives, narratives, questions, and gaps in these approaches, and explores ways to mobilize and elevate them to donors, researchers, and policymakers. Through this initiative, the Global Alliance, its members, and the contributing authors seek to better understand, synthesize, and mobilize the evidence base to create enabling environments for agroecology, regenerative approaches, and Indigenous foodways where supportive research, policy, and investments can flourish and benefit all.

This project engaged 17 contributing teams representing geographic, institutional, sectoral, gender, and racial diversity. They include organizations and networks of practitioners, researchers, farmers and food providers, Indigenous Peoples, and foundations working on food systems at the national and international levels. Via written reports, interviews, and video, they outlined the evidence and gaps, as well as provided important insights into to how we understand knowledge and evidence; they also gave robust recommendations for how best to address these gaps and mobilize the evidence. Both individual meetings as well as two group meetings provided space to gather and share about the project process and to foster a dialogue about the themes and messages emerging about evidence, narratives, and mobilization strategies.

As a full synthesis of the 17 contributions, this compendium contains key insights and case studies about the evidence provided - stories of documentation, approaches used, and mobilization strategies. Visit The Politics of Knowledge interactive for an overview of this compendium/work. A series of articles (forthcoming) will delve into specific issues, insights, and evidence presented by the Contributors.

This compendium is a starting point, and while it does not aim to cover all existing evidence, it serves as a key place to collect perspectives on how we understand the diverse body of evidence supporting the viability of agroecology, regenerative approaches, and Indigenous foodways and to boldly articulate a knowledge and research agenda to transform food systems toward greater sustainability, security, and equity. 


\section{KEY MESSAGES}

1. The roots of agroecology, regenerative approaches, and Indigenous foodways represent a continuous source of knowledge that can inform a repaired relationship between people and nature. The evidence in support of agroecology, regenerative approaches, and Indigenous foodways via research, science, practice, social movements, and policy arenas is manifold. Diverse forms of evidence, knowledge, and expertise - including lived experience and traditional knowledge as well as case studies, scientific analyses, and peer-reviewed literature - are fundamental to shifting mindsets and forming the basis for action. The principles underpinning these inherently diverse and intercultural processes of co-creating knowledge, which have existed for thousands of years, need to be central to efforts to transform food systems.

2. Evidence in support of agroecology, regenerative approaches, and Indigenous foodways exists in a battleground - one of many over knowledge and power. The politics of knowledge all too often keep these approaches from being understood, taken up, and acted upon, even when we need them most. A narrow view of what counts as evidence means certain kinds of expertise are elevated over others and a broad array of evidence is not considered, documented, published, or heard. Entrenched histories that uphold colonial and Western ways of thinking and knowing continue to invalidate certain forms of evidence about food systems. Without diverse evidence, we will see more solutions that are not contextually relevant and have potentially harmful, unintended consequences.

3. The political power behind the dominant narratives that marginalize agroecology, regenerative approaches, and Indigenous foodways influences the way that evidence is considered and legitimizes existing power relationships in food systems. These dominant narratives question traditional foodways' comparative performance regarding yield, scaling potential, economic viability, and ability to address the climate and environmental crises. These narratives keep agroecology, regenerative approaches, and Indigenous foodways at the margins, despite evidence demonstrating their power to drive transformational change.

4. The evidence that props up dominant narratives tends to be very narrow in focus, which limits a nuanced analysis and understanding of the multiple social, economic, and environmental impacts of distinct food and farming systems, effectively short-circuiting longer-term transformational goals. What we measure dictates where investments and policies are directed. Measuring success, performance, and resilience through a wider systems lens provides evidence on the multifunctional benefits of agroecology, regenerative approaches, and Indigenous foodways.

5. A diversity of evidence that demonstrates the transformative potential of agroecology, regenerative approaches, and Indigenous foodways already exists. However, it is not always available or accessible to audiences who are asking for evidence, nor is it in the format they require. Encouraging and embracing diverse forms of evidence to be generated, gathered, and communicated increases the legitimacy of agroecology, regenerative approaches, and Indigenous foodways and helps identify gaps that need to be addressed. Ascendent narratives with the power and potential to transform and reshape food systems are 
rising in the face of the multiple and overlapping global crises we face: climate change, growing inequality, food insecurity and malnutrition, and biodiversity loss.

6. The co-creation, exchange, and mobilization of knowledge and evidence creates new entry points to systemic transformation and needs to be harnessed to facilitate action across food systems. Evidence on its own does not catalyze change due to structural barriers, such as short-term thinking, cheap food, export orientation, and narrow measures of success, that keep industrial food systems locked in place. Unlocking these structural barriers requires changing our research, education, and innovation systems.

7. To accelerate systemic transformation that will build equitable, sustainable food systems, we need to decolonize and democratize knowledge systems within education, research, and innovation. Deep reservoirs of knowledge about agroecology, regenerative approaches, and Indigenous foodways are multifaceted, context specific, involve place-based ecological understanding, and reflect diverse ways of thinking about evidence. These ways of knowing and diverse forms of evidence are central to informing and democratizing our education, research, and innovation systems.

8. Participatory, transdisciplinary research and action agendas that bring together farmers, researchers, policymakers, donors, consumers, and other actors across food systems are key to leveraging food systems transformation. These research and action approaches and outcomes will provide contextually relevant evidence and open spaces to discuss and address issues of reciprocity, equality, justice, and power. This is enabled through transparent, honest, respectful alliances of key actors committed to food systems transformation.

9. The continued absence of robust and consistent policy, institutional, and financial support for agroecology, regenerative approaches, and Indigenous foodways must be addressed. Funding for long-term research and inclusive programs designed in partnership with farmers and food provisioners, Indigenous Peoples, and women must be a key priority.

10. Funders and donors must step up to catalyze a transformative research and action agenda that: 1 ) is transdisciplinary; 2 ) is focused on political and social justice and the right to food and food sovereignty, and 3) challenges entrenched power, vested interests, and structural "Iock-ins." A bold agenda that lifts up the following five priorities is required:

Priority 1: Support comparative and systems performance research

Priority 2: Explore questions of scale, time, and space

Priority 3: Build capacity for transdisciplinary and participatory research and training

Priority 4: Support knowledge and evidence mobilization and communication

Priority 5: Accelerate transformational pathways 
SECTION 1
THE POLITICS
OF KNOWLEDGE 
This compendium begins with a discussion about the broader meaning of evidence, the power and politics that shape and infuse our understanding of evidence, what counts as evidence, the broad range of ways evidence is documented, and the historical, epistemological roots that shape our understanding of agroecology, regenerative approaches, and Indigenous foodways. The Contributors emphasized that the roots of agroecology and regenerative approaches lie in Indigenous foodways. Intercultural processes of co-creating knowledge have existed for thousands of years, and these inherently diverse processes need to be central to efforts to transform food systems. Entrenched histories that uphold colonial and Western ways of thinking and knowing continue to determine whether certain forms of evidence about food systems are considered valid. This makes evidence documentation and mobilization — and action — inherently political.

Deep reservoirs of knowledge about agroecology, regenerative approaches, and Indigenous foodways are multifaceted, context specific, involve place-based ecological understanding, and reflect diverse ways of thinking about evidence. To accelerate systemic transformation that will build equitable, sustainable food systems, we need to decolonize and democratize knowledge systems within education, research, and innovation.

A narrow view of what counts as evidence means certain kinds of expertise are elevated over others and a broad array of evidence is not considered, documented, published, or heard. The Contributors illustrated how diverse forms of evidence, including lived experience and traditional knowledge, must be considered hand in hand with case studies, scientific analyses, and peer-reviewed literature as both robust and valid to inform decision-making.

We start with descriptions of the key terms used in this compendium: Indigenous foodways, agroecology, and regenerative approaches. These descriptions are not static but are evolving and dynamic. While significant differences and variations in the application of these terms exist, they also share many principles and practices in common.

\section{INDIGENOUS FOODWAYS}

With their long-established foodways, Indigenous Peoples have experiential knowledge, skills, and storytelling practices to share and teach, including ways of gathering food, observing changes, and paying respect to the Creator and her gifts. The complex agroecosystems that Indigenous, pastoral, forest, and coastal peoples have developed and/or inherited throughout centuries are the primary source of evidence. Such complex farming systems, forever adapting to local conditions, have helped smallholder farmers, animal keepers, fishers, and food gatherers to sustainably manage harsh environments and meet their subsistence needs without having to depend on mechanization, chemical fertilizers, pesticides, or other technologies of modern agricultural science. ${ }^{2}$

The White/Wiphala Paper ${ }^{3}$ on Indigenous Peoples' food systems was prepared by the FAO's Global-Hub on Indigenous Peoples' Food Systems in advance of the 2021 United Nations Food Systems Summit and outlines the following characteristics of Indigenous food systems. 


\section{CHARACTERISTICS OF INDIGENOUS FOOD SYSTEMS*}

\section{What is the problem?}

- Indigenous Peoples and their food systems, knowledge, and practices have been and continue to be marginalized in policy. Numbering over 476 million worldwide, Indigenous Peoples live in over 90 countries and 7 sociocultural regions. They often reside in sites of rich biodiversity and possess rich biocultural diversity and knowledge that has been preserved for generations. Their participation in the drafting and implementation of food policy is crucial to the future continuation of their livelihoods.

- Indigenous Peoples' food systems cannot be characterized according to dominant conceptualizations of food systems that are presented as linear value chains. Indigenous Peoples' food systems do not follow linear value chains and comprise different values, systems of governance, and cultural relations to food compared to value-chain-oriented food systems. Indigenous Peoples' food systems emphasize circularity, and comprise many ways of obtaining, preparing, storing, and sharing food.

\section{What are the main characteristics of Indigenous Peoples' food systems?}

- Indigenous Peoples' food systems are embedded in a biocentric approach that is intimately tied to nature. Compared to specialized, input-intensive systems of conventional food production, Indigenous Peoples generate a diversity of foods with minimal intervention on the ecosystems and make use of inputs endogenous to the local system. Indigenous Peoples' food systems are efficient in resource use, with little waste and wide circulation of resources. Material inputs tend to be fully used and recycled locally.

- Indigenous Peoples' food systems promote the equitable distribution of resources and power, and support Indigenous identities and values. Food-generative practices are often localized, making use of communal resources and supported by traditional governance systems. Exchange is often barter-based or founded on reciprocal agreements. Indigenous Peoples' lands, waters, and resources are often used, managed, or governed collectively as a common resource under community-based management. Indigenous Peoples' systems of collective ownership of resources and food sharing can thus support inter- and intra-community cooperation, the cultivation and maintenance of shared identities, and healthy, resilient, and culturally appropriate food systems.

\section{What can Indigenous Peoples' food systems bring to the debate?}

- Indigenous Peoples' knowledge, practices, and worldviews differ from Western science and provide a valuable contribution to current debates on sustainable food systems. While the value of Indigenous Peoples' traditional knowledge has been recognized, Indigenous Peoples' views, cosmovisions, time-tested practices, and relational values continue to be excluded in science and policy. By itself, the contribution of systemic observation carried by Indigenous Peoples' traditional knowledge is a tested scientific approach. The sensitive inclusion of Indigenous Peoples' traditional knowledge in policy will support the sustainable management of natural resources and transformation of food systems for all.

- Indigenous Peoples occupy over a quarter of the world's land, and their food systems can help to preserve global biodiversity. There is evidence that lands and forests managed and governed by Indigenous Peoples are able to resist forest loss and experience lower rates of land conversion than forests within protected areas and undefined national forests. Indigenous Peoples' communities have persisted as custodians of the planet's food and genetic resources.

- Indigenous Peoples' food systems provide nourishment and healthy diets. Indigenous Peoples' food systems make use of several hundred species of edible and nutritious flora and fauna, including traditionally cultivated crops, crop wild relatives, and animal wildlife (including bushmeat, marine mammals, insects, and fish). Indigenous Peoples' communities are feeling the effects of the dietary transition, with increasing consumption of highly processed foods a growing public health concern. With Indigenous Peoples already suffering higher rates of malnutrition worldwide than their non-Indigenous counterparts, supporting the continuation of Indigenous Peoples' food practices is important to future nutritional health.

\footnotetext{
*As outlined in the White/Wiphala Paper. FAO, "The White/Wiphala Paper on Indigenous Peoples' food systems” (FAO, Rome, 2021).
} 


\section{AGROECOLOGY}

Agroecology and regenerative approaches build on Indigenous holistic approaches and cosmologies or "cosmogonies." Agroecology is an approach to farming that seeks to mimic ecological structures and functions in agricultural landscapes in order to maximize provisioning, regulating, supporting, and cultural services for a sustainable agriculture and livelihoods. ${ }^{* *}$ It is an approach that actively couples traditional and Indigenous practices and knowledge systems with transdisciplinary sciences, recognizing the power of plural ways of knowing for local socioecological change. ${ }^{4}$ The field of agroecology has evolved from an early focus on farm ecology toward a more integrative study of the ecology of food systems ${ }^{5}$ using a systems-based, transdisciplinary, participatory, and action-oriented approach. ${ }^{6}$ However, agroecology is not just a science and on-farm practice, but also a social and political movement that seeks to transform the dominant industrial food model by researching, implementing, and advocating for socially just, economically fair, and ecologically resilient models. ${ }^{7}$ In recent years, the concept of agroecology has gained momentum within international governance bodies as an agrifood systems paradigm that more effectively addresses the problems of hunger, poverty, and inequality while curbing biodiversity loss and providing more resilience to climate change. ${ }^{8}$ Here we share two recent frameworks from the FAO and Committee on World Food Security's High Level Panel of Experts (HLPE) that encompass the complexity of the science, practice, and movement of agroecology through guiding principles.

The FAO's "Ten Elements of Agroecology" (see Figure 1) opened donor recognition and interest in agroecological transition and policies. These elements were further elaborated when the HLPE published their paper

\section{FIGURE 1: FAO'S TEN ELEMENTS OF AGROECOLOGY}

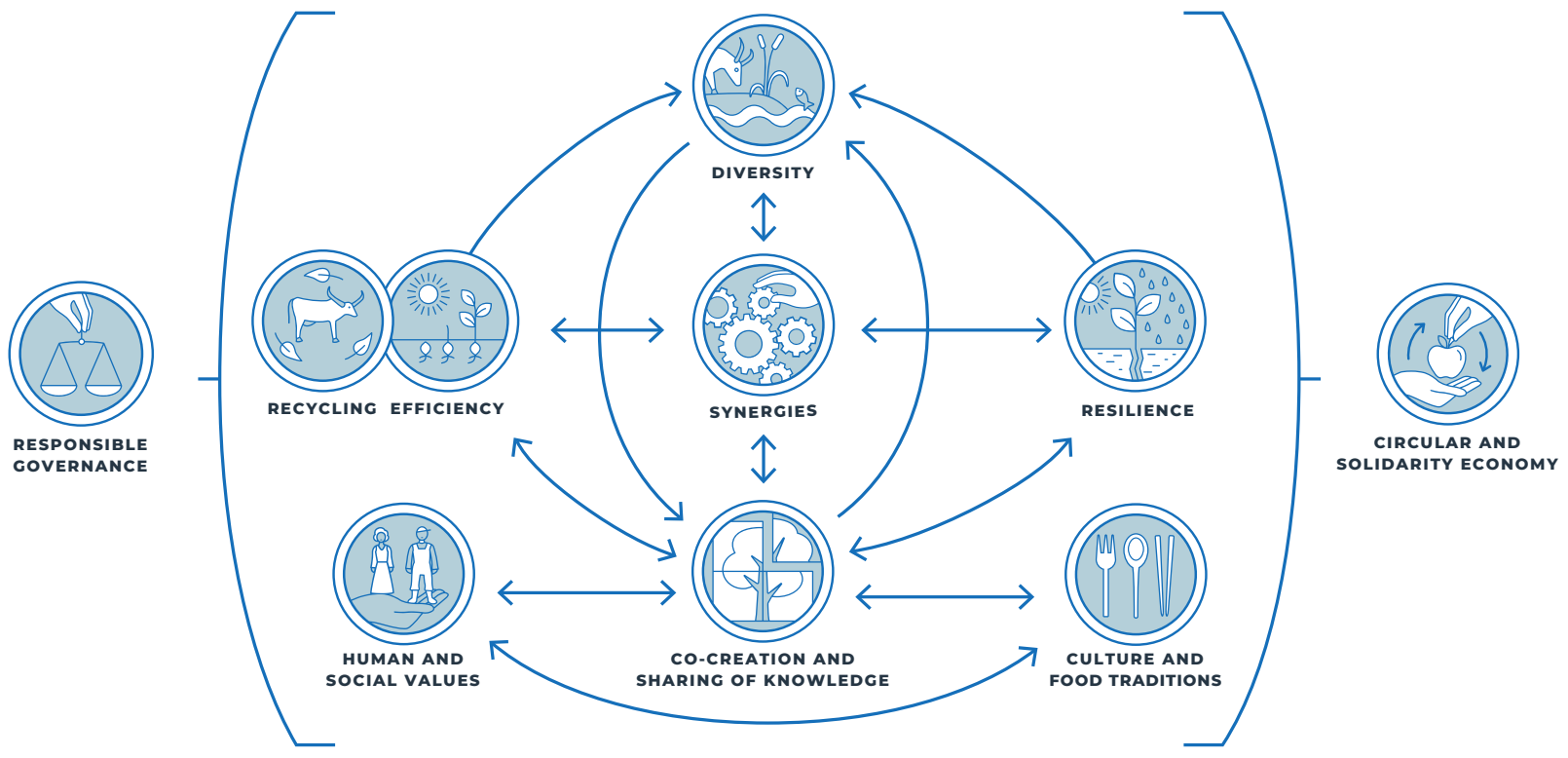

Source: FAO, "The 10 Elements of Agroecology” (2018). Website.

\footnotetext{
*According to Rosado-May, the Indigenous Peoples Hub at FAO has decided to use the word "cosmogonies" instead of cosmologies. Cosmogony refers to the set of spiritual beliefs, rites, religious practices, and customs that inform Indigenous Peoples' view of the ecosystem, nature, and the world. Spirituality/spiritual beliefs are an important feature of Indigenous Peoples' food systems. Cosmogony is used to refer to spiritual principles held by their societies that place the highest importance or emphasis in the universe or nature.
}

${ }^{\star \star}$ Agroecology as defined in the Oxford Encyclopedia (August 2021). Website. 
"Agroecological and Other Innovative Approaches for Sustainable Agriculture and Food Systems That Enhance Food Security and Nutrition" in 2019. ${ }^{9}$ The HLPE articulated 13 principles as key pathways in the transition to sustainable food systems (see Figure 2). These principles have been adopted by a wide range of donors and institutions.

FIGURE 2: KEY PATHWAYS IN THE TRANSITION TO SUSTAINABLE FOOD SYSTEMS

LEVEL 5 Build a new global food system based on participation, localness, fairness, and justice

LEVEL 4 Reconnect consumers and producers through the development of alternative food networks

LEVEL 3 Redesign agroecosystems

LEVEL 2 Substitute conventional inputs and practices with agroecological alternatives

LEVEL 1 Increase efficiency of input use and reduce use of costly, scarce, or environmentally damaging inputs
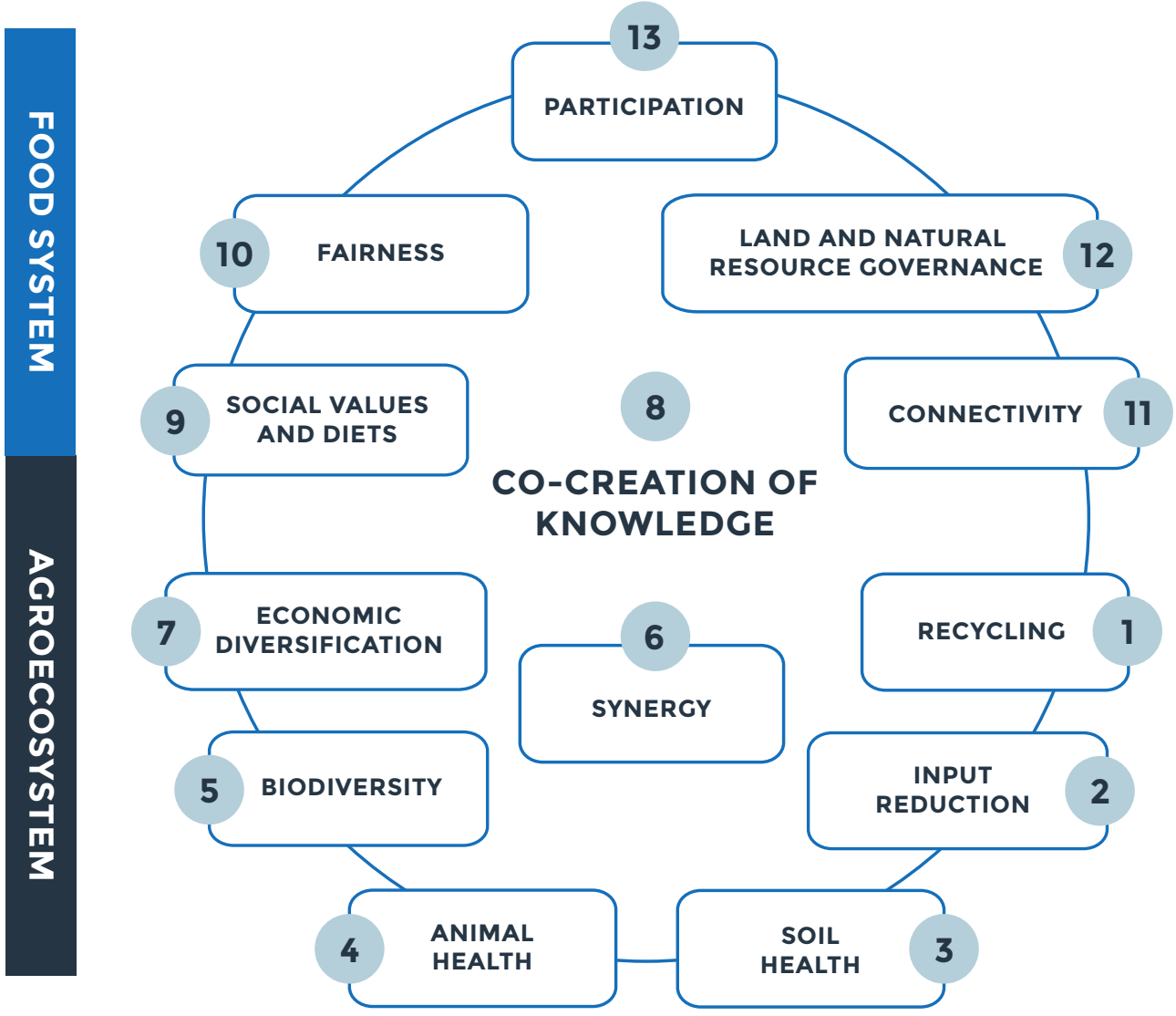

Source: HLPE, "Agroecological and Other Innovative Approaches for Sustainable Agriculture and Food Systems that Enhance Food Security and Nutrition," page 51 (2019). Website.

Agroecology is about cultivating a different relationship with the world around us, from which we draw our resources (living and non-living).

- AGROECOLOGY EUROPE 


\section{REGENERATIVE APPROACHES}

For the purposes of this compendium, we are using agroecology and regenerative approaches (instead of regenerative agriculture) with an acknowledgement that the foundation of these approaches lies in Indigenous food systems. While there are significant differences and variations in the application of these terms, they also share many principles and practices in common. For example, in a process led by IPES-Food, IFOAM Organics International, Agroecology Europe, FiBL, and Regeneration International in 2020 and 2021 , the organizations, along with over 800 signatories, found common ground across these terms by agreeing to uphold the HLPE'S 13 principles to guide food systems transformation (see Figure 2). ${ }^{10}$ As our Contributors have made clear, food systems approaches that aim to repair, regenerate, and transform our systems toward socioecological resilience must address the systemic issues of equity and power.

The FAO has endorsed definitions for "agroecology"11 and "sustainable agriculture"12 — both of which have been globally and politically accepted - but no universally accepted definition of "regenerative agriculture"13 exists to date. According to Regeneration International, regenerative agriculture "is a holistic land management practice that leverages the power of photosynthesis in plants to close the carbon cycle, and build soil health, crop resilience, and nutrient density."14 With a focus on addressing agriculture's contribution to climate change, regenerative practices: 1) contribute to generating/building soils and soil fertility and health; 2) increase water percolation, water retention, and clean and safe water runoff; 3) increase biodiversity and ecosystem health and resiliency; and 4) invert the carbon emissions of our current agriculture to one of remarkably significant carbon sequestration, thereby cleansing the atmosphere of legacy levels of $\mathrm{CO}_{2}{ }^{15}$

Regenerative agriculture is critiqued both for its lack of evidence, in part as a result of its weak definition, as well as its limited scope when it comes to on-farm practices, leaving the social, economic, and political issues of our food system unaddressed. The Contributors emphasized that regenerative agriculture is not interchangeable with agroecology, especially in today's iterations, in particular in the United States, where positive changes to soil management are being implemented but deeper structural problems in food systems related to equity, rights, and justice are left unaddressed. ${ }^{16}$

Omitting any mention of associated social and political transformation, regenerative agriculture can be seen as merely a reformist approach, which leaves it susceptible to greenwashing. Looking back at the work of Robert Rodale, an exponent of organic farming who coined the term "regenerative organic," it's interesting to note that both social and economic dimensions are included in his seven tendencies toward regeneration in agriculture: pluralism, protection, purity, permanence, peace, potential, and progress. ${ }^{17}$

The EnviroStrat contributors provided insight into these issues. Currently, there is no agreed-upon definition of regenerative agriculture in New Zealand. A recently published paper surmised that one of regenerative agriculture's distinguishing features is the holistic pursuit of continuous improvement across environmental, social, economic, and cultural outcomes. ${ }^{18}$ This is in line with the International Federation of Organic Agriculture Movements' (IFOAM) 3.0 vision, ${ }^{19}$ which emphasizes innovation, inclusiveness, consumer empowerment, transparency, and an outcomes-based approach. Despite the lack of definition or robust evidence for regenerative agriculture in New Zealand, the interest in the concept has been tremendous, driven by a swell of farmer and landowner interest, and propelled by a powerful yet simple narrative: consumers/markets are interested; it can help with low-carbon transition; and it is profitable. 
The EnviroStrat contributors noted that because the idea of regenerative agriculture emerged like a social movement, it also has political weight. The narrative that it is good for the environment, good for the consumer, and good for business has opened the door to allocation of government resources (science, extension, non-reimbursable grants) - particularly in the context of COVID recovery. The emerging consensus of the organic community in New Zealand and internationally is that regenerative agriculture is an expression of a set of principles and practices that have been espoused for eight decades by the wider organic community. The organic community accepts and encourages the exploration of these principles in order to create an overall transition strategy and regeneratively manage certified organic land, resulting in superior outcomes for people and the planet, and increasing land and business values.

\section{HISTORICAL CONTEXT: THE COLONIAL LEGACY OF INDUSTRIAL AGRICULTURE ${ }^{20}$}

A central theme that emerged from the Contributors was the importance of the historical context and legacies of colonial agriculture and global food regimes. When seen in the context of the evolution of agriculture, it becomes apparent that Indigenous foodways, agroecology, and regenerative approaches have a much greater time scale than industrial agriculture ${ }^{21}$ with its now well-documented negative impacts on nature, people, and society. ${ }^{22}$ The imposition of post-war industrial approaches, along with export orientation, led to the suppression of holistic approaches that have lasted for thousands of years. From China to Senegal, India to Mali, and across the Americas, diverse sustainable farming systems were replaced by modern, technologyintensive agriculture that privileged the production aspects of agriculture, giving rise to the extractivist paradigm "the Green Revolution," reflecting colonial mindsets.

Instead of starting from knowledge and local realities to continue to improve agriculture, we came up with innovations that uprooted everything, with unsustainable practices and a productivist model ... Cash crops like rice, groundnuts were introduced. The new model was introduced in a brutal way, without taking into account the existing one, without considering the negative impacts on the environment and human health. It is these production systems that uprooted the traditional system, which caused the populations to abandon all the traditional practices that helped to rebuild the soil health and fertility, in favour of large destructive monocultures. Most producers are still convinced that we can no longer produce without fertilizers and pesticides. We created a lot of hope by starting to talk about alternatives to agrochemicals, and gradually changing the mentalities of the communities.

- MARIAM SOW, ENDA PRONAT

As the Centro Latinoamericano de Investigaciones Agroecológicas (CELIA) explains, even before the Green Revolution began, scientists came to Mexico as early as the 1940s to explore how to modernize peasant agriculture to increase yields of grains. The perception of hunger and rural poverty was based on a Malthusian view of the world: Human population was growing exponentially, and food production could not catch up. Closing the gap between the growing population and food production, according to this view, could only be achieved through increasing grain yields by combining newly developed seed varieties — mostly wheat, maize, and rice - with heavy applications of fertilizer and carefully controlled irrigation. ${ }^{23}$ Increasingly, 
scientists and policymakers merged "development" and "modernization" narratives with "population bomb" and "feed the world" narratives to reinforce support for high external input agriculture while downplaying evidence of serious trade-offs and true costs. The Green Revolution later provided the impetus for a broadbased platform for policy advocacy that was adopted and perpetuated by major international donors and agricultural development programs.

Many Green Revolution projects have failed in their efforts to overcome hunger and malnutrition. ${ }^{24} \mathrm{~A}$ key reason cited is that focusing too narrowly on increasing crop yields to feed people does not adequately take into consideration the fact that hunger today is not so much a consequence of yields being too low or of global supplies being unable to meet demand. Rather, it is due to structural inequities in the food system: unequal distribution of resources; poor post-harvest handling and food distribution; lack of access to land; political strife; inequality; climate change; and other challenges. While the Green Revolution focused its efforts on the immediate benefits of increasing agricultural output through new technologies, it overlooked more significant environmental, political, economic, and social factors. ${ }^{25}$

The Green Revolution was never held to the standard of empirical evidence one would expect, as Agroecology Research-Action Collective (ARC) notes. Rather, the promotion of Green Revolution technologies was based almost solely on agricultural experiment station results. These systems of production were piloted and promoted with scant evidence of long-term food security, nutrition, or sustainability outcomes, and were massively supported with capital and public resources. Now that industrial agriculture technologies have "locked in"* and gained legitimacy, their negative impacts are coming to light and being documented. ${ }^{26,27}$

As our Contributors argued, the Green Revolution gave rise to a colonial form of science that marginalized traditional and Indigenous knowledge rooted in systems thinking. Instead, it elevated a positivist, reductionist approach to research and evidence that is poorly suited to addressing the systemic crises we face, let alone sustainably managing an agroecosystem. In the next section, we explore how different ways of knowing contribute to food systems transformation.

We advocate for an approach to "evidence" rooted in cognitive justice that recognizes the right of different forms of knowledge to coexist but add that this plurality needs to go beyond tolerance and into an active recognition of the need for and the value of diversity.

- CENTRE FOR AGROECOLOGY, WATER AND RESILIENCE; AGROECOLOGY NOW!; AND UNIVERSITY OF VERMONT AGROECOLOGY AND LIVELIHOODS COLLABORATIVE (CAWR-ALC)

\footnotetext{
*In their 2016 report "From Uniformity to Diversity," IPES-Food identified a series of lock-ins and systemic barriers that were referenced by a number of Contributors as a way to understand the political economy and power relationships that hinder the acceptance of agroecology and regenerative approaches.
} 


\section{EMBRACING DIFFERENT WAYS OF KNOWING: TODAY'S OPPORTUNITY}

The Contributors repeatedly emphasized that there are many ways of knowing, all equally valuable and necessary for food systems transformation. These ways of knowing are inherently intercultural, in exchange with one another, dynamic, and fluid. These include scientific knowledge, Indigenous knowledge, farmer and traditional knowledge, the knowledge held by civil society and community-based organizations, lived experience, and other ways of knowing that form the foundational knowledge base for agroecology, regenerative approaches, and Indigenous foodways.

What we value and measure is dictated by lived experience, cosmogonies, worldview, language, spiritual beliefs, cultural norms, ${ }^{28}$ and science. Contributors asserted that these ways of knowing exist within broader epistemological frameworks and provided robust examples of how research can build knowledge that serves the needs of people and planet.

An essential vision of agroecology and regenerative approaches, according to The Indigenous Partnership for Agrobiodiversity and Food Sovereignty (TIP), is interculturality. Agroecology and regenerative approaches were born as a result of an intercultural process in which different ways of learning, constructing, and passing on knowledge (for example, scientific and Indigenous) coexist in a safe environment, allowing conditions for synergies to happen with those interactions.

Along with interculturality goes the concept of co-creation of knowledge: different cultures and knowledgeholders working together, creating new knowledge. ${ }^{29}$ The McKnight Foundation's Collaborative Crop Research Program (CCRP) Farmer Research Network's definition of knowledge is instructive here, and includes scientific knowledge (frameworks, methods, and insights from different disciplines, drawing upon qualitative, quantitative, or mixed methods), and Indigenous or traditional/local knowledge (experiential, tacit, individual, and collective).

Through millennia, Indigenous foodways, and those who have practised agroecology and regenerative approaches, have developed time-tested methods to know, appreciate, and measure the richness, diversity, and abundance of their practices through different forms of expression. Agriculture, animal, and marine cultivation have evolved as vast bodies of knowledge through the accumulation of observation, experimentation, and adapting to biophysical and societal changes, mutual discourse, and sharing. As Rosado-May et al. see it, successful traditional farmers (whose food production systems are the result of centuries of experience passed from one generation to the next) apply ecological concepts in their practices; for example, allelopathy to control weeds and soil microbial population, multitrophic interactions in insect populations, or polycultures that are more productive per unit of area than monocultures. Each year traditional farmers design and manage their systems based on years of accumulated experience, maintaining the resilience of their food systems. ${ }^{30}$

Indigenous Peoples and non-Indigenous food systems, regardless of the method, can greatly benefit from an innovative approach; one that draws the best from traditional knowledge and from the scientific method behind conventional knowledge. This approach requires a safe space in which different ways of constructing knowledge coexist, giving opportunity for synergy to occur. This is called an intercultural process.

- THE INDIGENOUS PARTNERSHIP FOR AGROBIODIVERSITY AND FOOD SOVEREIGNTY (TIP) 
In the acts of growing and producing food, these ways of knowing have been intimately connected to diversity. The heterogeneity ${ }^{31}$ inherent in agricultural biodiversity, in diets around the world, in agricultural landscapes and ecosystems, in the methods of growing and gathering food, and in sociocultural dynamics and markets have continuously shaped the ways of knowing our food systems. ${ }^{32}$ For humans, nurturing and cultivating the biodiversity around us have been a matter of survival, a necessity for food security and health, an act of communion with nature, intimately connecting places and landscapes with knowledge and culture. The diversity of nature is to be savoured, celebrated, and remembered through culture, custom, and tradition. Heterogeneity in food - in plants, trees, fruits and vegetables, animals, and aquatic and microbial species is to be experienced by all the senses: seen, tasted, smelled, touched, and heard. It is embedded in ritual and spirituality, and inextricably tied to the act of cultivating, gathering, knowing, and sharing our food. Those who grow and gather food know that diversity matters and have worked since the dawn of agriculture to conserve, defend, and multiply the abundance of nature, ecosystems, and species around us.

The Contributors emphasized that agroecology, regenerative approaches, and Indigenous foodways are, first and foremost, about a different relationship with the world from which we draw our resources. This reflects an ecological worldview that reifies the living world and the complex dynamics of living beings, their interactions and interdependencies, and the coevolution of humans and animals, microbes, plants, and pests, etc., over time. It suggests a move away from worldviews that homogenize and reduce nature as separate from human beings. ${ }^{33}$

Agroecology and regenerative approaches are context specific, but their principles have general relevance. They enable us to orient processes, systems properties, practices, and performances to assess and strengthen resilience. ${ }^{34}$

Western science and financing structures too often exclude and/or ignore other forms of knowledge, tending toward simplification, generalization, and reducing complexity. ARC, like many of the Contributors, places an emphasis on broadening the field of knowledge and evidence beyond the dominant scientific assessment model, and countering the hierarchy of evidence, which is highly controlled, reductionist, and privileges quantifiable science over qualitative and transdisciplinary knowledge approaches. ARC stresses the importance for agroecologists to lay claim to this territory, instead of crossing into the terms that industrial food systems have set through their power. ${ }^{35}$

ARC invokes epistemological pluralism (many kinds of knowledge are needed), while critiquing current scientific methods that paint an incomplete or biased picture about the practice and potential of agroecology. ${ }^{36}$ Similarly, Centre for Agroecology, Water and Resilience; Agroecology Now!; and University of Vermont Agroecology and Livelihoods Collaborative (CAWR-ALC) invoke the concept of epistemological justice to underline that not being inclusive of different ways of knowing is a form of injustice. ${ }^{37}$ The Contributors highlighted that the nature, origin, and scope of knowledge, belief systems, and the epistemic justification for food systems transformation all play a central role in how we understand and mobilize the evidence for agroecology, regenerative approaches, and Indigenous foodways in support of food systems transformation.

The importance of local knowledge in agroecology thus requires a shift from a knowledge approach dominated by Western science to one where local, traditional, and Indigenous knowledge is viewed as equally 
important and are integrated in transdisciplinary agricultural knowledge systems. The capacity to know agroecology is only possible through a complex process centred around social learning and is developed through networks of "diverse actors as a group in collective, practical research and knowledge exchange." ${ }^{\text {"38 }}$

\section{What constitutes evidence?}

What constitutes evidence is a subjective matter influenced by a person or group's epistemology, or what they consider to be valid knowledge. The Contributors articulated that combining information from diverse ways of knowing, in particular coupling Western science with local, traditional, and Indigenous forms of knowledge through transdisciplinary processes, contributes to rigorous evidence that is contextually relevant. This is particularly important in the context of agroecosystems where long-term, intimate relationships between people and nature offer a deep reservoir of experiential knowledge and wisdom that must be valued.

There are multiple forms of valid evidence, and these need to be linked with particular attention paid to traditional or local knowledge (that is, not subordinating traditional or local knowledge under scientific knowledge). Contributors emphasized the importance of locally relevant, transdisciplinary, inclusive, and systems-based research that aims to recognize the intersection of ecological, health, social, and economic outcomes. Contributors articulated the importance of the co-creation of innovation processes inclusive of traditional, farmer, Indigenous, and scientific knowledge, as well as noted that all contribute to produce relevant evidence, with many examples provided across the contributions.

One such example is the Collaborative Crop Research Program (CCRP) of the McKnight Foundation. CCRP works to produce evidence that includes data and information on what works (for example, for farmers managing a specific pest) as well as evidence that illustrates how change happens. This latter type of evidence relates to the broader experiences and understandings that can support changes in policy and practice, such as how agroecological markets develop, how national programs support public research (for example, what kinds of leadership training can shift the way institutions support change), and what people think is possible and desirable. Ideas about evidence evolve over time, through the ongoing efforts, innovation, creativity, and curiosity of farmers and those who support them: researchers, field staff, support organizations, and others.

CCRP supports building evidence through processes that often bridge different ways of knowing. In other words, research is not done only by scientists, and evidence is not produced exclusively in a positivist research paradigm. We strive to bring into dialogue different forms of knowledge (aka "knowledge mutualism" or "epistemological pluralism"). Relevant types of knowledge include scientific knowledge of diverse disciplines, as well as local knowledge (for example, Indigenous and traditional knowledges).

- COLLABORATIVE CROP RESEARCH PROGRAM (CCRP) 
The Soils, Food and Health Communities (SFHC) Malawi project team outlines what constitutes evidence in their work: ${ }^{39}$

1. Information gathered using established scientific research that uses acceptable research design, methods, and measures/indicators, measured empirically;

2. Grey literature including reports by governments and institutes;

3. Farmer stories, perspectives, and experiences, shared orally;

4. Visual evidence - field visits, observations, photographs, maps, and videos that provide visual materials; and

5. Speeches, news stories, and documents that provide evidence for changes in policy and narratives that influence policy.

CELIA outlines two predominant disciplinary approaches that generate scientific evidence in agroecology. The first approach, largely grounded in natural science research, focuses on the analysis of ecological processes at the farm and landscape levels that generate information on agronomic and ecological processes important for improving the management of agroecosystems and their surrounding environment. The second approach sees agriculture as a complex socioecological system examining broader social, cultural, and political issues of the agrifood system. This socioeconomic and cultural dimension is centred on the endogenous development of rural communities, and the political dimension centres around the construction of alternatives to industrial agriculture through collective action.

According to CELIA, although the influence of agronomic and ecological disciplines has strongly shaped agroecological thought, the field has evolved through participatory methodologies and transdisciplinary research incorporating social science perspectives and local forms of knowledge. This more systemic and integrated approach is also evident in both the participatory resilience assessments methodologies carried out by many organizations ${ }^{40}$ and the assessment tools developed by larger institutions to assess the performance of agroecosystems, such as the FAO's Tool for Agroecology Performance Evaluation (TAPE).

Agroecology requires an approach to knowledge that transcends compartmentalized, reductionist, market-led, and elitist knowledge systems in favour of bottom-up, people-led, holistic, and transdisciplinary approaches to knowledge and wisdom.

- CENTRE FOR AGROECOLOGY, WATER AND RESILIENCE; AGROECOLOGY NOW!; AND UNIVERSITY OF VERMONT AGROECOLOGY AND LIVELIHOODS COLLABORATIVE (CAWR-ALC)

In Latin America, CELIA identify three currents of thought around agroecology, each generating its own type of evidence: ${ }^{41}$

1. Scientific agroecology focuses on research in ecological processes and multifunctional design of agroecology at the farm and landscape scale. Topics include the role of biodiversity in the biological control of pests, weeds, and disease; soil fertility; and the impact of diversification (polycultures, agroforestry systems, productivity, and resilience to climate change). 
2. Practical agroecology focuses on documenting practices that avoid use of chemical and high-energy inputs, making use of the emergent properties of the whole farming system (that is, recycling nutrients, building the soil organic matter, preserving agrobiodiversity and resources, etc.). These studies are conducted on farmers' fields or field experiments but extend to research on land tenure, community seed banks, solidarity markets, and other community-based social innovations such as knowledge sharing via collective pedagogical methods (for example, Campesino a Campesino exchange ${ }^{42}$ ).* Significantly, these action-research approaches have forced a redefinition of agroecology beyond the farm, to include the social, cultural, landscape, and political/transformative dimensions, and demand systemic solutions/actions at multiple scales.

3. Political agroecology, a more radical current, draws attention to power relations such as class and gender, which underlie inequitable access to natural resources, and which produce ecological degradation and erode human rights. Political agroecology is concerned with broader food systems, especially the conventional agrifood system dominated by large corporations, market ideologies, and governments. Whereas the study of agroecology in Latin America began with biophysical and ecological concerns, a broader political economy of food systems focus has enabled the dovetailing of agroecology with food sovereignty and transformative approaches.

Adopting a broader, more complex, and nuanced approach to knowledge production can be challenging, as it takes more time, requires special skills, and can be harder to communicate in the usual scientific/academic fora.

- COLLABORATIVE CROP RESEARCH PROGRAM (CCRP)

In summary, what constitutes evidence depends on both who is asking and what they are asking. A farmer may well be more satisfied with evidence that they see on a neighbour's farm than with a global meta-analysis peer-reviewed article. In reflecting on what constitutes evidence, the Contributors emphasized the importance of democratizing the way research is carried out, both in terms of the methodologies and processes and also in terms of what is being measured in order to produce contextually relevant evidence. This includes a focus on farmer agency, where farmers can define and run their own experiments, and where farmer-to-farmer exchanges serve to share evidence. Contributors also stressed a focus on participatory processes that link different actors in the co-creation of knowledge that builds evidence by and for those most affected. These approaches are guided by the principles of collaborative research, accountability, equity, transparency, ethical conduct, and reciprocity. Furthermore, these approaches can serve as a means to explore and address issues of inequality and power differences among participating actors and actors in the food system.

\footnotetext{
*The farmer-to farmer knowledge-sharing methodology is also carried out by Schola Campesina in their farmer-led training programs (see their website).
} 


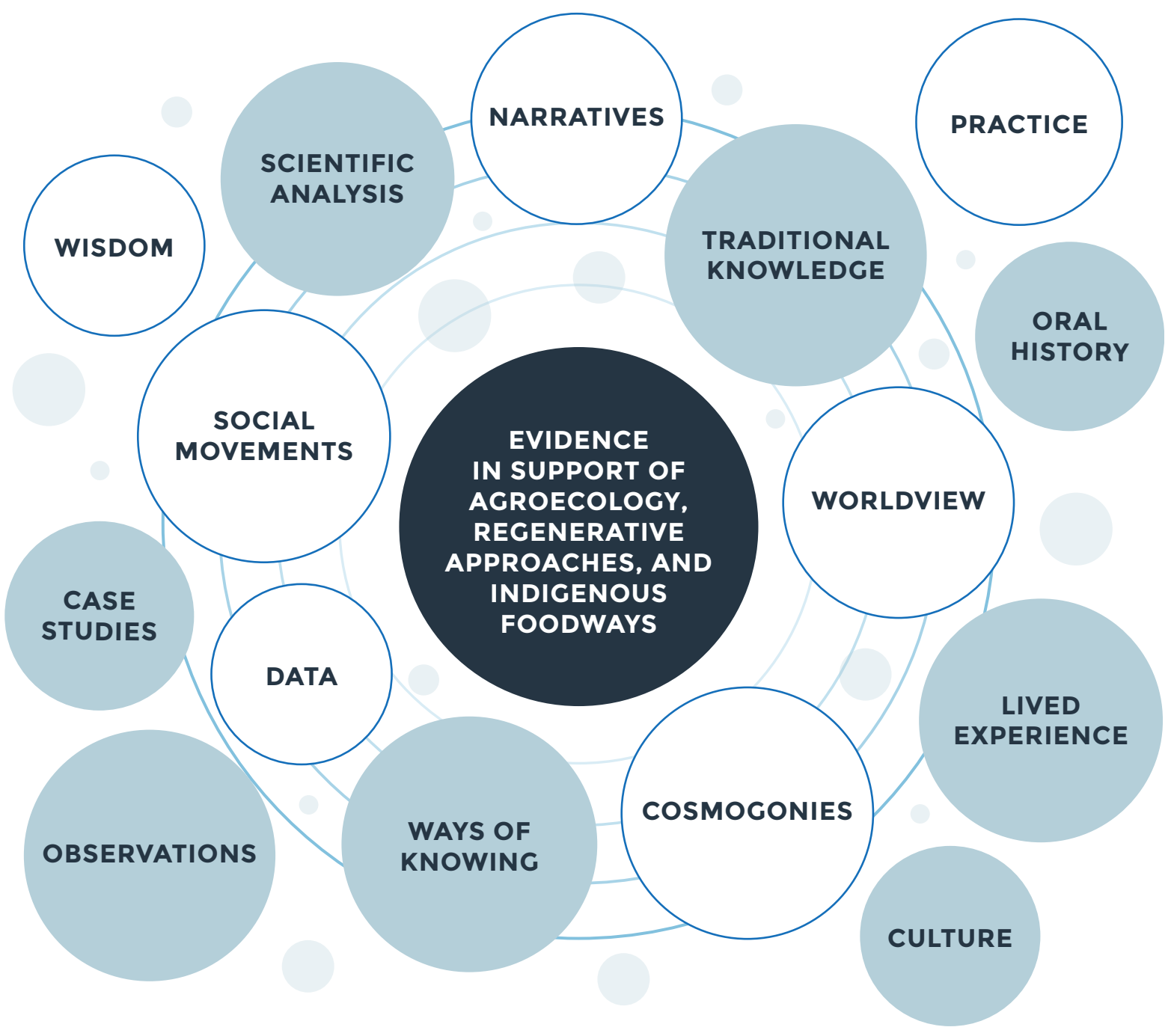




\section{CASE STUDY: EVIDENCE ON AGROECOLOGY: FOR WHOM AND FOR WHAT?}

\section{Agroecology Fund}

Agroecology is attracting growing interest from multilateral agencies, the academic community, policymakers, funders, and consumers. With this visibility comes a demand for evidence that agroecology does indeed provide solutions to the socioeconomic and environmental crises generated by the way we produce, process, market, and consume food. In most cases, "evidence" is currently a synonym for "scientific research that can be used to convince policymakers."

Generating and disseminating evidence to amplify agroecology was a critical discussion at a global Learning Exchange ${ }^{43}$ organized by the Agroecology Fund (AEF) in India, in February 2020. Three urgent priorities emerged from discussions among AEF's grantees, funders, and allies: 1) the need for a new narrative of what constitutes evidence; 2) the need for evidence-gathering to be participatory and creative; and 3) the need for AEF to offer financial resources to grantees for gathering and disseminating evidence for agroecology.

The AEF embraced these recommendations and partnered with Statistics for Sustainable Development (Stats4SD) to launch the Grassroots Evidence for Agroecology (GEA) initiative, which turns traditional evidence methods on their head. The main GEA objective in the 2021 pilot stage is to support grassroots organizations to document and communicate evidence about the agroecological solutions they are building on the ground. That is, they identify the evidence they need to convince their target constituencies to change behaviour, whether farmers or policymakers. The research and evidence agenda is not externally imposed. GEA's approach is that evidence is not a synonym for data or information. While good information derived from science, monitoring and evaluation, testimonies, etc., is a foundation of evidence, they are to be considered building blocks and applied to decision-making along with other forms of knowledge and evidence.

In the GEA pilot phase, four collaboratives that had received grants from the AEF are participating in this evidence co-creation process with Stats4SD's accompaniment. The cases are varied, from examining diversified traditional markets as income support in Kenya to a knowledge exchange approach as a way for getting better soil management in Mexico. The methodology for building the evidence-based cases involves the steps described in Figure 4. The approach asks: What is the desired change and what are useful entry points? The methodology has been tested and improved by the organizations involved. This has resulted in two fully developed cases and three more cases in progress that will be disseminated at the beginning of 2022.

The results of this pilot with Stats4SD and grantees will guide AEF's future actions on how best to support organizations in documenting and communicating evidence on agroecology. Many agroecological solutions are being applied on the ground by grassroots organizations across the world. It is time to make those solutions more visible, as demonstrated local champions. AEF's belief is that when organizations and networks embedded in agroecology movements own the evidence process and can convincingly present cases that move their constituents and targets, we will see sharp advances in amplifying healthy and resilient food systems. 


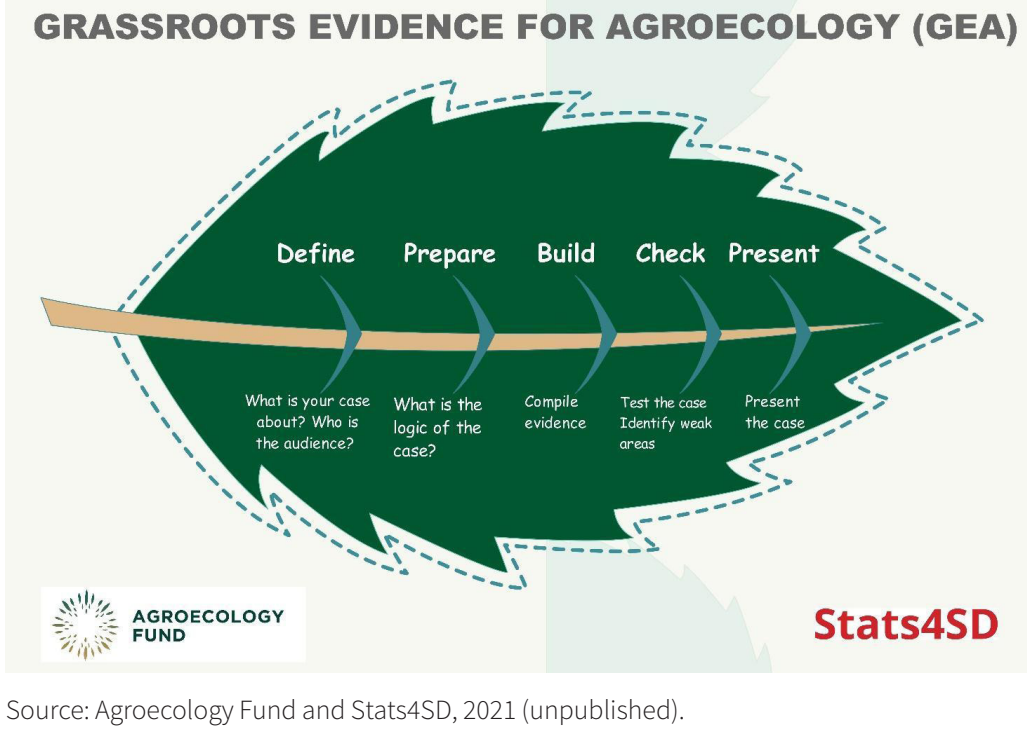

\section{Whose evidence counts?}

In a world mediated by the power of knowledge, evidence encompasses the deliberate act of seeking, organizing, and presenting information based on one's worldviews and epistemological precepts. The evidence in support of Indigenous foodways, agroecology, and regenerative approaches coming from research, science, practice, social movements, and policy arenas is manifold, yet it exists in a battleground one of many over knowledge and power.

Evidencing agroecology is just one fraught front in a broader battlefield over knowledge and power, which is entangled in even more profound material and immaterial struggles. As we engage in the political process of producing, communicating, and mobilizing evidence, we cannot lose sight of these limitations, and must strategize about how to engage in "evidencing" as part of a more complex theory of change.

- CENTRE FOR AGROECOLOGY, WATER AND RESILIENCE; AGROECOLOGY NOW!; AND UNIVERSITY OF VERMONT AGROECOLOGY AND LIVELIHOODS COLLABORATIVE (CAWR-ALC)

Whose evidence counts? Why does some evidence take precedence over others? What are the assumptions and choices behind this? And what can evidence reveal or conceal? The Contributors were emphatic that evidence-making is not merely a technical exercise. As CAWR-ALC put it, what counts as evidence, and what evidence is mobilized for, are highly contested processes, deeply shaped by different kinds of power relations. Research on knowledge use and evidence mobilization shows that evidence influences policy choices in many different ways, not just to provide knowledge for problems to be solved. For example, evidence can be used as munition to support decisions or to avoid responsibility for unpopular decisions. ${ }^{44}$ 
Farmers, advocates, researchers, scientists, and others are asking urgent and existential questions, imploring decision-makers to heed the existing evidence. Proponents of agroecology, regenerative approaches, and Indigenous foodways are often told: "Show us the evidence." "We need more data." and "We need science-based decision-making." This compendium is an effort to showcase the wide range of evidence that exists in support of the efficacy of these approaches. It also aims to illuminate key underlying issues related to the politics of knowledge that often keeps these approaches from being understood and taken up. This underscores the importance of upholding diverse knowledge systems and reshaping evidence-making to contribute to systems transformation. ${ }^{45}$ Insights on the politics of knowledge and evidence synthesized from the Contributors include:

Hierarchies of evidence: In Western science, certain kinds of expertise and scientific disciplines are elevated over others. Many benefits of diverse, agroecological, and regenerative approaches are complex and difficult to quantify, in part because they are slow, long-term processes. Easily quantifiable data is often given preference over more complex systems dynamics that are harder to assess. This bias also operates to exclude other knowledge sources, such as traditional and Indigenous knowledge. In addition, the financing structures of research often mean that commercializable products receive funding, whereas innovations that are social and ecological in nature often struggle to gain wider recognition and resources. The Contributors emphasized that the problem is not Western science per se but rather the power structures that elevate it over and above other forms of knowledge in the evidence-building process.

Distrust of science: Those who have been historically marginalized, whose ways of knowing have been disregarded and misused, may have a distrust of science, especially when it has been practised as an instrument of oppression. The Contributors recognized this reality and the understandable skepticism that sometimes exists. Robust examples of how research can build knowledge that serves the needs of people and planet were provided, as illustrated in the sections that follow. The Contributors, through their on-the-ground work and research, demonstrated that co-created research and knowledge is possible, as is building evidence by and for those most affected (farmers, their families, and communities) that is grounded in principles of inclusion, equity, and respect for situated knowledge. ${ }^{46}$

English language bias: There is a substantial amount of published scientific evidence that goes unnoticed by English speakers, as it has been published in other languages - much of it in the Global South and Majority World. This includes documents and/or scientific articles and grey literature, academic theses, technical and conference reports, articles not in English, and reports or stories in local newspapers or magazines. ${ }^{*}$ This is in addition to the vast number of unpublished testimonies and real cases from successful agroecological farmers, agricultural and food-producer organizations, and related institutions.

For example, one of Miguel Altieri's first books on agroecology was published in Spanish in 1983 and translated soon after to Portuguese. There is a long history of this literature on agroecology in Latin America and Spain, and articles documenting this can be found in the journal Agroecology and Sustainable Food Systems. The magazines LEISA and CLADES have decades of documentation on the experiences, successful systems, and

\footnotetext{
*Rosado-May offers an illustration by mentioning the international meeting of the Mexican Society of Agroecology (2019) with numerous (non-English language) conference papers and discussions on various aspects of agroecology as a science, movement, and practice.
} 
practices of agroecology — often using non-Western framings of knowledge and experiential learning. ${ }^{*}$ The majority of this literature has gone unnoticed in the United States and Europe. As Altieri et al. show, between 2011 and 2018, 3120 Spanish language scientific papers were presented at SOCLA (Latin American Scientific Society for Agroecology) events and conferences alone. Three main categories account for almost half of the contributions: 1) agroecology and organic production; 2) agroecology, research, and pedagogy; and 3) traditional/agroecological knowledge. ${ }^{47}$

Evidence itself: As the meaning of agroecology and its definition are vast and contested, there are competing interpretations that range from a transformative agroecology to a technocratic understanding of agroecology. ${ }^{48}$ The evidence for agroecology as a technical practice is very different from the evidence for agroecology that acknowledges its complex social, cultural, political, ecological, and economic dimensions. Furthermore, transformative agroecology considers evidence one small (and fraught) part in a process of social transformation. As evidence often reflects a narrow, reductionist, and depoliticized approach, fixating on evidence is itself a mode of reshaping agroecology in ways that many argue reflect a process of co-optation. ${ }^{49}$

As articulated earlier, the Contributors strongly critiqued the positivism embedded in evidence framing and gathering. As ARC notes, science has been reduced to quantitative metrics and data. ARC raised the notion of reconstituting evidence-making to include the critical "immaterial territory" in the cognitive landscape that agroecologists and industrial food proponents are battling over. They suggest it is important for agroecologists to lay claim to this territory instead of crossing into the terms that industrial food systems have set through their power.

The science, technology, and policies that have mobilized around the industrial food system have helped entrench a knowledge regime that is widely perceived as much more legitimate and credible than agroecology, despite its many environmental and social problems. ${ }^{50}$ From a decolonial Indigenous perspective, an "evidence" pursuit for legitimizing agroecology looks potentially absurd. Demanding that people produce particular forms of scientific evidence to show that agriculture works does not take into account the evidence for ways of producing and gathering food that has kept the planet fed for 10,000 to 12,000 years. ${ }^{51}$

Evidence, power, and legitimacy: Power can be exercised by framing issues in certain ways, by legitimizing some knowledge producers and processes over others, by defining the problems that need solutions, or through accounts of reality that promote one vision over others. ${ }^{52}$ The many different ways of mobilizing evidence can gear decision-making processes toward opening up to a plurality of possible foodways and commitments to diverse food systems or, on the contrary, contribute to narrowing the field of options and promoting the idea that only one way forward exists, that is, capital-intensive industrial agricultural intensification.

\footnotetext{
* LEISA, a journal on low external input sustainable agriculture, was originally established in Peru and went on to become Farming Matters. CLADES was a major journal that no longer exists. See also videos describing early agroecological experiences in Chile (1993): https://www.youtube.com/watch?v=6-hWQK_vlnE, and another describing agroecology in the United States (1998): https://www.youtube.com/watch?v=Poq8Cr-tW5w\&t=73s; as well as Miguel Altieri's overview of sustainable agricultural systems design in Latin America: Fabian Banga, "Agroecología en Acción," YouTube, January 15, 2016, https://www.youtube.com/watch?v=6-hWQK_vInE.
} 
Understanding how framing can narrow or widen our field of vision reveals how evidence mobilization influences decision-making - and how power can uphold the most commonly seen narratives while suppressing or even silencing alternative solutions and foodways that also exist. ${ }^{53}$ There are many situations where the evidence for a particular trajectory, technology, or pathway are robust (for example, cover cropping) but has yet to be adequately supported because it lacks "thick legitimacy." In contrast, there are many cases where robust evidence against a technology, or product (such as tobacco), or development pathway (such as fossil fuel-based agricultural intensification) is ignored or buried. Evidence can be cherrypicked, obfuscated, or manipulated to serve political goals. For example, the call for more evidence in the face of criticism has been a preferred strategy used by industry to sow doubt when confronted with questions around the safety of tobacco, the impacts of pesticides, the desirability of genetically modified organisms, the link between cardiovascular disease and sugar, and, currently, on climate change. ${ }^{54}$

ARC points out that evidence gathered and rendered visible in industrial agricultural regimes is often in a form that can be readily turned into a commodity value. For example, genetically modified seeds, climate-soil data, and GPS-equipped farm equipment are equally also forms of intellectual property that companies can enclose and commodify. ARC concludes that different approaches to gathering evidence reflect different pathways to power or theories of change, and shape how support for agricultural development and agroecological transitions happen.

The Contributors questioned how evidence is positioned within the broader global dialogue about systems transformation. While policymakers and researchers fixate on gathering evidence, most evidence fails to capture the full depth and breadth of existing knowledge. Power and politics are central to defining, collecting, reporting, and acting on evidence. In summary, the evidence in support of Indigenous foodways, agroecology, and regenerative approaches coming from research, science, practice, social movements, and policy arenas is manifold. Understanding how evidence is mediated by knowledge and power, how it gains and loses legitimacy in the eyes of different actors, is an important part of knowledge generation and evidence-building.

\section{What diverse evidence reveals}

In light of this contested ground, many ways of knowing don't count as evidence, seldom get measured or heard by those outside local communities where evidence is generated, and rarely appear in reports or publications. How and what farmers and food providers know of their ecosystems, their variability and dynamism, often fails to count as evidence - and therefore gets neglected in agricultural research, policies, and development programs. This means that agroecology, regenerative approaches, and Indigenous foodways are overlooked in discussions about food systems transformation. Beyond counting as legitimate evidence, seeing what matters is crucial for food systems transformation.

The Contributors pointed to the vast evidence that exists for agroecology, regenerative approaches, and Indigenous foodways in various fields of knowledge. This includes evidence on farm viability, income and

\footnotetext{
* "Thick legitimacy" is when people accept a certain model of agriculture as credible and authoritative, creating consent for their use and existence. (See Maywa Montenegro de Wit and Alastair lles, "Toward Thick Legitimacy: Creating a Web of Legitimacy for Agroecology," Elementa: Science of the Anthropocene 4).
} 
The "evidence" is the testimony and voices of the villagers in the participating communities, men and women. The "evidence" is what the visitors see in the fields and the local markets. The "evidence" is what local traditional, religious leaders, and innovative farmers say from their experience about agroecology and the benefits obtained.

- GROUNDSWELL INTERNATIONAL

productivity, crop protection, mobilizing trophic networks and biodiversity, carbon cycles and climate change, ecosystem services, food security, nutrition, and more. ${ }^{55} \mathrm{~A}$ number of meta reviews and studies were referenced by the Contributors and are listed in the Supplementary References. For example, in their review of 17 studies (most from Asia and South America), D'Annolfo et al. show that adopting agroecological practices made a positive contribution to improving financial capital. ${ }^{56}$ Bezner Kerr et al.'s review demonstrates that use of agroecological practices can strongly contribute to improving food security and nutrition. ${ }^{57}$ The FAO TAPE team documented multiple positive impacts of agroecology on the environment, food security, and farmers' incomes using the TAPE methodology.

In study after study (see the Supplementary References), agroecology, regenerative approaches, and Indigenous foodways have been identified as one of the main solutions to addressing climate and environmental unsustainability, food insecurity, and socioeconomic inequity. CELIA indicates that evidence has been garnered through the identification and organization of existing scientific knowledge that accounts for the effectiveness and positive impacts of agroecology in agronomic, ecological, economic, and social terms, focusing its analysis at the farm level, community, region, and/or the entire food system. Particular attention has been placed on the contributions of agroecology to:

- enhance crop yields and animal production and total farm output;

- increase stability of production through diversification;

- enhance farm resilience to climate change; and

- conserve biodiversity and the natural resource base.

Based on a review of 279 articles, reports, and studies, the CELIA group analyzed the strength of the evidence of agroecological approaches on a series of subcategories of various agronomic, environmental, social, economic, and health-nutrition dimensions of agriculture and the food system. Much more evidence has been documented in the agronomic/ecological realm than in the more sociopolitical and economic realms. Their team found significant evidence that agroecological approaches involving whole systems change support more stable levels of total production per unit area, produce economically favourable rates of return, provide a return to labour and other inputs sufficient for a livelihood acceptable to smallholder farmers and their families, and ensure soil and water protection and conservation as well as enhanced biodiversity. In addition, evidence shows that agroecological practices and designs enhance resilience to climate change and generate acceptable food production levels without external chemical inputs..$^{58}$ See Table 1 for a summary of these evidence types.

The proof is the joy that reigns in the family, and the testimonies of the producers. - ENDA PRONAT 
TABLE 1: CATEGORIES OF IMPACTS IN AGROECOLOGICAL SYSTEMS

CENTRO LATINOAMERICANO DE INVESTIGACIONES AGROECOLOGICAS (CELIA)

\section{ENVIRONMENT}

BIODIVERSITY

- Ecological restoration of degraded landscapes

- Wildlife conservation and enhancement

- Conservation and enhancement of beneficial fauna and flora for agriculture

- Recovery and conservation of native seeds

- Promotion of ecosystem services (carbon sequestration, pollination, biological pest control, etc.)

\section{LAND/SOILS}

- Soil regeneration and conservation

- Protection against degradation (erosion, contamination, etc.)

- Improvement of soil quality and fertility (increase of organic matter and biological activity, etc.)

\section{WATER}

- Water conservation and efficient use

- Water harvesting and reuse

- Water quality improvement

\section{PLANT HEALTH}

- Reduced disease incidence and damage

- Increased biological control of pathogens by antagonists

- Lower insect pest populations and less crop damage

- Increased presence of natural enemies for biological control of pests

- Less use of chemical or organic pesticides (botanical, microbial, etc.)

- Weed suppression, less use of herbicides

\section{PRODUCTIVITY}

- Increasing total farm production

- Stabilization of specific crop yields

- Over production in polycultures (LER)

\section{RESILIENCE}

- Adaptation to climate change

- Increased resilience to climate change

- Socioeconomic and health/nutrition

\section{NUTRITION}

- More diverse production with higher nutritional output

- Increased dietary diversity 
CATEGORIES OF IMPACTS OF AGROECOLOGICAL SYSTEMS

\section{NUTRITION}

HUMAN HEALTH

SOCIAL

ECONOMIC

CULTURAL
- Increased access of rural households to diverse and healthy foods

- Contribution to urban food security

- Less exposure to agrotoxins

- Increased immunity derived from higher consumption of vegetables and fruits

- Lower incidence of diseases

- Better development (growth and lack of deficiencies) of children

- Greater community cohesion

- Increased cooperation and solidarity

- Increased capacity-building

- Alliances with consumer groups

- Increased participation and empowerment of youth and women

- Reduced technological dependence

- Lower production costs

- Participation in alternative markets

- Access to fair prices in local/regional markets

- Reduced indebtedness

- Employment generation

- Improved income

- Maintain elements of traditional agriculture

- Use of traditional knowledge and practices

- Greater territorial rootedness

- Pride in cultural identity 
Many agroecological solutions are being applied on the ground by grassroots organizations across the world. It is time to make those solutions more visible, as demonstrated and presented by local champions. Our belief is that when organizations and networks embedded in agroecology movements own the evidence process and can convincingly present cases that move their constituents and targets, we will see sharp advances in amplifying healthy and resilient food systems.

- AGROECOLOGY FUND

In parallel, there exist thousands of documented case studies of successful agroecological, regenerative approaches and Indigenous foodways around the world, many of which are documented through local or regional alliances, civil society organizations, and universities. There are too many to list here, but examples of these include those published by LEISA magazine, Agroecologia journal, Agroecology Learning Alliance in Southeast Asia, IPES-Food (2016, 2018), African Food Sovereignty Alliance (AFSA) (2015 to 2020), FAO Agroecology Knowledge Hub, World Future Council (2018), Biovision (2020), and the Global Alliance for the Future of Food (2018 to 2021). Among these case studies are "beacons of hope" and "lighthouses" that document transformative shifts toward sustainable food systems through agroecology. In addition, there are many more stories on video by farmers, fishers, pastoralists, Indigenous Peoples, and youth in the form of testimonies, field documentation, information, and training tools. Many publications, research papers, web posts, training modules, media articles, and videos are found in languages other than English. A larger number remain in the hands of farmer-researchers and their communities - documented but unpublished.

While we do not aim to provide an exhaustive review of the evidence in support of these approaches (although the Supplementary References provide a reservoir of literature), this section highlights the diversity of types of evidence that exist, evaluating ecological, economic, and social factors, and makes the case for the importance of using transdisciplinary methodologies and valuing plural ways of knowing. In the next section, we present five dominant questions and narratives that tend to marginalize agroecology, regenerative approaches, and Indigenous foodways. For each one we widen the lens for analysis and provide evidence from the Contributors. 
SECTION 2
THE QUESTIONS
THAT HOLD BACK
FOOD SYSTEMS
TRANSFORMATION 
Key questions and debates exist about the dominant narratives related to agroecology, regenerative approaches, and Indigenous foodways. Each Contributor was asked to outline the common questions, narratives, and arguments encountered against agroecology, regenerative approaches, and Indigenous foodways and the counter-arguments that are revealed through the evidence they document. The reflections on these questions, and the evidence provided, form the basis of this section. Five central questions were identified that reflect key debates and tensions about the transformative potential for agroecology, regenerative approaches, and Indigenous foodways. We provide some case studies and examples of the evidence provided by the Contributors to address these questions, but these responses are not meant to be an exhaustive review of the evidence.

\section{QUESTION 1: CAN THESE APPROACHES FEED THE WORLD?}

\section{From simplistic productivity measures to holistic big-picture impacts}

The narrative of feeding the world is often underpinned by concerns about population growth, growing hunger and malnutrition, and climate change. As Centre for Agroecology, Water and Resilience; Agroecology Now!; and University of Vermont Agroecology and Livelihoods Collaborative (CAWR-ALC) explains, this serves to embed productivity as the key challenge in feeding populations, and de-emphasizes the underpinning political economy that is the root cause of food insecurity. The "feed the world" frame is frequently used in conjunction with eye-catching statistics from high-profile publications, with the added proposition that world food production will need to increase by at least 50\% by 2050 compared to 2012 levels, while in Sub-Saharan Africa and South Asia, output will have to more than double. ${ }^{59}$ However, many have argued that the problem of hunger in the world is not a problem of scarcity, it is a problem of distribution, poverty, lack of access, lack of power, inequality, and waste. ${ }^{60}$ An exclusive focus on yield disregards important sociocultural and ecological trade-offs. It downplays distributive and social justice issues related to the right to food, the root causes of poverty, and social exclusion, focusing on agricultural intensification and global trade as a means of addressing food insecurity. ${ }^{61}$

Skepticism that agroecology, regenerative approaches, and Indigenous foodways can feed the world is shared by some agricultural development donors and organizations - as borne out by interviews conducted by the Global Alliance for this evidence-gathering exercise. * Small-scale peasant farming is seen as inefficient and not viable, and thus "peasants" need to be replaced by "modern" and more "commercial" farmers. In this view, success is measured on both the investments made in external inputs and the final crop or animal product yielded and production per hectare, while the provision of ecosystem integrity and services, agrobiodiversity, and/or nutrition become secondary factors. However, as several Contributors noted, the "feed the world" narrative's narrow focus on yield limits a nuanced analysis and understanding of the multiple social, economic, and environmental impacts of distinct farming systems. What we measure will dictate where investments and policies are directed. Measuring performance and resilience through a wider systems lens provides evidence on the multifunctional benefits of agroecological and regenerative approaches. FAO TAPE discusses the finding that the multifunctionality of family farmers allows them to act on multiple fronts, including producing

\footnotetext{
*Five interviews were conducted with donors/staff who fund agricultural programs and research to gauge their perspectives
} on agroecological and regenerative approaches and Indigenous foodways. 
most of the world's food, acting as stewards of nature by preserving and developing biodiversity, preserving and sharing traditional knowledge, and contributing to the resilience of people and nature. The Contributors provided evidence for comparative yields as well as the link between on-farm diversity and food and nutrition security. Evidence is also provided for the multiple essential benefits beyond yield that are required for sustainable food systems.

\section{Biodiversity is strongly linked to health and nutrition}

Several of the Contributors showed evidence of promising yield performance while linking these practices to improved dietary diversity, food security, and nutrition outcomes. Results from FAO TAPE Mali case study ${ }^{62}$ show that more advanced agroecological farms are in general more productive, use much fewer external inputs, and are more profitable. This is correlated with farms that are more strictly linked to territorial markets, which provide better opportunities for commercializing agroecological products and contributing to the food security of the area. ${ }^{63}$ This study also shows better dietary diversity and less expenditure for food, which suggest higher levels of household food security.

\section{Studies done on a whole-farm basis suggest the great potential of agroecological} approaches to "feed" as well as "nourish" the world.

- SOILS, FOOD AND HEALTHY COMMUNITIES (SFHC)

Soils, Food and Healthy Communities (SFHC) noted that some research on crop yields suggests that on a per-crop basis, agroecological farms have, on average, about 20\% lower yields compared to conventional farms. ${ }^{64}$ Whereas studies done on a whole-farm basis, in which a range of diverse crops are grown under agroecological systems, show that agroecological farms are more productive than conventional farms by as much as 80\%. ${ }^{65}$ Recent modelling studies demonstrate that organic agriculture with a diverse set of crops, including legumes, has potential for addressing food and nutrition security requirements in many parts of the world, while being more sustainable than conventional agriculture. ${ }^{66}$ Given the limited amount of investment in agroecology, these findings suggest good potential for it to feed as well as nourish the world, if supported with more conducive policies and greater funding.

It is striking to note that the yield response to biological inputs is higher than to that of chemical inputs. The traditional argument against the alternative agricultural models to chemical-based agriculture is that the yield of crops under the alternate models is lower than those under chemicals. But the experience of Andhra Pradesh Community-managed Natural Farming (APCNF) is contrary to this hypothesis. As a matter of fact, there are no significant differences between the yields of natural farming and non-natural farming across all the crops. Hence, there would not be any threat of food security from natural farming to society at large.

- ANDHRA PRADESH COMMUNITY-MANAGED NATURAL FARMING (APCNF) 
Agricultural biodiversity is a centrepiece of agroecology, regenerative approaches, and Indigenous foodways - and diversity is strongly linked to health and nutrition. Bezner Kerr et al. (2021) have shown in their review that the use of agroecological practices can strongly contribute to improving food security and nutrition. A majority of analyzed studies (78\% of 56 studies) found evidence of positive outcomes in the use of agroecological practices on food security and nutrition of households in low- and middle-income countries. Agroecological practices that enhance agricultural biodiversity included crop diversification, intercropping, agroforestry, integrating crop and livestock, and soil-management measures. More complex agroecological systems that included multiple components (for example, crop diversification, mixed crop-livestock systems, and farmer-to-farmer networks) were more likely to have positive food security and nutrition outcomes. ${ }^{67}$

ENDA Pronat in Senegal stated that farmers participating in their programs show that agroecology can be as productive as conventional agriculture once soil fertility is restored. They emphasized that agroecology is not a return to traditional agriculture but instead based on both local traditional knowledge and scientific knowledge. Andhra Pradesh Community-managed Natural Farming (APCNF) highlighted several comparative studies they have conducted on farms and have found that farms practising natural farming had similar yields or improved yields as compared to conventional farms. They also noted financial savings due to reduced costs for synthetic inputs. The evidence provided by the Contributors demonstrates not only that yields on farms implementing agroecological and regenerative practices can be comparable or superior, but that because these farms are more diversified, they are providing better food and nutrition security through more diverse diets.

\section{Farmer-led science and technology is cost-effective and adapted to context}

In the "feed the world" narrative, detractors of agroecology cast it as "anti-science," * and as a rejection of modern technologies essential for farmer incomes and productivity. Agroecology is said to be a nostalgic return to the past and traditional ways of farming that only worked with low population densities and shifting agriculture. It is positioned as an ideological approach that will deny millions of people access to modern agricultural techniques, creating hunger, and denying farmers useful technology such as genetically modified crops.

For Groundswell International, the dominant agricultural system currently promoted in Africa (intensive, inputdependent) provides an illusion of choices to Africans, but in the end locks them into reliance on purchased inputs and methods that do not build long-term resilience. Farmers lose their agency in having knowledge or experience in a range of methods. Groundswell International argues that as long as the technological options (including genetic modification) are controlled by a handful of companies who demand intellectual property regimes that require farmers to continually purchase inputs and limit public research and debate on these technologies, then a choice is not really being offered up to African farmers or consumers. ${ }^{68}$

Moreover, Agroecology Research-Action Collective (ARC) pointed out that technologies embedded in farmer-led science are not only more cost-effective, but also more fit for the purpose, easier to adopt, and lead to more

\footnotetext{
*For example, see Joseph Opoku Gakpo, "Science, Not Fear, Will Drive Ghana’s Decision on the First GMO Crop, Regulators Vow," Cornell Alliance for Science (2021).
} 
system-wide benefits beyond their intended use. Externally driven technologies are often much more costly, less adaptable, and propel changes on farms and in landscapes toward greater simplification, often with unexpected trade-offs. ${ }^{69}$ The Andhra Pradesh Community-managed Natural Farming (APCNF) program has shown how agroecological and regenerative approaches can work hand in hand with science and technology, including robust information and communications technology and management information systems that continuously track field activities and support all aspects of the program. Technology should not be promoted as an end in itself, but as a means to an end, with farmers engaged in the development and application of technologies, and with attention to data sovereignty. ${ }^{70}$

\section{Funding and support increases viability and impact}

Finally, the sampling of studies provided by Contributors highlight some metastudies, and local case studies illustrate the yield potential of agroecology, regenerative approaches, and Indigenous foodways. The examples also illustrate the need to use a systems lens to measure success and the importance of democratizing science and technology. The Contributors also emphasized that the viability of these examples would be enhanced with greater financial and institutional support.

Mariam Sow of ENDA Pronat in Senegal responds to the "feed the world" narrative in this way: "We are told that with the growing population, agroecology will never be able to provide a satisfactory answer to hunger. Researchers have always been on the alert, saying that by 2050 Africa's population will be far too large and that Africa will not be able to produce enough to feed its people, and therefore land must be left to multinationals to produce more. Today we need to conduct very visible experiments to go to scale. We have to prove that what we are doing with a handful of producers can be a lever to move toward changes at the level of the territories. We must demonstrate that agroecology is viable enough to feed the world, to ensure food and nutrition security. At this level, we lack the funding that allows us to make our experiments more visible and to go to scale."

As recent studies by Centre for Agroecology, Water and Resilience (CAWR), Coopération Internationale pour le Développement et la Solidarité (CIDSE), Biovision Foundation for Ecological Development, and others have demonstrated, agroecological practices are showing great success on the strength of farmer innovation and knowledge - despite the minuscule levels of funding. Financial support for programs and research in agroecological and regenerative approaches, as well as Indigenous foodways, is currently extremely low. ${ }^{71}$ For example, from EU funding, projects partially supporting agroecology represent only $2.7 \%$ of the EU funds channelled through Food and Agriculture Organization, International Fund for Agricultural Development, and World Food Program projects between 2016 and 2018. ${ }^{72}$ Greater levels of funding for programming and public research toward transformative agroecology would significantly increase the viability, performance, and ability of such programs to widen their scale and deepen their impacts. 


\section{CASE STUDY: FARMING FOR SOIL FERTILITY, FOOD SECURITY, AND NUTRITION IN MALAWI}

\section{Soil, Food and Healthy Communities}

The Soil, Food and Healthy Communities (SFHC) program works with over 15,000 farmers in more than 500 villages in Northern and Central Malawi. It is a participatory organization in which farmers exchange knowledge to improve soil fertility, food security, and nutrition. SFHC's main methodology is participatory agroecology and participatory knowledge co-production and sharing. This involves farmers working together to produce and share knowledge about crop production, land management, and nutrition. Farmers actively take part in research, including problem identification, research design, data collection, and analysis. Transdisciplinary approaches - blending many different research disciplines and farmer knowledges — are utilized in the research. Field demonstrations are also used when introducing new agroecological methods to farmers. The SFHC has a farmer training centre and farms where these field demonstrations take place. Participatory visual and geospatial methodologies are also used, including photovoice and participatory GIS.

The SFHC program has documented significant use of agroecological practices and supported on-farm training in Malawi and Tanzania, and developed an integrated curriculum (agroecology, gender and social equity, nutrition, climate change) that has been used in Tanzania and Malawi. These have resulted in significant improvements in food security, nutrition, gender relations, and resilience in Malawi and Tanzania.

A recent study of the SFHC program concluded that the agroecological practices used by farmers have increased household food security and nutrition. This has been enhanced by the methodologies employed by the program, such as farmer-to-farmer training and discussion groups, and direct consumption pathways for improving agricultural incomes. Farmers reported that they have been able to regain control over their seeds, fertilizer, land, and labour. In addition, the study found that agroecological approaches reinforced social support practices such as food and seed sharing. All these outcomes are essential for long-term community food security. ${ }^{73}$

Farmers in the SFHC program have contributed to innovative doubled-up legume agroecology practices that have become an official technology promoted by Malawi's national agricultural extension program. SFHC also participated in the Government of Malawi Seed Policy reform to support farmers' right to save seed. 
CASE STUDY: INDIGENOUS FOODWAYS AND BIODIVERSITY AMONG THE MAYA AND CHAKESANG-NAGA

\section{The Indigenous Partnership for Agrobiodiversity and Food Sovereignty}

For the Yucatec Maya, the milpa is at the heart of their food production system. According to Toledo et al., a milpa contains 300 to 500 plant and animal species. ${ }^{74}$ The approach is not to maximize the yield of a single species or variety, but rather to manage the balance of the system through biodiversity. The yield per land-use unit is lower than a specialized use approach, but the sum of all the parts at play per land-use unit is greater. It is called "land equivalent ratio." In a very good year for corn grown in a milpa, for instance, the yield is around 2.0 ton/ha. The production is mostly for family consumption, but eventually about $10 \%$ of it is sold within the community.

Based on the findings of several authors, ${ }^{75}$ the traditional farming system in North East India is made up of four subsystems: shifting cultivation, homestead gardening, bun (terrace farming), and wet paddy cultivation. Among the four, shifting cultivation harbours the second-highest diversity of food plants, with more than 50 recorded from a single community. The highest is found in homestead gardens (more than 60), but because of the limited area of cultivation (plots are found around the house), shifting cultivation is more important for food security. Bun is a transition that has occurred in the last 40 years with the decline in forest, especially in the central uplands of Meghalaya. In this farming system, the number of food plants cultivated is less than 20. This system will become more important in the future. Lastly, there is the wet paddy cultivation. Rice is the main food plant supplemented by cultivation of crops like potatoes, carrot, mustard, and other vegetables, after rice has been harvested.

The Chakesang-Naga have mastered the art of terrace construction in steep slopes for rice cultivation, something that is absent in Meghalaya. In all of these traditional farming systems, external inputs are not used, but rather, substituted with fire and ash from the debris, animal manure, and leaving the land fallow for soil improvement and management. Pest control is done by recourse to Indigenous knowledge, which also includes preparation of biopesticides. Irrigation is non-existent, with the moisture requirements of the food plants being met only by the seasonal rains. Production is mostly for self-consumption, with the surplus sold to the local consumers.

For food production, the Yucatec Maya revived the use of the iknal system (described by Rosado-May et al. ${ }^{76}$ ), which is a platform for knowledge transmission within the community. Farmers exchange experiences to learn from each other in solving problems in their crops and discuss issues such as the presence of pests that had not been seen before in plots where conventional methods had been used. Sharing seeds and exchange of food are also more visible. Strategies such as including previously neglected species in their diet, selling products in small wheel-markets, or using digital social media have all been re-established in both Indigenous regions.

As many farmers were not dependent on external inputs, they were not affected by the COVID-19 pandemic. There is no knowledge of how to transition from conventional to sustainable food systems for the crops grown with external inputs in Yucatec Maya or Northeast India; and there is little knowledge of how to enhance the traditional method for food production in order to increase yield without external inputs. Thus, Indigenous farmers will face a difficult situation post-pandemic. The probability of going back to business as usual is very high, unless there is a shift in paradigms on how to think about moving to sustainable food systems for millions of Indigenous farmers. 


\section{QUESTION 2: CAN THESE APPROACHES BE SCALED?}

\section{From a focus on farms to food systems transformation}

The evidence on the performance and scaling potential of agroecological and regenerative approaches and of Indigenous foodways is growing, ${ }^{77}$ and can now be used to challenge the dominant narrative that their performance is limited and can never reach the scale of food production to feed large numbers of people or lift them out of poverty. This narrative envisions agroecology as marginal, effective only at small scale but incapable of performing at greater levels. The Contributors shared their experiences and evidence of successful scaling in different contexts and regions of the world.

Scaling of agroecology and regenerative approaches goes beyond just the spreading of a set of technologies (to more small farms or on larger farms) but is a process of amplifying a whole new paradigm to build sustainable food systems rooted in equity, justice, and reciprocity. In its broadest sense, "scaling" refers to processes that result in more and more farmers practising agroecology, encompassing more territories, and engaging people in the processing, distribution, and consumption of agroecological and regenerative foods. As an alternative paradigm to conventional agriculture, one that requires systemic changes for success, scaling involves vertical processes (referring to creating enabling policies, markets, and other institutional factors) and horizontal processes (referring to the geographical spread of practices, farmer-to-farmer, across communities, organizations, and regions), ${ }^{78}$ where social movements are key forces for change.

\section{Scaling requires social and political change}

Under what circumstances and conditions are local experiences able to scale out and up in the face of such systemic barriers? As is evidenced by the experiences of the Andhra Pradesh CNF program, the incredible scaling out and up of this approach is successful due to deep social processes like farmer-tofarmer and woman-to-woman methodologies, enabling policies, engaged government officials, effective agroecological practices, and supportive external allies. Scaling experiences are context dependent, often non-linear, and engaged in multidimensional processes. Based on a review by Mier y Teran et al., ${ }^{79}$ the following enabling drivers were identified: 1) recognition of a crisis that motivates the search for alternatives; 2) social organization; 3) constructivist learning processes; 4) effective agroecological practices; 5) mobilizing discourses; 6) external allies; 7) favourable markets; and 8) favourable policies.

The McKnight Foundation's Collaborative Crop Research Program (CCRP) discusses how their Farmer Research Networks are key drivers of the scaling of knowledge by providing a pathway to research that supports farmer agency while broadening processes of sharing. Farmer research networks aim to enable large-scale farmer participation in agroecological research and development in a way that enhances the agency of participants. They are envisaged as a social innovation that supports the agroecological transformation of smallholder agriculture and food systems. Farmer Research Networks strengthen rural organizations while contributing to more relevant research that considers local contexts. Farmer Research Networks and the knowledge they produce can represent a broad range of farmers as well as diverse ways of knowing. Farmer Research Networks amplify the impact of farmer-centred innovation systems and allow farmers to tap into existing knowledge. They rely on their own experiments to learn and test new ideas, but also learn from others in their networks. 
These are examples of scaling relevant to smaller farms, but what about on larger farms? Can the diverse principles of agroecology and regenerative approaches be implemented on large-scale farms? CELIA cited Tittonel et al., ${ }^{80}$ who provide an insightful analysis using two large-scale agricultural territories as case studies and identify five key areas of research that need to be addressed to inform the agroecological redesign of large-scale systems: 1) breeding for diversity; 2) scalable complexity (for example, with multispecies systems and service crops); 3) managing carbon, nutrient, and water cycles beyond fields and farms; 4) sharing the cultivated landscape; and 5) co-innovation with farmers, value chains, and policymakers. ${ }^{81}$

EnviroStrat discussed the challenges of scaling organic and regenerative approaches at a national scale in New Zealand. They state that going to scale requires evidence, policy support, and appropriate resourcing. With regulatory changes on the way in New Zealand, including an Organic Product Bill, a first carbon budget period, and water and resource management reforms, and with increased demand in markets for organic products, this creates the perfect opportunity to move away from a siloed approach into approaches that can capture a total concept for food systems transformation. They state that it will be important to work from the ground up through market placement and being responsive to consumer and customers' needs. How the organic sector aligns and builds adaptive and collaborative frameworks is crucial in building a purposeful transition and scale.

Regenerative agriculture is the solution to many of the problems produced by modern agriculture. By eliminating soil disturbance, diversifying plant communities in cropland and rangeland, reducing agrichemical use, and integrating animaland plant-based agriculture in stacked enterprises, regenerative food systems improve soil health, sequester carbon, reverse desertification, increase biodiversity, and increase farm resilience. Research is sorely needed to scale and transfer the anecdotal reports of successful regenerative farms to mainstream agriculture. - ECDYSIS FOUNDATION

Scaling of these approaches faces considerable barriers in many regions of the world. These include but are not limited to: ideological barriers to its political acceptance; international trade and export orientation; marginalization of women; monopoly seed laws; and concentration of power among transnational corporations. Overcoming these barriers requires social and political transformations and the undoing of structural lock-ins. ${ }^{82}$ A transdisciplinary research and action framework that brings together multiple actors to collectively identify the contextual barriers, lock-ins, and solutions can be a powerful force for change.

\section{Evaluating transformation requires diverse social and ecological indicators}

Scaling is catalyzed through agrifood transitions or transformations. In order for success to be replicated, it is important to contextualize the many ways that transitions and scaling happen. As outlined by ARC, key components for scaling and transformations include: spatial scaling (uptake by larger, diversified farms and over wider regions and landscapes); social scaling (including through effective farmer-to-farmer education and training, mass media, and popular education); and political scaling (through deepening individual farmers connections to farmer and social movements, mobilizing popular support for agroecological and 
regenerative approaches "from below," and influencing with policy change and accountability "from above"). Given that these transitions are multidimensional, evaluating and characterizing them requires not just a diversity of social and ecological indicators but also a participatory approach that gives agency to farmers and other actors.

The FAO's TAPE methodology was recently created in order to harmonize evidence about the multidimensional nature and benefits of agroecological approaches globally. This tool includes a score card entitled "Characterization of Agroecological Transition" (CAET), which uses the FAO's 10 Elements of Agroecology to evaluate the level of agroecological transition of agricultural systems. A TAPE pilot project tested by communities in Mali shows that farms that are more advanced on agroecological indicators are more productive, use fewer external inputs, and are more profitable - in part because they are better linked to territorial markets that provide commercialization of agroecological products. They also score higher on dietary diversity and food security. From a social perspective, agroecology in Mali is beneficial for family farming because most advanced agroecological farms employ more members of their family in the agricultural production. In particular, young people show a much lower propensity to emigrate because they can find decent jobs in agroecological production. Finally, from an environmental perspective, agroecology is linked to better soil health, more agrobiodiversity, and greater presence of beneficial animals and pollinators.

Well-defined agroecological techniques and practices seemed to be among the main reasons that some farms performed better than others in their agroecological transitions. In addition, women's involvement in decision-making concerning household and farming activities, access to resources, decision-making on the use of income, and women's participation and leadership activities within rural communities were associated with an increase in the CAET score.

- FOOD AND AGRICULTURE ORGANIZATION, TOOL FOR AGROECOLOGY PERFORMANCE EVALUATION (FAO TAPE)

The FAO's TAPE is one tool among several developed globally to evaluate the systems performance, broadly defined, of these approaches. Participatory research and action go hand in hand with agroecological transformations and scaling. This is enabled through transparent, honest, respectful alliances of key actors in a local territory (farmers, academics, consumers, in some cases local government officials), with actors internationally (researchers, academics, etc.). These alliances should be rooted in principles of equality, justice, and reciprocity. 
CASE STUDY: SOCIAL NETWORKS SCALE NATURAL FARMING TO MORE THAN 1 MILLION FARMERS IN INDIA

\section{Andhra Pradesh Community-managed Natural Farming (APCNF)}

The Andhra Pradesh Community-managed Natural Farming (APCNF) initiative is the world's largest agroecology program in terms of number of farmers enrolled. Its real success lies in its innovative scaling-out strategy of farmer-to-farmer extension systems. This involved identifying "Champion Farmers" who act as trainers on agroecological and regenerative practices. There is 1 farmer trainer per 100 farmers. This farming is knowledge-intensive and not input-intensive; hence, intensive accompaniment by farmers, peer support, and agricultural extension play a key role. Women's self-help groups play a similar critical role in collective action, knowledge dissemination, supporting each other during transition, financing members to purchase the inputs required for natural farming, monitoring, and managing the program.

As agroecological and regenerative approaches are knowledge-intensive, the program has established longterm knowledge-sharing programs, since a farmer requires 3 to 5 years to make the transition. Since the trainers are themselves practising farmers, their credibility is very high and they are able to motivate farmers to change. In addition, APCNF's scaling strategy takes a "whole village" approach, with the objective to convert all village farmers to natural farming practitioners. The target is all small and marginal farmers and tenant farmers in the village, who constitute more than 85\% of the farmers. It takes 5 to 6 years to transition all the farmers in a village. Seeing other farmers reaping the benefits of natural farming has drawn the remaining farmers to gradually transition in this direction. The support of the state Agriculture Department in the transition process has also been a very important factor for the success of the program.

The APCNF program demonstrates that natural farming is not only highly beneficial, but it is also scalable in a reasonable period of time, provided there is a proper strategy in place to scale it up. Over the last 4 years, the number of farmers enrolled to practice natural farming has increased from 40,000 farmers in 2016 to around 700,000 farmers and farm workers in 2021. The target for 2021-22 is 1.05 million farmers and farm workers. The program envisions all estimated 6 million farmers and all 2 million landless farm workers in Andhra Pradesh bringing the entire cultivable area in the state under natural farming. 
CASE STUDY: SCALE AND THE MULTIDIMENSIONAL PERFORMANCE OF AGROECOLOGY

\section{Food and Agriculture Organization - Tool for Agroecology Performance Evaluation (FAO TAPE)}

Community-based assessment tools are critical in gathering and sharing qualitative as well as quantitative evidence to solve problems. Such tools have existed for decades and are built on participatory and pedagogical foundations and participatory research methodologies - many of which originated in Latin America. ${ }^{83}$ More recently, FAO has built on these methodologies to develop the Tool for Agroecology Performance Evaluation (TAPE) as an analytical framework to assess and produce comparable and harmonized evidence of the multidimensional performance of agroecology to support transitions toward sustainable food systems. TAPE aims to: ${ }^{4}$

- Inform policymakers, development institutions, and other stakeholders by creating references to the multidimensional performance of agroecology and its potential to contribute to multiple SDGs;

- Build knowledge and empower producers through the collective process of producing and sharing data and evidence based on their own practices; and

- Support agroecological transition processes at different scales, in different locations, and different timeframes by proposing a diagnostic of performances over time and by identifying areas of strengths/ weaknesses and enabling/disabling environments. ${ }^{85}$

TAPE was developed through community testing in Mali and Cambodia, in collaboration with practitioners, local organizations, governments, communities, and farmers. The results of both pilot tests showed a positive relationship between higher levels of agroecology transition and quantitative agroecological performance, such as higher productivity per hectare and per person, higher agrobiodiversity per farm, less inputs expenses, and stronger local market connections. It also revealed the potential of TAPE to meet the need for a collection method that provides comparable data and complements existing data. Local organizations participating in the TAPE tests recognized that the tool helps address the different dimensions of agroecology transition, considers different scales, is linking theory to level of practice, and is beneficial to promote agroecological practices and for advocacy purposes.

\section{CASE STUDY: THE SCALING OF AGROECOLOGY IN CUBA}

\section{Centro Latinoamericano de Investigaciones Agroecológicas (CELIA)}

For 30 years, the Cuban people have been transforming their food system, resulting in one of the most successful agroecology scaling experiences in the world. Key drivers of this transformation include: 1) an economic crisis that opened political space for organic and agroecological farmers and researchers to gain power; 2) several progressive land reforms that strengthened small farmers and the cooperative sector; 3) decentralization of food systems planning and distribution to the municipal level; 4) an exemplary national urban agriculture program; 5) a highly successful farmer-to-farmer training program; and 6) several supportive government policies. ${ }^{86}$

Successful scaling of agroecology is rooted in the Cuban revolution's commitment to science, universal education, and social organization. It laid a foundation of strong agricultural institutions, an educated society, 


\section{CASE STUDY: THE SCALING OF AGROECOLOGY IN CUBA}

and a culture of solidarity and collaboration that catalyzed strategic alliances between government, farmers, researchers, students, the media, consumers, and other key actors. Government and non-government institutes charged with education, training, research, and extension adopted bottom-up, participatory, popular education and transdisciplinary approaches that facilitated co-innovations and helped this knowledge-intensive type of agriculture to spread.

The practices implemented across farms in Cuba today demonstrate the integrated systems that enable broad and successful scaling: 1) a diversity of biological products for pest management and maintenance of plant and soil health, many of which are produced by local government agriculture departments; 2) municipallevel compost facilities; 3) co-innovations between farmers and researchers that have increased diversity on farms; 4) participatory plant-breeding programs; and 5) many other integrated and diverse practices and systems that contribute to social and ecological resilience.

The National Association of Small Farmers (ANAP) Farmer to Farmer Movement — and its representation and impact at the cooperative, municipal, provincial, and national levels - has been integral to Cuba's agroecology scaling success. More than half the Cuban peasantry (200,000 farming families) have been trained in agroecology. ${ }^{87}$ The Urban, Suburban and Family Agriculture Program, initiated in Cuba during the early days of its 1990s economic crisis, has played an essential role in helping diversify the Cuban diet by increasing access and availability of fresh fruits, vegetables, and medicinal plants in a country where $80 \%$ of the population is urban. With strong government support at local, provincial, and national levels, urban and peri-urban farms have spread across the entire country and represent $14 \%$ of the agricultural land. ${ }^{88}$

Over the past 30 years, several progressive agrarian reforms have been implemented aimed at decentralizing land management from large state farms to smaller non-state cooperative farms. As a result, agricultural land management has transitioned from being $80 \%$ state managed in the early 1990 s to more than $70 \%$ under cooperatives and family farms today, totalling 3.5 million hectares. ${ }^{89}$ This shift has brought higher levels of agricultural and food diversity, productivity, and efficiency as well as embedded local food systems.

Sparked by a drop in tourism due to the pandemic and a severe tightening of the U.S. embargo in recent years, Cuba is facing another economic crisis. In this context, Cuba continues to make stronger commitments to strengthening agroecology and building a support structure for food sovereignty. In 2020, the Cuban government passed a National Plan for Food Sovereignty and Nutritional Education, and an Agroecology Law is being developed in 2021. Coupled with this legislation are several laws and plans that provide legal structures to promote local food systems planning and territorial development, that decentralize power, and that seek to build stronger and more resilient communities. This is all within a framework of increasing resilience to socioecological shocks and stressors such as the climate crisis and the 62-year-old U.S. embargo. 


\section{QUESTION 3: CAN THESE APPROACHES PROVIDE MEANINGFUL LIVELIHOODS?}

\section{From drudgery to sustainable livelihoods}

"Agroecology will only keep farmers poor" goes the well-worn narrative.* Agroecological and regenerative approaches are deemed insufficient for farmers to gain viable livelihoods and incomes. These approaches are said to keep farmers in a perpetual state of poverty and subsistence, inflicting them with intensive and drudgerous manual labour, and preventing them from climbing out of poverty and onto the pathway of modern agriculture as farmer entrepreneurs. Inherent in this narrative is that small scale is necessarily inefficient; that farmers and Indigenous Peoples' own knowledge systems play a limited role in innovating at this level of farming; and that mechanization or technological innovation in small-scale farming is non-existent or actively discouraged. ${ }^{90}$ However, these analyses rarely take into account how the political economic system not only works against these approaches but undermines them.

CAWR-ALC state that such discursive frames often portray peasants, traditional rural communities, and farming as backward, low quality, inefficient, and unproductive. They can demobilize food producers and rural communities interested in agroecology by preventing them from launching or expanding agroecological experiments. At the same time, these narratives often present large-scale producers and industrial forms of agriculture as modern, productive, tidy, entrepreneurial, and representative of "good" farming, and insist that it is in farmers' and society's best interests to minimize the number of people unfortunate enough to be farmers. ${ }^{91}$

\section{Experimentation and knowledge-sharing support sustainable livelihoods}

As SFHC points out, while it is true that agroecology, regenerative approaches, and Indigenous foodways are often more labour-intensive, they are also vectors for community advancement: farmer-to-farmer exchanges, experimentation, co-production of knowledge, and intergenerational learning. It is precisely in these collective spaces where grassroots innovation and learning happen. They note that there has been very little research on the actual labour requirements of agroecological practices, which vary tremendously. Some methods, such as intercropping and mulching, may reduce labour needed for weeding. The acts of making organic inputs, such as compost or botanicals, may require more time than purchasing synthetic fertilizers or pesticides, but for some farmers it is a choice worth making to harvest healthy and abundant crops and to use their savings to invest in other parts of their farm. If there is more support to farmers using these methods, increased labour needs on farms could lead to more employment in the agricultural sector. A global study looking at the relationship between crop diversity and employment found that there was higher employment from farms that had greater crop diversity. ${ }^{92}$ The crucial component here is actually compensating farmers adequately for taking on more labour and knowledge-intensive methods - through true cost accounting, subsidies, support for agroecological markets, and other support mechanisms. SFHC's research with highly food-insecure households, including HIV-affected families, demonstrates that these methods can be used by highly vulnerable farmers to improve livelihoods, food security, and nutrition in a relatively short (2- to 3-year) period. 93

${ }^{*}$ For an overview of world hunger issues and common narratives, see Moore Lappé and Frances and Joseph Collins, World Hunger: 10 Myths (New York: Grove Press, 2015), and Raj Patel, Stuffed and Starved (Toronto: HarperCollins, 2007). 


\section{CASE STUDY: AGROECOLOGY IN CHINA: BACK TO THE FUTURE OF FOOD}

\section{Institute of Rural Reconstruction of China (IRR-China)}

Historically, agriculture was a way of life for people in China - it was not only about providing food, clothing, and sustenance, but also about enjoying the natural environment in the countryside and feeling the affection of neighbours in the community. What agriculture provides to human beings is far from just producing food or making money, explains Prof. Luo Shiming, one of China's leading agroecology experts. It plays a huge role in maintaining the environment for the planet, for human survival, the human spirit, religion, and community culture. Farmers also incorporated multiple forms of food production, such as traditional rice-fish-duck systems. However, colonization impacted farming models and mindsets. The imperatives of industrial agriculture replaced these values with the utilitarian imperatives of producing more and making more money.

Industrialized agriculture and big farms were introduced in China via colonization, which generated conducive conditions for capital-intensive farming and promoted large-scale agricultural development. At the same, large farms influenced agricultural policies as well as established the expansion of agribusiness. Compared to the longstanding Rhine model and Asiatic model of small-scale farming that lasted more than 6000 years, this model fundamentally changed the face of farming. ${ }^{94}$

Until three or four decades ago, agriculture in China created "positive externalities" based on smallholder farmers practising traditional agriculture beneficial to the conservation of resources and the environment. It created not only food security but also food safety, with few of the food-quality incidents that have been common in recent years. Furthermore, due to the use of natural inputs, the environment suffered less pollution, and the industry itself did not generate high profits. Farming was based on cooperation, with farmer cooperatives being the financial backbone, based on a credit system built on trust. The outcome was sustainable rural livelihoods for millions of farmers, and stable rural life. In the last two decades, the interest in ecological agriculture has risen, not from scientists but more from middle-income city consumers who are looking for safe, quality food. This has led to the blossoming of all kinds of agroecological and regenerative initiatives, from natural farming to farmers' markets to modern digital techniques (such as watering and applying organic fertilizer). A growing number of farmers' markets, such as Beijing Farmers Market, aim to reconnect farmers and eaters, and urban and rural communities. They are also a platform for farmers to share knowledge and ideas, as well as raise awareness of local agroecological foods through education and training. People coming to the farmers' market are able to meet farmers and learn about their produce, while some farmers have started planting at market sites, inviting consumers to visit the farm (a form of trust-building and participatory guarantees or PGS), and organizing activities around them. Thus, with the rise of agroecological and regenerative approaches, agriculture in China that had become focused on singular objectives is now embracing multiple objectives. 
Groundswell International challenges the view that agroecology is anti-mechanization. They advocate for appropriate mechanization designed to reduce work and drudgery, particularly for women and their workloads. More research is required on the design of low-cost, appropriate tools and methods to reduce labour, particularly in transport, water lifting, weeding, and sowing. Agroecology also seeks to reduce weeding requirements through cover crops, such as the APCNF'S "Pre-Monsoon Dry Sowing" technique in India, which allows for 365-days-a-year soil cover. There are other appropriate low-cost tools and machines to make transport and other farm tasks easier. ${ }^{95}$

Research shows that the transition to agroecological and regenerative practices (not quite a wholesale transition to agroecology itself) is increasingly taking hold even among North America's industrial farmers. ${ }^{96}$ An interview with Mad Agriculture illustrates how flexible financing and peer-to-peer technical support can accelerate transitions to organic production. ${ }^{97}$ As Agroecology Europe points out, studies of economic performance by van der Ploeg and others ${ }^{98}$ have shown that agroecology generates levels of stability in income and employment that are superior to other forms of production, even as agroecology does not depend on subsidies and incentive measures. This high performance is maintained despite the fact that the proportion of funding going toward transformative agroecology and regenerative approaches is minuscule in comparison to the majority of funding that goes to "business as usual" in agriculture — either having no positive impact or, worse, resulting in negative consequences for ecosystems and people. Similarly, APCNF found the adoption of agroecological and regenerative natural farming practices has reduced the cost of cultivation by $14 \%$.

What agriculture provides to human beings is far from producing food or making money. It plays a huge role in maintaining the environment of the whole planet, the environment for human survival, and even human spirit, religion, and community culture.

- INSTITUTE OF RURAL RECONSTRUCTION OF CHINA (IRR-CHINA)

Mariam Sow of ENDA Pronat underscores the elements of joy and fulfillment, and the satisfaction that emerges from a successful agroecological harvest or progress on the path to agroecological transition. The proof of this often intangible benefit is, she says, in "the testimonies of the producers and the joy that reigns in the family." ${ }^{\prime \prime 9}$ Related to this aspect is the rapidly increasing engagement of young farmers in agroecological transitions.

In Latin America, participatory research in agroecology has attracted the attention of youth as a means to break away from both the entrapment of the chemical agriculture treadmill and the uncertainties of migrating to the big city. Rural youth forming farmer-research teams (known as CIALS) ${ }^{100}$ are growing in Honduras, Nicaragua, and Guatemala, among other countries. Youth entrepreneurship as well as the use of communications technologies have strengthened the stature of agroecological and regenerative approaches, as well as Indigenous foodways, as the way of the future. ${ }^{101}$ 


\section{CASE STUDY: ORGANIZING YOUTH IN EUROPE TO BE FOOD SYSTEM LEADERS}

\section{Agroecology Europe}

Young people around the world are engaging deeply in driving agroecological transitions - both as new farmers and as innovators creating new forms of solidarity markets that connect growers and eaters. Youth are seeing agroecology as a multifaceted response to the global climate, biodiversity, and food crises. With the challenges presented by aging farming demographics, particularly in the Global North, young farmers represent a vital force in advancing knowledge-intensive agroecological and regenerative approaches for meaningful livelihoods and reshaping the future of food.

Agroecology Europe is involved in organizing youth and farmer forums every two years, as well as other related events, in an effort to strengthen and grow the agroecology community. Importantly, their goal is to engage young people as the farmers, professionals, teachers, trainers, and key actors of tomorrow to amplify agroecology and broadly implement it on the ground. Communication and engagement takes place through various events and activities, webinars, and factsheets on agroecological practices, providing examples of agroecological evidence and experience.

In 2020, the Agroecology Europe Youth Network (AEEUYN) carried out a mapping initiative of agroecology in many European countries. This research was part of a large effort to gather knowledge about the diversity of existing initiatives, examples, and practical cases in agroecology, as well as to advance research, education, and support capacity-building and skills development. Key findings of the mapping exercise confirmed a strong appetite for social solidarity economy practices in agriculture, and the urgent need to increase training and education opportunities in agroecology in Europe. ${ }^{102}$

The Network is planning an Agroecology Youth Forum in 2022 in France, which will bring together youth from different European countries to exchange knowledge and experiences in agroecology, but also to launch new initiatives in different countries for expanding agroecology. 


\section{Territorial markets create demand for agroecological products}

While agroecological, regenerative approaches, and Indigenous foodways are often dismissed as marginal, and seen as unviable sources of livelihoods, it is usually by neglecting to mention that the market does not compensate farmers adequately for growing food ecologically. Furthermore, one often encounters the assertion that more gainful livelihoods and employment opportunities will come largely by participating in competitive, globalized markets for "agripreneurs" who can thrive in a technology-driven, digital environment. The inherent assumption is that access to international markets will automatically increase farmers' incomes and, therefore, their food security by enabling them to buy more food.

In fact, markets will not work for agroecology in the absence of enabling policies that are attuned to the context of agroecological and regenerative approaches, and Indigenous foodways. As a recent AFSA symposium underscored, shaping markets for agroecologically produced foods through enabling policies has massive potential for transforming food systems. ${ }^{103}$ The first step toward this is to understand territorial markets, described as "highly diverse markets through which most of the food consumed in the world passes, which may operate at a local, cross-border or regional level, in rural, peri-urban, or urban settings, or all of these contexts; and are directly linked to local, national, or regional food systems in that food is produced, processed, and traded within these systems." * Territorial markets, deeply rooted in local contexts and cultures, are well placed to support the inclusive, diverse, and relationship-oriented nature of agroecology. Policies to support local investment, farmer cooperatives and enterprise, and public procurement can help scale out markets for agroecology, regenerative approaches, and Indigenous foodways. ${ }^{104}$

In addition, a recent empirical study of experiences across Europe by van der Ploeg et al. shows the economic potential of agroecology for sustaining livelihoods of family farmers. ${ }^{105}$ Thirteen case studies from different European countries - including from cattle and crop-livestock farming — provide evidence that agroecological farming can lead to higher farm incomes than conventional or industrial farming, as well as create more employment per hectare, using less fossil fuel, connecting dynamic markets as well as producers and consumers, and making positive contributions for biodiversity conservation and scenic landscape maintenance. ${ }^{106}$

SFHC highlights the enormous potential of agroecological and regenerative approaches for rebuilding relationships between urban dwellers and rural agroecological producers, as well as supporting urban agroecological initiatives. To do so, they argue, requires: 1) investment in the post-production space (agroecological markets); 2) initiatives to support shifts in consumption patterns and demand; 3) subsidies for low-income urban households to afford healthy, diverse food; and 4) public procurement for programs such as school meals to incorporate agroecological products. All of these initiatives will help strengthen demand and support an agroecological transition that could mean feeding cities with agroecology. This is also supported in FAO's research in Mali, which shows that more advanced agroecological farms are, in general, more productive and profitable partly because they are more directly linked to territorial markets that provide better commercialization of agroecological products and that contribute to the food security of the area. ${ }^{107}$

\footnotetext{
*Mamadou Goita's definition of territorial markets, as cited in AFSA's report, "Shaping the Future of Food Markets in Africa: What Kind of Markets Do We Need for the Transition to Agroecology?", AFSA Food Systems Conference Report (October 2020).
} 


\section{Revaluing cultural and ecological knowledge enhances community well-being}

Agroecological and regenerative approaches and Indigenous foodways grow more than food — they grow meaning. With their emphasis on knowledge, ingenuity, and co-creation, these approaches are in sharp contrast to the dominant agricultural model's dehumanizing, reductionist, and single-dimensional approach, where outputs are the focus and inputs (including people and the environment) are disposable, as the Contributors pointed out. The argument for agroecological livelihoods is closely linked to knowledge, creativity, and the solidarity economy - a values-based approach to economic well-being that prioritizes the welfare of people and planet over profits and growth. The emphasis is on agroecology's connections with the agency and autonomy of food producers, family farming as a way of life, and the importance of smallholders to rural areas. ${ }^{108}$

Food sovereignty movements have long argued for the importance of farmers' agency and meaningful livelihoods in agroecology. "Our diverse forms of smallholder food production based on agroecology generate local knowledge, promote social justice, nurture identity and culture, and strengthen the economic viability of rural areas. As smallholders we defend our dignity when we choose to produce in an agroecological way," proclaimed the International Forum for Agroecology. ${ }^{109}$ La Via Campesina, an international movement that coordinates peasant organizations of small- and middle-scale producers, agricultural workers, rural women, and Indigenous communities from Asia, Africa, America, and Europe, invokes the value of the peasant way of life in their framing of agroecology. Social movements and farming families often highlight how agroecology can improve farmers' livelihoods by helping them rely less on — or avoid altogether — input and credit markets, expensive technologies, and exploitative long supply chains. ${ }^{110}$

Indigenous Partnership evaluated the resilience of farming systems during the COVID-19 pandemic in Yucatan, Mexico, and North East India. Farmers were using both conventional and traditional approaches and asked the following questions: "How can I transition to a system that uses less, or substitutes external, inputs without losing yield? How can I strengthen my traditional knowledge to improve yield?"111 In the Yucatan, Mayan community members revived a traditional knowledge-sharing platform so farmers could exchange information and learn from each other to solve problems in their fields, share seeds, and exchange food. In Meghalaya, India, the sale of wild and previously neglected species grew and digital social media led to increased interest in wild food plants. ${ }^{112}$

Agroecological and regenerative approaches and Indigenous foodways also give life to cultural expression, but as CAWR-ALC suggests, we have not yet devised sufficient indicators to capture the value and importance of cultural and ecological preservation. There is no shortage of voices articulating the magnitude of these values in terms of well-being, but measuring them and providing evidence of their worth remains elusive. An emerging narrative links agroecology with alternative definitions of well-being and living in harmony with nature."113 


\section{CASE STUDY: POLITICAL SUPPORT UNDERSCORES THE VIABILITY OF PASTORALISM}

\section{Hassan Roba (The Christensen Fund, Kenya)}

Nomadic pastoralism systems are one of the oldest food production systems in the world. These low external input systems rely on the movement of livestock through a landscape following the available natural fodder, which changes with the seasons and the rains. When it rains, pastoralists follow the nutrient fluxes that change quickly with rain. This system relies on the natural changes of the ecosystem. When there is a good rain, there are quick grasses that grow, and pastoralists move there quickly to harness that resource. Then they go back to other areas, which have been rested for a while, and treat that as pasture. This is a very old system that people have used, learned, and grown with, and it has supported their production and their livelihoods.

Many challenges face these traditional systems. First, there are issues with land access and tenure. The government is taking prime land, and so there is, in general, more competition for land. Second, markets for pastoralists are limited. Third, increased frequency and severity of droughts are affecting the available natural pasture lands and the health of the livestock. These shocks are used against them, and governments claim that their food systems are not viable because they cannot absorb sudden shocks. The resilience of the pastoral system is broken by external intervention.

However, pastoralism in Kenya contributes to 20 to 30\% of the gross domestic product (GDP), accounting for $50 \%$ of agricultural GDP. In recent years, the government has begun to provide more services to pastoralists, such as medical and veterinary services. In 2016, a new significant land law was passed that recognizes customary tenure rights associated with this pastoral system. This land policy is contributing to sustainable natural resources management. With more secure land tenure, there will be better planning and shifting, and resting for the land. Supporters of this law are now focused on the process of land registration for communities, so they will have secure customary tenure rights.

In the last few years, recognition for pastoralism has been growing globally, through groups like WISP (Wilder Lands for Mobile People), WAMIP (World Alliance for Mobile Indigenous Peoples), and others. A recent report by PASTRES* turns debates about meat production and climate change on their head, and provides evidence in support of extensive pastoral systems. ${ }^{114}$ The FAO voluntary guidelines have also been very supportive of the land use by pastoralists. At the regional level, there is now a policy by the African Union. Internationally, there is a changing environment in support of evidence that is drawn globally to put policies in place. At the national level, groups of policymakers and legislators, mostly from pastoral areas, are forming cohorts, pushing for the government to appreciate and recognize this system. It's also bearing fruit. In Kenya, for example, there is a Coffee Board and a Cereal Board, but not a Pastoralist Board. This is linked to a colonial mentality, because coffee and tea are colonial crops that were grown during the colonial period in the highlands. Many governments have inherited this type of thinking that commercial export-oriented production should be the main focus.

*Pastoralism, Uncertainty and Resilience: Global Lessons from the Margins (PASTRES) is a research program funded by the European Research Council (ERC). 


\section{CASE STUDY: POLITICAL SUPPORT UNDERSCORES THE VIABILITY OF PASTORALISM}

The majority of farmers in Kenya are subsistence smallholders. The agricultural areas where family farming is possible with agroecology, in small plots, is currently seen as a viable livelihood system. To some extent, pastoralism is now being recognized, especially with crop failures in other parts of the country. Internal policies are shifting, mostly due to practical observation and research that tells them "this is gold that you have forgotten." Experiences from countries like Botswana, which depend purely on pastoralism or on livestock for their economy, are examples of this livelihood's viability. Kenya is now asking itself, Why not introduce the livestock industry as an income-generating industry when it just requires some small development or support? Considered next to other systems that require a lot of external inputs - fertilizer, pesticides, labour ... all those things are very demanding - this is a relatively easy system. This is a process of shifting the mentality. The work is not yet done; it is a struggle. 

AND SOILS CRISES?

\section{From silver-bullet solutions to a repaired relationship between people and nature}

With elements of biophysical knowledge, scalable practices, and strong social change foundations, agroecology, regenerative approaches, and Indigenous foodways represent some of the most viable systemic responses to climate change by enhancing resilience and innovations in land and ecosystems-based adaptation and mitigation. The holistic nature of these approaches are more systemic than narrowly focused technology-centric solutions that often serve to instrumentalize nature and enable offset-trading regimes that do not address the root causes of the climate crisis.

With the Earth's ecosystems degrading at an alarming rate, the narratives of quick, emergency response often serve to uphold false or silver-bullet solutions — even in the face of evidence of failure — and delay or altogether eliminate the necessary transformative solutions from addressing these deep systemic crises. The Contributors noted that while many vested interests derive benefits from these solutions, smallholder farmers and food producers often do not. Such solutions include tackling the climate emergency through geo-engineering or large-scale carbon capture; fixing depleted soils or managing pests in Africa with targeted doses of agrochemicals; or preserving biodiversity through setting aside lands while intensifying agricultural production. Here we share reflections and evidence provided by the Contributors on agroecology, regenerative approaches, and Indigenous foodways potentials to address these interconnected crises.

\section{Systemic responses to climate change increases resilience}

SFHC articulates how agroecology can be a true solution for enhancing ecosystems and their functions, as well as biodiversity, based on principles of ecology. As climate change intensifies and livelihoods become more complex, agroecology has emerged as an alternative to improving agricultural productivity while maintaining ecological integrity. Recent works by SFHC and its partners, working on the Farms for Biodiversity project, have focused on linking agroecological practice with ecosystems, ecosystem service use patterns, and biodiversity conservation. ${ }^{115}$

As an adaptive strategy to increased occurrence of droughts as a result of the climate crisis, the APCNF is experimenting with a unique innovation to harness atmospheric water vapour in order to allow dry sowing, increase soil and crop performance, and grow crops 365 days a year. This is a major breakthrough in the development of agriculture. Natural Farmers from Anantapur took up Pre-Monsoon Dry Sowing (PMDS) in their fields in May (2018 and 2019), without waiting for monsoons to set in, and prolonged the growing season. The use of high quantities of manure-based Ghana Jiwamrutam* and mulch has resulted in maintaining adequate moisture levels in the soil for seeds to germinate and establish themselves before the rains. The pilot has shown promising results, as the crop yields have continued to grow throughout the year (even in a drought year), promising higher production and incomes for farmers in this region.

*Ghana Jiwamrutam is a cow dung soil fertility preparation used in natural farming. 
An APCNF study to compare greenhouse gas ( $\mathrm{GHG}$ ) emissions in natural farming versus conventional approaches was carried out with World Agroforestry (ICRAF). The estimates indicate that APCNF techniques reduce the impact of agriculture on the climate system as compared to the same crops grown under conventional techniques. Based on management activities carried out on typical farms, the GHG budget on APCNF farms was lower than that of the conventionally grown crops for all six production systems. The difference ranged between 29\% for Bengal gram to 81\% for maize. For three of the six crops (chilies, cotton, and maize), emissions on typical APCNF farms could be expected to be less than half that of conventional farm emissions. These results indicate that a typical farm using APCNF has a much more benign impact on the climate system and is more environmentally sustainable in terms of GHG emissions than the typical high-input conventional systems. APCNF produces fewer emissions than conventional fields across all crops, often less than one-half. Lower emissions and higher or the same yields results in an average of 70\% less GHG intensity across crops (not area weighted). ${ }^{116}$

The CELIA cites several studies that demonstrate the resilience of agroecological farms in the face of extreme weather events such as droughts and hurricanes. Documented agroecological strategies that reduce vulnerabilities and increase resilience to the impacts of climate change include crop diversification, maintaining local genetic diversity, the integration of animal and crop systems, soil organic management, water conservation and harvesting, and more. ${ }^{117}$ CELIA emphasizes the importance of a full redesign of agroecosystems based on context-specific socioecological factors in order to build climate resilience.

For example, in 2011, a group of Latin American agroecologists associated to REDAGRES* engaged in a one-year survey of small farming systems in seven countries to identify and assess agroecological systems that resisted and/or recovered from extreme climatic events such as droughts, storms, floods, or hurricanes. ${ }^{118}$ Based on these findings, researchers and farmers developed a manual with two main sections: 1) a simple methodology, with diverse vulnerability and resilience indicators, that farmers can use to assess their relative vulnerability and identify actions to enhance the resiliency of the farm; and 2) a description of the main socioecological principles and practices that farming families can use individually or collectively (at the community level) to enhance the adaptive capacity of farming systems to climate change. The methodology allows researchers and farmers to understand the agroecological features of the farming systems and the social strategies used by farmers that allowed them to resist and/or recover from extreme weather events. Due to the context-dependent diversity and complexity of practices that can lead to greater socioecological resilience, these types of self-assessment and co-innovation methodologies that bring together farmers and scientists are important tools to scaling agroecology, regenerative approaches, and Indigenous foodways.

A rapid assessment of evidence of agroecology as a climate change adaptation and mitigation strategy was conducted by the CGIAR Research Program on Climate Change, Agriculture and Food Security. ${ }^{119}$ While the assessment found strong evidence of positive impacts of farm diversification on climate adaptation, it pointed out the great need for more research on agroecology and climate mitigation, particularly at landscape levels (such as through agroforestry), as well as many evidence gaps (such as in animal integration, and multi-scalar

${ }^{*}$ REDAGRES = Red Iberoamericana para el Desarrollo de Sistemas Agrícolas Resilientes al Cambio Climático, which translates to English as IberoAmerican Network for the Development of Agricultural Systems Resilient to Climate Change. 
analysis), and a large data gap with respect to agricultural emissions from the Global South. It recommends priority investments in agricultural diversification at the farm and landscape levels, and an urgent research focus on the scaling and performance aspects of agroecological and regenerative approaches vis-à-vis climate change. In other words, the tremendous potential of these approaches for system-wide impacts remains to be fully explored. ${ }^{120}$ It's important to note that this study did not include the breadth of studies from Latin America and the Caribbean that are published in Spanish or Portuguese.

\section{CASE STUDY: FARMER-MANAGED NATURAL REGENERATION IN SUB-SAHARAN AFRICA}

\section{Groundswell International}

Farmer-Managed Natural Regeneration (FMNR), developed by farmers in Sub-Saharan Africa, is an effort to mitigate the destructive impact of practices involving cutting trees and burning land to create "clean" land for farming - in the context of increased pressure on land and dramatic declines in farmer fallowing. By observing nature's way of working - with living forests of stumps and roots continuing to sprout trees and shrubs each year - farmers have developed innovative ways to allow trees to naturally regenerate on farms. They manage pruning, density, and tree varieties, integrating them into their farming systems, so that trees benefit rather than compete with annual crops. This way of regeneration also continues to allow access to wood (for fuel, shelter, etc.) and to fodder for livestock while improving soil biology. These agroecological techniques have led to impressive regreening at scale, in contrast with projects that involved planting out trees from nurseries, which generally failed due to drought, termites, livestock, etc.

FMNR also reduces surface and air temperatures through dispersed shade (which is crucial in the Sahel, a global temperature hotspot); fosters "bio-irrigation" (brings up water from deep down up to make moisture available to crop roots); and increases soil organic matter and moisture retention under the canopy of the trees. The result is increased crop growth.

Finally, FMNR is a low or "no cost" practice that often serves as an excellent entry point for farmers to begin their transition toward applying other agroecological principles and practices and that can spread farmer to farmer. 


\section{Preserving biocultural heritage conserves biodiversity}

Agricultural biodiversity is at the heart of food systems and critical for food, fuel, fodder, and livelihoods. Heterogeneity in seeds and animal breeds is the centrepiece of agroecological and regenerative approaches. Even in intensive, mixed farming (agroforestry, silvo-pastoral production) biodiversity has shown to be highly beneficial to aggregate biodiversity, heterogeneity within species, soil, ecosystem health, and productivity.

The alarming loss of biodiversity, particularly agricultural biodiversity, has focused growing attention on its main driver: agricultural expansion and related land-use change. There are calls for land sparing by intensifying production, thereby conserving biodiversity. However, experiences of land appropriation without free, prior, and informed consent of Indigenous and local communities are a worldwide concern, and colonial-style land conservation approaches have been cautioned against by many. The worldwide evidence on successful Indigenous and community-led conservation areas (ICCAs), biocultural protocols, and other customary land-use approaches is strongly indicative that these approaches perform the multiple functions of biodiversity and ecosystem conservation, sustainable use, and livelihoods while protecting territorial rights and fulfilling the food security and well-being objectives of local communities.

Moreover, as SFHC notes, the "land sparing while intensifying production" approach assumes that other land will be set aside for conservation - but there is no guarantee that this will happen. More intensified land may mean land degradation (through increased pesticide use, for example), which makes it harder for wild biota such as birds and insects to survive, even if they are only migrating through an agricultural landscape. It also assumes that intensified farming increases food availability, but intensified agricultural production often leads to the production of export crops not destined for food production. This could worsen rural food insecurity by reducing land availability for smallholders, degrade water and soil systems that smallholders also use, and increase the number of people working as farm workers under precarious working conditions. ${ }^{121}$

SFHC tested a different approach to this question, carrying out a participatory study with Malawian farmers using geospatial methods to map out and manage their farmland. Farmers who used agroecological methods undertook to reduce their land area under production because they were getting higher and more diverse food production compared to conventional methods. They chose to keep more land under fallow to restore degraded forests. Farmers using agroecological methods were also more supportive of efforts to conserve biodiversity and support ecosystem functions. ${ }^{122}$

For the Palestinian Heirloom Seed Library (PHSL), agricultural biodiversity is intimately linked with a peoples' social, cultural, and political identity. The work of the PHSL involves recovering heirloom seeds and putting them back in the hands of the community - against a violent backdrop of land expansion and settlement, as well as agribusiness expropriation of land and seeds. "Heirloom seeds also tell us stories, connect us to our ancestral roots," says PHSL founder Vivien Sansour. Palestinian heirloom seed varieties are under threat, and for Sansour, "many of these farmers are the heroes who have been safeguarding these precious seeds and the knowledge they carry." Aside from their cultural significance, seed and agricultural biodiversity are a critical food, nutrition, and livelihood strategy for Palestinian communities facing the daily challenges of food shortages and climate change. ${ }^{123}$ 


\section{Re-establishing soil and community health as the foundation of food systems}

The critical importance of soil health in agroecological and regenerative approaches cannot be understated, as it is the bedrock of growing healthy food and communities. SFHC notes the strong narratives circulating today that African soils are so degraded that they cannot produce food without chemicals and improved seeds. Many soil scientists claim that synthetic fertilizer is required in Africa because of heavily depleted soils (including a loss of phosphorus, which cannot be easily sourced from organic materials). Related to this is the claim that ecological agriculture cannot resist pest and disease disasters, and that the "heavy artillery" of chemical pesticides is needed to combat major threats to crops (such as the Fall Army Worm). ${ }^{124}$

SFHC responds to this narrative with evidence from other parts of the world (such as India) that increased synthetic fertilizer use leads to excessive water and soil pollution, and farmer dependence on purchased inputs, increased debt, and the need to transition away from this model of agriculture. It is unwise to encourage African farmers toward a model that is fundamentally flawed, and whose true costs and trade-offs were never measured, SHFC notes.

Agroecological and regenerative methods provide much more than nutrients; they provide organic material that supports soil structure and helps reduce soil erosion and soil degradation in Africa. In discussing their experience with these methods, including greater crop biodiversity, crop rotation, and incorporation of organic materials, farmers in Malawi have observed improved soil health and increased crop yields, or at least a level of stability. For SFHC, it is not just a matter of agroecological versus non-agroecological, but rather a transition and continuum: At lower levels of the agroecological transition, with just input substitution, there may be little difference between agroecological and conventional farming, which may become more visible and effective through knowledge-intensive methods and improvements in landscape quality. This points to the bigger issue that there has been very limited investment and research in agroecological and organic agriculture in Africa, and considerable research needs to be done to test different biological alternatives to synthetic fertilizer, including the potential for replacing phosphorus in particular, such as rock phosphate, as well as measuring other impacts from the use of organic agriculture. ${ }^{125}$ 


\section{CASE STUDY: CREATING TRANSITIONS TO REGENERATIVE AGRICULTURE}

\section{Ecdysis Foundation}

In Estelline, South Dakota, USA, scientists are working with Ecdysis Foundation to advance the research on how regenerative agriculture can grow food while conserving soils, biodiversity, and environmental health across the country. Ecdysis was established by Jonathan Lundgren to support a national network of scientific hubs for regenerative farming research. Lundgren, an entomologist, aims to reimagine agriculture using ecological principles, based on independent, farmer-driven research. "The revolution in regenerative agriculture cannot occur without reimagining agricultural science," he says.

Based out of Blue Dasher Farm in South Dakota, Ecdysis provides research and development for innovative and scalable practices of redesigning agroecosystems to be more resilient and produce healthier food, profitably, by increasing biodiversity and reducing disturbance to farmland.

The main research strategies include:

1. Identifying key regenerative food systems in different regions that can have trickle-down effects on food communities;

2. Validating successful regenerative operations relative to conventional food production strategies using a systems-level approach;

3. Using prevalent farmer strategies and creating roadmaps for farmers wanting to transition to regenerative production systems; and

4. Using mechanistic and observational studies to help optimize regenerative systems. Focal food systems include rangeland, pastured dairy, perennial and annual crops, orchards, and honey bees.

Ecdysis places a strong emphasis on farmer, rancher, and beekeeper-driven research questions, and empowers producers by involving them in the actual research projects - from systems design to guided citizen science. Through the 1,000 Farms Initiative, Ecdysis aims to grow regenerative agricultural models nationally and beyond, establishing a network of facilities around the country that can address local and regional contexts. According to Ecdysis, "We anticipate a paradigm shift in the way food is produced in this country, and we want to have answers ready for farmers when they are ready to farm in nature's image." 


\section{CASE STUDY: COLLABORATIVE CLIMATE RESILIENCE IN THE ANDES}

\section{Collaborative Crop Research Program}

The Andes encompass the highlands (2,500 metres or higher above sea level) of Bolivia, Ecuador, and Peru. The CCRP Andes Community of Practice supports integrated and diverse production. Funding is directed toward local food systems and markets, nutrition, seed networks focused on conserving and enhancing agricultural biodiversity, ecological pest management, risk management focused on climate variability, and soil health. Pathways to change in the Andes include integrating different knowledge systems, taking a landscape approach, incorporating natural and human systems, and providing various options for different contexts. Collaborative Crop Research Program (CCRP) emphasizes social and horizontal learning approaches based on trust and respect at all levels and scales.

The three pillars of the Andes Community of Practice's capacity-strengthening strategy are:

1. Improving research relevance through participatory approaches and a utilization focus.

2. Improving research quality, including the ability to embrace and explain social and biophysical variability, focusing on agroecological systems using mixed methods, and connecting local and global knowledge.

3. Communicating and sharing learnings with various audiences.

Three core projects (led by Prosuco, Proinpa, and the Universidad Mayor San Andres) in Bolivia are each building Farmer Research Networks that focus, in part, on the challenge of documenting weather patterns and climate, providing forecasts for farmers in the high Andes, and building a knowledge base that brings together both scientific and traditional Indigenous knowledge. They are answering the question: How can different forms of knowledge be brought together to support farmers' decision-making and build agroecological and climate-related evidence?

These three organizations have different research focuses and experience working with farmers, but all are located in the high Andes of Bolivia. In 2016, they began discussions aimed at building connections between work being done in each project; for example, the development of an app (weather underground); the use by farmers of a weather-monitoring tool called the Pachagrama; monitoring data from meteorological stations; and Indigenous knowledge of climate-related indicators in the natural environment (for example, plants, animals, insects, clouds, and more). They also shared in common a desire to build Farmer Research Networks bringing together researchers, NGOs, other rural organizations, and farmers within a participatory approach that values farmer knowledge and agency.

These projects link agricultural planning with local knowledge; specifically, how farming decisions are made based on local perceptions and information on climate. By promoting an intergenerational dialogue about the utility of local knowledge, the culture is kept up to date and dynamic, as debate and dialogue allows knowledge reconfiguration that is responsive to current processes and developments. Through these projects, an integrated climate-planning tool is being developed, based on local knowledge (natural indicators related to weather patterns, flora, and fauna) and scientific knowledge (historical data from weather stations) to help farmers make agricultural planning decisions based on improved forecasting tools used to predict short- (1 to 2 days), medium- (3 to 10 days), and long- (seasonal) term meteorological conditions. The purpose 


\section{CASE STUDY: COLLABORATIVE CLIMATE RESILIENCE IN THE ANDES}

of these tools is to reduce the vulnerability of smallholders to climate variability and change, and be able to react to the weather in an efficient manner. For example, farmers can decide when to plant based on longterm forecasts, when to harvest and dry based on medium-term forecasts, and react to short-term forecasts of frost or hail by applying bioles (biofertilizers and fermented products) to crops, lighting small fires in the fields to keep crops warm, and even launching firecrackers to disperse hail clouds.

The key insights related to evidence include:

- Building and spreading agroecological knowledge requires a dialogue between local and global knowledge systems to generate innovation and adaptation in continually shifting contexts.

- Promoting the interrelation of local and global knowledge is a step toward egalitarian relations between different types of knowledge with potentially important implications for intercultural relations, transdisciplinarity, and meaningful collaboration.

- Interactions among projects are key to building evidence and supporting farmers. 


\section{QUESTION 5: CAN THESE APPROACHES ACCELERATE TRANSFORMATION?}

\section{From corporate capture to food sovereignty, rights, and deep structural change}

The related frames of food sovereignty, human rights, and justice are often used to advance a transformative agroecology. Acknowledging the critical place of "agency," the HLPE has added this element to their longstanding definition of food security. Social movements and researchers see agroecology as an essential component of, and pathway toward, food sovereignty. Agroecology represents an on-the-ground articulation of food sovereignty through the practices of food producers. Specifically, the concept of food sovereignty has been taken up around the world as a political project of food systems transformation, rooted in agroecology and the democratization of agriculture and food. As such, it embodies a discourse that affirms the rights of peoples to define their food and agriculture systems as well as their rights to territory and self-determination. ${ }^{126}$

\section{Agroecology represents an on-the-ground articulation}

of food sovereignty through the practices of food producers.

- CENTRE FOR AGROECOLOGY, WATER AND RESILIENCE; AGROECOLOGY NOW!; AND UNIVERSITY OF VERMONT AGROECOLOGY AND LIVELIHOODS COLLABORATIVE (CAWR-ALC)

Drawing on both food sovereignty and human rights frameworks, civil society organizations defend the rights of peoples to healthy and culturally appropriate food produced through ecologically sound and sustainable methods - as well as the rights of food producers to use and manage lands, territories, water, seeds, livestock, and biodiversity. Many of these collective rights are now officially recognized in the UN Declaration on the Rights of Peasants and Other People Working in Rural Areas (UNDROP). ${ }^{127}$

\section{Advancing food sovereignty upholds human rights}

Several of the Contributors noted that while the notion of food sovereignty, rights, and social justice largely work to frame a transformative agroecology, they can also be deployed in depoliticized ways, or interpreted narrowly as national or regional food self-sufficiency. This can feed into nationalistic, exclusionary tendencies, or become a way to promote national corporate interests. While couched as expressions of "rights" and focusing on individual choice, these approaches can obscure the power dynamics that limit the options available to farmers or citizens. The private sector's pursuit of intellectual property rights for seeds and statements regarding the right to choose which products or technologies to use are two such examples. Promoting the idea that farmers are individual consumers who should have the unimpeded right to use industrial chemicals, or that consumers should be free to choose the products they like, fails to acknowledge the trade-offs for other approaches and the constraints and factors going into such "choices," and perpetuates the narrative of simultaneous co-existence of many models of agriculture. ${ }^{128}$ 


\section{CASE STUDY: TE WAKA KAI ORA'S HUA PARAKORE INDIGENOUS VALIDATION AND} VERIFICATION PROCESS

\section{EnviroStrat}

The relationship between food sovereignty, organic and regenerative approaches, and the Māori worldview is meaningful. Emerging trends of food sovereignty (control over the way food is produced, traded, and consumed), food equity (equal access to quality food and food-producing resources), and food security (access to sufficient, safe, and nutritious food to meet dietary needs and food preferences for an active and healthy life) make critical informed decision-making for farming and food operations paramount.

In the last 20 years, New Zealand has seen the emergence of a Māori/Indigenous renaissance in selfdetermination. To support a deeper paradigm shift in New Zealand, the framework of organic regenerative practices is being explored in conjunction with a Māori worldview and proposes to take the whole country on a journey of learning. Indigenous values and decision-making processes can align both with other international projects and regenerative, organic commercial ventures. This is an example of how Indigenous knowledge, in this case the Te Ao Māori (Māori worldview), can be intertwined with Western concepts to promote a unique system for food production that integrates people and nature.

This has given rise to a need to express a verification process using cultural lenses. Established by Te Waka Kai Ora (the National Māori Organics Authority) in 2001, Hua Parakore has developed its own Indigenous validation and verification system. As Dr. Jessica Hutchings (Ngāi Tahu, Gujurati) notes: "The enduring relationship of Māori interests to the organic sector in Aotearoa (New Zealand) is a testament to the values each holds, especially in regard to Papatūānuku (Earth Mother) and Ranginui (Sky Father). ${ }^{129}$ As Māori we recognize and practise kaitiakitanga, a cultural form of resource stewardship which is often complimented by organic values and practices. When it comes to food production, there are a range of systems in place by Māori producers which are 'organic' by definition and there is definitely an affinity between Māori and organic practices."

The Hua Parakore system is a Māori food sovereignty and food production system based on Māori cultural values that supports food-secure futures for Indigenous communities and involves growers, producers, cooks, bakers, and farmers. They are staunchly opposed to the use of chemicals, fertilizers, and GMOs in agriculture and all food production.

The Hua Parakore system has applicability across other regenerative and natural farming methods, such as agroecology, regenerative agriculture, and, of course, organics, acting as a korowai (cloak) around these other systems. The Hua Parakore system supports food sovereignty and food security for whānau Māori (Māori families and communities). It supports local māra kai (food garden) initiatives as well as agriculture and horticulture. There are Hua Parakore-verified producers both on farms, marae (tribal meeting spaces), and with Māori food outlets across Aotearoa. Hua Parakore is also available to other Indigenous producers around the world, and as such there are Indigenous producers that are Hua Parakore-verified, such as MA'O Farms in Hawaii. 
CASE STUDY: TE WAKA KAI ORA'S HUA PARAKORE INDIGENOUS VALIDATION AND VERIFICATION PROCESS

Synergies between Māori Values and Organic Regenerative Agriculture Propositions: ${ }^{130}$

\section{COMMON MĀORI VALUES}

WHANAUNGATANGA — Valuing relationships and the will to work together.

PONO - Being honest, open, and accountable of actions.

RANGATIRATANGA - Striving for excellence in everything that we do.

AUAHATANGA - Being innovative and passionate about what we do.

MANAAKITANGA - Caring for and supporting one another.

KAITIAKITANGA - Guardianship of what is important.

\section{EXPRESSION IN ORGANIC REGENERATIVE PRACTICES}

POTENTIAL — Of resources and those managing them together.

PURITY - Without contamination the potential for growth increases.

PLURALISM - Increased diversity of experiences, capacities, opportunities, and openness to new experiences.

PERMANENCE - New, more positive behaviours take root and provide a deeper meaning to life.

PROGRESS - Capacity for well-being and enjoyment increases.

PROTECTION - Improvement in reliance of land and strength of the people.

From a food systems governance perspective, this case study illustrates how Indigenous knowledge systems can inform and shape organic and regenerative agriculture sectors while upholding food sovereignty and collective rights as well as Indigenous values and decision-making processes.*

*For further information on Hua Parakore and Te Waka Kai Ora, see https://www.tewakakaiora.co.nz/. 


\section{Gender equity and feminist agroecology are key to systems transformation}

In the agricultural and food production sector - where the majority of women (80\%) in developing countries gain their livelihoods - gender discrimination, violence, and inequality are common. Women often lack rights to land and productive resources, as well as access to finances and technology; are excluded from decision-making; experience gender-based violence; and are disregarded for their knowledge systems. Yet around the world, women are leading the fight for more equitable food systems and playing a central role in the science, practice, and movements of agroecology. The Contributors showcased the many ways in which women play these roles: Women possess sophisticated knowledge of agricultural biodiversity that influences farmers' research. Women organize and carry out collective action, such as creating self-help groups and mobilizing their communities and movements. Women manage the programs undertaken by village and regional committees, often carrying out the financing required to purchase local materials and inputs. In addition, women provide essential support and labour to their farms and households — harvesting and selling cash crops in the market, growing additional crops for household consumption, and providing care for their families. ${ }^{131}$

As a number of the Contributors highlighted, in Africa, as in many parts of the world, it is women who are leading the fight against the oppression of the agro-industrial food system - and its violent consequences for people and the land. In many regions of the world, feminism is a common thread in agroecology and food sovereignty, bringing together the decolonization, Indigenous reconciliation, and anti-poverty and racial justice movements. Feminist ecological approaches combine anti-colonial and Indigenous perspectives in order to reconstitute non-hierarchical relationships among people, between people and nature, and, through this shift, between people and their food. ${ }^{132}$

Agroecology, with an expressed horizontal learning and co-creation approach — along with strong links to human rights and food sovereignty - is seen as an equalizing force for gender. Movement actors and researchers are emphasizing the link between agroecology and gender justice, and a "feminist agroecology" that gives power to women's movements and enables them to take their place as primary agents of change, challenging dominant power to confront colonialism, racism, capitalism, and patriarchy in the food system. A common phrase in these movement circles is "Without feminism, there is no agroecology."

\section{Inclusive governance facilitates transparency and accountability}

Participation and democratization are at the heart of transformative agroecology, putting collective agency in the hands of organizations of agricultural producers and citizens. For CAWR-ALC, this is primarily a mobilization frame that provides a vision and a basis for the process and governance-oriented principles of agroecology (as outlined in the HLPE). For example, by shifting the focus from agriculture to the entire food system, a wider range of stakeholders can be meaningfully involved in designing and assessing policies for agroecological transformation, thereby linking participation with the holism frame, which emphasizes the interconnectedness of elements in agroecological food systems. Moreover, several authors argue that promoting multi-actor collaborations at the territorial scale, for instance in the form of food policy councils, is a particularly enabling factor in agroecological transformations. ${ }^{133}$ 
By shifting the focus from agriculture to the entire food system, a wider range of stakeholders can be meaningfully involved in designing and assessing policies for agroecological transformation.

- CENTRE FOR AGROECOLOGY, WATER AND RESILIENCE; AGROECOLOGY NOW!; AND UNIVERSITY OF VERMONT AGROECOLOGY AND LIVELIHOODS COLLABORATIVE

Similarly, FAO TAPE considers participatory, "responsible" governance as key to agroecological transitions. It argues that transparent, accountable, and inclusive governance is required at multiple scales; for example, to ensure equitable access to nature, including land. Further discursive links can be made between participation and other domains of agroecology transformation. Some associate agroecology with the commons, stressing collective approaches to environmental stewardship and knowledge. ${ }^{134}$ Michel Pimbert calls for different forms of radical democracy and active citizenship in the governance of research and knowledge production for agroecology. ${ }^{135}$ Others emphasize the collaborative character of agroecological systems of exchange, embodied, for example, by cooperatives, participatory guarantee schemes, and community-supported agriculture, which are often community-based, embrace participatory decision-making, and strive toward inclusivity. ${ }^{136}$

ENDA Pronat works to implement agroecological practices at the scale of family farms. Family farming groups and organizations, as well as other community stakeholders (elected officials, teachers, technical services, etc.) are being strengthened and made sustainable through the development and implementation of mechanisms and tools for local and sustainable governance of natural resources. This process is increasingly taking shape in 10 targeted municipalities through the establishment of multistakeholder consultation frameworks, local natural resource management agreements, or ecological land management plans, thus constituting a first stage of implementation of the scaling out and scaling up of the agroecological transition.

A widely cited institutional example of participatory governance in agroecology is Brazil's integration of agroecology into public policy and discourse, guided by a long history of interactions between the state, social movements, agricultural producers, and researchers. This social dialogue played a key role, both in building convergence within civil society around a shared framing of agroecology, and in proactively shaping the state's understanding that the development of agroecology requires a state-civil society dialogue. It led to the adoption of the National Policy on Agroecology and Organic Production (PNAPO) and the associated plans guiding its implementation. ${ }^{137}$ However, over the last six years, the Bolsonaro government has significantly altered the political space for agroecology and national governance institutions, illustrating the fragility of participatory governance supported by the state. The agroecology movement in Brazil continues to look for ways to strengthen governance spaces at the city and state level that have a more progressive vision, such as the campaign carried out by the National Articulation of Agroecology (ANA) to create a national network of agroecological cities. 


\section{ASCENDANT NARRATIVES}

The pandemic has exposed the starkly different contributions of various agricultural models under stress. Short-chain, more multifunctional systems strongly connected to local realities have survived and even thrived: local seed businesses and agroecological markets, local food infrastructure, community seed sharing, rewilding and cultivating abandoned urban and peri-urban lands, animal- and bee-keeping, new municipal services, and new school gardens, to name a few. Indeed, many have developed new innovative features (such as using online technologies) and strengthened existing ones. ${ }^{138}$ On the other hand, the long, linear value chains of the industrial agricultural system have revealed fragility: the unavailability of seeds, labour shortages, supply chain rigidity. ${ }^{139}$ "During this past year," says CELIA, "we have witnessed how agroecology offers the best agricultural system able to cope with challenges posed by ecological ruptures like climate change and COVID-19, by exhibiting high levels of diversity and resilience."'140

The Contributors identified key questions, debates, and narratives related to agroecology, regenerative approaches, and Indigenous foodways. They also provided evidence from their perspectives, places, and initiatives that address these questions, revealing how narratives are, or are not, influenced by our understanding of the evidence.

The Contributors had many ideas in common when it comes to lifting up shared narratives that have the power to resonate with key audiences. We see these as "ascendent narratives" with the power and potential to transform and reshape food systems in the face of the multiple and overlapping global crises we face: climate change, growing inequality, food insecurity and malnutrition, and biodiversity loss.

- The interconnectedness narrative: The interconnectedness of the multiple crises — in their root causes and their systemic solutions - leads us directly to agroecology, regenerative approaches, and Indigenous foodways. It also strengthens the argument that singular technical fixes cannot solve these problems, will distract us from systemic change, and often create further problems.

- The resilience narrative: The dynamism and inherent capacity of agroecology, regenerative approaches, and Indigenous foodways to build climate and ecological resilience and to foster biodiversity and sustain ecosystems as a way to withstand multiple shocks to the system by maintaining a diversity of options.

- The multifunctionality narrative: The co-benefits of agroecology, regenerative approaches, and Indigenous foodways — societal, ecological, economic, health, well-being. This dynamic and multifunctional system is the "way out of the trap" of multiple global crises.

- The political narrative: Agroecology, regenerative approaches, and Indigenous foodways are a political response, and entail a shift in power and paradigm toward a new society. Agroecology, regenerative approaches, and Indigenous foodways are about food sovereignty and democratizing the food system. They are about the rights of peasants; the rights to food, land, waters, and seeds; and the rights of agricultural and food workers. They are also a powerful narrative of self-determination.

- The engine of innovation narrative: Lauding the dynamic power of agroecology, regenerative approaches, and Indigenous foodways to generate vital new ideas and systemic solutions that drive community agricultural development, sustainable food systems, and enrich local and national economies. These approaches are constantly adapting to respond to changing socioecological realities. 
- The good food is good health narrative: The higher quality, taste, and variety of agroecologically grown foods, and their superior organoleptic properties, compared with the harmful human health impacts of chemically grown foods.

- The hopeful way of life narrative: Strengthening the narrative of farming as a way of life, and the dimensions of intergenerationality, social solidarity, and food sovereignty (including Indigenous foodways). The narrative of young farmers taking on stewardship of the land and renewing rural communities. This is also a narrative of building a new world with hope.

- The Indigenous roots narrative: The intimate connections and roots of agroecology, regenerative approaches, and Indigenous foodways, cosmovisions, and cultures (including pastoral, coastal, and forest peoples, and hunter/gatherer communities). A continuous source for learning to inform a repaired relationship between people and nature.

- The relationships narrative: Agroecology, regenerative approaches, and Indigenous foodways are relationship-intensive (as well as knowledge-intensive). Where agroecology, regenerative approaches, and Indigenous foodways are at work, community is engaged, relationships are rekindled, and society flourishes. Relationships bring together growers with eaters, farmers with policymakers, youth with elders, and humans with the land, animals, and nature - in other words, a reconnection with our ontological selves. 
SECTION 3
MOBILIZING
KNOWLEDGE AND
EVIDENCE FOR
FOOD SYSTEMS
TRANSFORMATION 
The Contributors were asked to share how they communicate and mobilize evidence as well as their key audiences. What rose to the fore was the shared belief that the acts of gathering and mobilizing evidence are deeply connected - involving peer-to-peer methodologies for exchange and transmission. This approach is reflected in the case studies and stories throughout the compendium. An important question, posed by Andhra Pradesh Community-managed Natural Farming (APCNF), is Who are we building evidence for? This is a key determinant of the approach and methodologies of evidence-gathering and how it is mobilized.

\section{THE DIFFERENCE BETWEEN INTRINSIC AND EXTRINSIC STRATEGIES}

For APCNF, the first type of evidence is intrinsic. ${ }^{141}$ That is, demonstrating practical, field-level evidence for more farmers to undertake natural farming. Groundswell International added that there is plenty of proof of the value of intrinsic evidence: "Our communication work is most effective and most clearly evident at the community level in changes in farmer practices. This has been generated by evidence presented at meetings, field visits, exchange visits, and radio broadcasts."142

For more than 20 years, the SFHC program has used participatory farmer-to-farmer strategies to generate and share knowledge. They conclude that "the combination of farmer stories, observing change over time in rural communities, and measuring impact with a wide range of indicators has been part of what has convinced us that these approaches hold solutions to our multiple crises."143

In the experience of the McKnight Foundation Collaborative Crop Research Program (CCRP) Farmer Research Network, when research is developed and conducted by farmers, it is more relevant to their concerns, needs, and interests. With greater engagement and ownership of the research, farmers are more likely to share and engage with others in "farmer-friendly" ways. Power relations shift from scientists to farmer-researchers, and at times from men to women, as they increase their control of the research agenda and funding. This also highlights the continuum between intrinsic and extrinsic evidence.

Learning from other farmers and from your own observations is often much more convincing than being told what to do and being given a pre-set package which doesn't suit your situation.

- GROUNDSWELL INTERNATIONAL

The second type of evidence is extrinsic evidence that serves to build essential buy-in from governments, policymakers, donors, foundations, and consumers for larger societal impacts, and for spreading and scaling up agroecological, regenerative approaches and Indigenous foodways. The nature, format, and tone of this approach to evidence mobilization may be significantly different depending on the audience, as it must appeal to those outside the farming community and can run up against many different opinions and commonly held narratives.

CCRP's support for its Farmer Resource Network is a good example of intrinsic evidence-gathering and strengthening rural organizations while contributing to agroecological research and development. The networks are able to represent a broad range of farmers as well as diverse ways of knowing, to amplify 
the impact of farmer-centred innovation systems, and to allow farmers to tap into existing knowledge. They rely on their own experiments not only to learn and test new ideas, but also to learn from others in their networks. They are organized into regional communities of practice that include local and international scientists and students, farmer organizations, effective local and international development organizations, and innovative food processors. In CCRP's West Africa Community of Practice, women and men work together in the Farmer Research Networks to foster agroecological intensification of sorghum and pearl millet based production systems, to develop local seed systems and value chains, and thereby to improve livelihoods and nutrition in the region. As a unique feature of the West Africa Community of Practice, farmer organizations in the region are growing, both in size and influence on agricultural research and development. CCRP is also engaged in donor networks like the AEF, Global Alliance for the Future of Food, and an informal network of bilateral, multilateral, and philanthropic donors who meet regularly to share information about their work on agroecology.

The best proof to convince a producer, a scientist, or a decision-maker is to take him on an exchange visit to a producer who practices agroecology and who succeeds in what he does on the productive level (food security, income generation, and savings) but also shows the health benefits. This is what speaks most to the general public.

- ENDA PRONAT

Extending the sharing of knowledge and evidence into policy influence is also critical. ENDA Pronat and SFHC have created multistakeholder platforms to share results and discuss ongoing research on a regular basis with the government. As ENDA Pronat notes, the evidence produced from the monitoring and evaluation of their agricultural projects is not considered sufficiently credible in the eyes of decision-makers, who often call for scientific data to back up the documentation. Hence the importance of producing this evidence in collaboration with recognized research institutions. Others have argued for establishing new methods and frameworks for monitoring and assessment that capture and make visible key agroecological characteristics such as meaningful participation and heterogeneity at multiple scales. SFHC notes that their partnership with researchers at Cornell University has provided legitimacy to their work by jointly publishing in high-impact peer-reviewed journals that the government of Malawi recognizes as solid evidence. 


\section{CASE STUDY: CITIZENS JURIES IN INDIA}

\section{Centre for Agroecology, Water and Resilience; Agroecology Now!; and University of Vermont Agroecology and Livelihoods Collaborative (CAWR-ALC)}

The prajateerpu (people's verdict) was a participatory process designed to allow the people most affected by the Vision 2020 for food and farming in Andhra Pradesh to shape a vision of their own, based on their experiences and evidence. The deliberative process combined citizens' juries and scenario workshop methods with safeguards, such as an oversight panel and witnesses as well as widespread use of the media.

Prajateerpu was effective in linking excluded local voices and visions of food and farming futures with national and international policymaking. After critically reviewing the evidence presented to them, the members of the farmers' jury - most of whom were women - offered a broad vision of a very different future compared to the one planned for them from above. ${ }^{144}$ Their vision for the future of food and farming was widely shared by the media, and the entire process had a significant impact on development policies in the State of Andhra Pradesh and beyond, including the UK Government's overseas aid priorities for Andhra Pradesh.

Throughout India, the policy impacts of prajateerpu inspired civil society organizations, peasant networks, and activist scholars to organize other citizens' juries on topics of major importance for small-scale peasant farming in India. For example, the Raita Teerpu (farmers' verdict), which took place in the State of Karnataka in 2009, focused on the priorities and governance of agricultural research. The Raita Teerpu brought peasants (especially women) together with dalits and Indigenous people from different parts of Karnataka in a single platform to assess the benefits of ongoing agricultural research in India. It helped them to debate and analyze the relevance of research for small-scale and marginal peasants. After carefully listening to evidence presented by specialist witnesses from government, the private sector, research institutes, activists, and the peasants themselves, the jury of marginalized small-scale farmers and landless farm workers presented their policy recommendations to decision-makers and the media in Bangalore, the capital of the State of Karnataka.

The extensive use of media (radio, television, newspapers, recordings in local languages, etc.) before, during, and after the Raita Teerpu ensured that over 10 million households followed these citizen deliberations and heard the jury's recommendations on what kind of agricultural research is needed for marginalized peasants who represent the majority of the population in Karnataka and rural India. In turn, the food and farming futures envisioned by marginalized peasants, Indigenous Peoples, and pastoralists from dryland India were fed into the international forum on the governance of agricultural research. The process itself enabled strong movement-building for food sovereignty and democracy in South India. 


\section{THE ROLE OF RELATIONSHIPS IN STRATEGY}

All of the Contributors agreed that relationships are key to advancing transformative agroecology and regenerative approaches. By and large, there are too many reports, news stories, and "state of the world" publications, resulting in report fatigue. While the words and numbers can be powerful and convincing, their effect over time decreases. Real human relationships often rekindle connection and peer-to-peer inspiration by distilling simple, effective messages that impact opinion and action.

As Agroecology Research-Action Collective (ARC) noted, wherever agroecology has been scaled successfully, it is thanks to deep relationships, social organization, and networks of collective education and influence. They point to the importance of knowledge mobilization through such collective entities as consumer associations, farmworkers' organizations, and youth networks. ${ }^{145}$ Similarly, ENDA Pronat has utilized collective and peer-topeer knowledge exchange and mobilization strategies for over three decades, as described in the case study that follows.

According to local organizations, the most convincing evidence at the community level comes from the farmer's testimony and experience of agroecology practices and benefits. Horizontal transmission of knowledge between farmers is therefore key, and several mechanisms and methods exist and have proven to be effective, such as Farmers' Field Schools ${ }^{146}$ or peer approaches through model or master farmers experimenting with agroecology practices and sharing them among communities.

- FOOD AND AGRICULTURE ORGANIZATION, TOOL FOR AGROECOLOGY PERFORMANCE EVALUATION (FAO TAPE) 


\section{CASE STUDY: MOBILIZATION STRATEGIES IN SENEGAL}

\section{ENDA Pronat}

The action research carried out by ENDA Pronat and its partners has gradually evolved since 1986 from a scale limited to individuals (fields or family farms) and producer groups to more global scales involving rural communities at a village or landscape level. Tools such as farmer field schools, the exchange of experiences and knowledge between farmers in different zones, the capitalization of farmer experiments, and the village approach have fostered joint learning and dissemination, and have been taken up in practice. There are now 16 municipalities engaged in agroecological transition at different levels. ENDA is particularly focused on the support, investment, and consolidation of local dynamics to strengthen the credibility of the evidence by the peasants and to demonstrate to the state that they can go to scale. ENDA Pronat is focused on working with crops on which local food security is based.

In their knowledge mobilization, advocacy, and scaling efforts, ENDA first established multistakeholder consultation frameworks, local natural resource management agreements, or ecological land management plans. They forged links with several research institutes of the Joint Laboratory for Ecological Intensification (LMI-SOL), which brings together national and international research, education, and training institutions in order to coordinate efforts, jointly develop action strategies, and co-design new working methods based on experiences to facilitate the scaling up of an agroecological transition in Senegal. This is particularly the case with the Dynamique pour la Transition Agroecologique au Senegal (DyTAES) and the Alliance for Agroecology in West Africa (3AO).

Among recent flagship results, ENDA Pronat cites the commitment of local authorities in the emergence of a network of 50 municipalities and green cities of Senegal (REVES), which aims to contribute to the development of territorial policies based on the principles of agroecology, especially in terms of good governance of natural resources. The evidence that ENDA Pronat and NGO partners produce from the monitoring and evaluation of agricultural production are not considered sufficiently credible in the eyes of decision-makers. Hence the importance of producing this evidence in collaboration with recognized research institutions. It is in this sense that within the framework of the DESIRA Fairs and AVACLIM projects, during the second half of 2020, ENDA Pronat participated in several meetings with its scientific partners from ISRA, CIRAD, and IRD to co-design a multicriteria evaluation method of the effects of agroecological practices and the analysis of the barriers and levers to the scaling of the Agroecological Transition.

To engage a wide range of producers, consumers, and the public, ENDA has organized Agroecology Days (since 2008) for higher education in ecological and organic agriculture, featuring fairs and tastings of agroecologically grown products. These are broadcast on Senegalese television. ENDA Pronat created a song and a musical video about agroecology with a group of Senegalese singers. They set up a professional program in higher education in ecological and organic agriculture because they believe that it is fundamental to teach agroecology in university courses. ENDA Pronat also collaborates with elementary schools on environmental education (related to environmental protection and notions of agroecology) to instill good behaviour in children from an early age. ENDA Pronat are active on social media and post videos on our YouTube channel. 


\section{CREATIVE MOBILIZATION}

Seeing is believing, and relationships with diverse farmers that are managing successful regenerative farms are the first evidence. Learning from them is key. From these roots, practising and experiencing regenerative food systems personally is also extremely important evidence.

- ECDYSIS FOUNDATION

It is clear from the case studies and examples provided that evidence comes alive when it is mobilized in both intrinsic ways (between farmers' and food producers' own communities) and in extrinsic ways (to policymakers and governments, to consumers and concerned public, and to external researchers and scientists). The Contributors showcased a wealth of creative mobilization approaches, such as supporting platforms that encourage peer-to-peer research or providing funding to farmers' organizations to coordinate farmer seed fairs and exchanges, with many outlining key strategies for communicating and influencing specific audiences, including which narratives work best for which audiences. The importance of relationships, solidarity, and mutualism was seen as critical to enable deeper knowledge exchange, discourse, and the kind of long-term engagement that can accelerate agroecological transition, building on science, practice, and movement.

In relation to evidence mobilization, it is important to reiterate the priorities that have emerged from Agroecology Fund's (AEF) discussions with grantees, funders, and allies: 1) the need for a new narrative of what constitutes evidence; 2) the need for evidence-gathering to be participatory and creative; and 3) the need for AEF to offer financial resources to grantees for gathering and disseminating evidence for agroecology. ${ }^{147}$ 
SECTION 4
TOWARD A
TRANSFORMATIVE
RESEARCH AND
ACTION AGENDA:
FIVE PRIORITIES 
Indigenous Peoples and farmers have long recognized the interconnectedness between our food systems, health, and the planet. This holistic, transdisciplinary, and inclusive understanding of food systems is essential for the public good and a transformative research agenda that addresses critical gaps.

The Contributors illustrated that transformational change is possible, it is happening, and it involves systemsbased, participatory, and action-oriented research that is generating evidence about the indivisible ecological, health, social, and economic impacts of agroecology, regenerative approaches, and Indigenous foodways. This evidence is well documented in a diversity of ways - in the scientific literature, by farmers and food provisioners, by Indigenous Peoples, by civil society, and by research institutions - and is increasingly being accepted by policymakers, donors, and private-sector actors. The Contributors emphasized the importance of the social and political transformations that are a central part of transitions to agroecology, regenerative approaches, and upholding Indigenous foodways.

The Contributors illustrated a number of gaps that, when considered together, represent a transdisciplinary research and action agenda. The priorities outlined in the following pages bring together multiple actors to collectively identify the contextual barriers (lock-ins) and surface appropriate solutions as powerful forces for change. Key to this is providing support to the organizations of farmers, food providers, and Indigenous organizations who are generating knowledge, building evidence through practice, and are engaged in participatory research and action. Through solidarity and alliances of principle actors (farmers, researchers, consumers, governments, businesses) in territories as well as at the national and international levels, this research and action agenda must be designed to co-create and mobilize knowledge and evidence that informs policy and investments to enable agroecological transformation. These alliances should be rooted in principles of equality, justice, inclusion, and reciprocity.

Synthesizing the recommendations identified by the Contributors, five priorities are identified, forming the basis of a transformative research and action agenda. The first and second priorities address the need to shift the type of information we are collecting to build evidence, with a focus on research that is systemsoriented, comparative, longitudinal, and landscape-focused. The third priority is a call to build capacity for transdisciplinary, participatory, and action-oriented approaches. Advancing equitable and resilient food systems requires a shift in not only what we are researching but how and for whom we do research. The fourth priority brings attention to the importance of knowledge and evidence mobilization and communication. Oftentimes the evidence in support of these approaches exists but is not communicated effectively in the appropriate format to diverse audiences, or it is not shared beyond a farm or community. The fifth priority addresses key governance and policy changes that are required to build pathways for transformation. While these five priorities are primarily addressed to funders/donors, universities, and research institutions, they are also relevant to governments, civil society, farmer organizations, and other actors who are interested in food systems transformation.

The Contributors emphasized that a transformative research and action agenda must:

- Advance political justice elements of food sovereignty, gender equity, and rights to land and seeds.

- Boost investments in public research and development that focuses on agroecology, regenerative approaches, and Indigenous foodways, with a focus on the public good rather than private interests. 
- Assist farmer and food producer organizations to strengthen knowledge and evidence mobilization strategies for their own movements, as well as advocating for more supportive policies and practices.

- Build capacity for participatory, multidisciplinary, multi-actor research and action, and support co-innovation with farmers, value chains, and policymakers.

- Strengthen transdisciplinary and feminist agroecology methodologies that break down colonial and patriarchal knowledge regimes, and lift up the agricultural knowledge systems of women, Indigenous Peoples, and other marginalized communities.

- Reform the current system for academic valuation so that outcomes other than scientific publications and policy briefs are encouraged and hence better allow co-inquiry, participation, and democratization of knowledge.

- Convene diverse actors, including funders supporting agricultural research, to understand tensions related to research, action, and agroecological transitions and to continue co-creating knowledge with an emphasis on farmer-to-farmer dialogues and knowledge sharing through horizontal networks of exchange.

- Develop and mainstream innovative approaches and methodologies that highlight good practice case studies and ascendant narratives in agroecology, regenerative approaches, and Indigenous foodways in order to influence research and policies.

\section{PRIORITY 1: SUPPORT COMPARATIVE AND SYSTEMS PERFORMANCE RESEARCH}

Agricultural research is too often very narrow in focus, measuring a limited number of indicators, like yield, and with a strong bias toward quantitative indicators. This limits a nuanced analysis and understanding of the multiple social, economic, and environmental impacts of distinct food and farming systems, effectively short circuiting longer-term transformational goals. What we measure dictates where investments and policies are directed. It is important to measure success, performance, and resilience through a wider systems lens in order to provide evidence on the multifunctional benefits of agroecology, regenerative approaches, and Indigenous foodways. The "Summary of Evidence Gaps Identified by the Contributors" (see Table 2, page 88) outlines priority areas where systems-based research is necessary. The FAO's TAPE tool is an illustration of the kind of methodology that captures systemic impacts.

Research that compares, through a systems performance analysis, the relative true cost and true value for the environment, health, and society — of agroecological and regenerative approaches and Indigenous foodways as compared to industrial food systems is a key priority. In particular, comparative studies are needed to assess how these systems perform in the face of impacts from the climate crisis in relation to the reduction of GHG emissions; their capacity to effectively sequester carbon, and enhance biodiversity, ecosystem, and soil health; as well as how they perform in relation to diverse adaptation needs around the world. Groundswell International emphasizes the importance of critically assessing the efficacy and viability of "business as usual" (in particular, industrial agriculture), as well as assessing how traditional agriculture is adapting to forces of climate change and land degradation. Similarly, comparative evidence is required to assess and enhance the resilience of agricultural systems where the performance of traditional farming has been eroded due to socioecological changes (that is, population pressures or irregular rainfall). Comparisons 
are also needed about the impacts on farmers who are transitioning or have transitioned to agroecology (from whatever initial set of practices) vis-à-vis those in the same communities who have not transitioned. ${ }^{148}$

While measuring overall agroecological performance under adverse conditions is essential, many Contributors, including Agroecology Europe and McKnight Foundation Collaborative Crop Research Program (CCRP) Farmer Research Networks, remind us not to overlook variability and the importance of gathering complementary evidence from multiple points and sources. One of the most important paradigm shifts that CCRP promotes in terms of agroecological evidence is "a move away from looking at averages and silver bullets to embracing and trying to understand variability. Locally gathered information and data under a shared framework are useful for building robust evidence and telling a larger story by bringing together many different sources of information."149

The Contributors mentioned an additional gap: evidence related to the capacity of Indigenous foodways to foster resilient ecosystems, biodiversity, and provide food and nourishment for the community. The relationship between Indigenous foodways and climate adaptation and resilience is notably under-examined. As the Intergovernmental Panel on Climate Change (IPCC) notes with high confidence, "approaches informed by Indigenous knowledge and local knowledge ... can accelerate wide-scale behaviour changes consistent with adapting to and limiting global warming to $1.5^{\circ} \mathrm{C}$." However, IPCC acknowledges that we still don't know how to measure the full extent of the knowledge of Indigenous Peoples: "Indigenous and local knowledge includes information about past and present climate states. Assessing this knowledge and integrating it with the scientific literature (including IPCC findings), remains an ongoing challenge."150 Understanding the variability across Indigenous foodways, as well as the viability of this knowledge to support climate adaptation and resilience, is a critical priority.

The Contributors offered the following actions to advance Priority 1:

- Establish research programs, in collaboration with farmer-researchers, to assess the comparative evidence of the performance of agroecological and regenerative approaches vis-à-vis other approaches, including industrial agriculture.

- Support Indigenous-led research on climate-resilient food systems.

- Support the implementation of tools and methodologies that accurately assess the true value of food systems and support holistic comparisons between agricultural approaches and models (for example, TCA, TAPE, ACT, MESMIS). *

- Expand the scope of evidence-assessment tools to include qualitative information, storytelling and digital tools, and innovative methodologies to capture the vast agroecological and Indigenous knowledge that already exists.

- Support transdisciplinary research to understand the variable and context-specific impacts of agroecological approaches through farmer-led research at differing scales and biophysical and ecological regions.

\footnotetext{
${ }^{\star}$ TCA = True Cost Accounting; TAPE = Tool for Agroecology Performance Evaluation; ACT = Agroecology Criteria Tool; MESMIS = Marco para la Evaluación de Sistemas de Manejo de Recursos Naturales Incorporando Indicadores de Sustentabilidad (in English, Framework for Evaluation of Natural Resource Management Systems Using Sustainability Indicators).
} 


\section{RESEARCH CHALLENGES IN AGROECOLOGICAL AND REGENERATIVE APPROACHES ${ }^{151}$}

\section{Agroecology Europe}

In their contribution, Agroecology Europe synthesized the research challenges they have identified in their collective research. This list illustrates the range and scope of research priorities identified by their interdisciplinary team.

- Integrating agroecology into agrifood systems. Agroecology emphasizes different elements in the food system, such as a reliance on diversity, recycling of elements, and seeking strategies. The emphasis on these would reconstitute existing agrifood chains and require the creation of new chains that involve producers as well as consumers or local authorities (for example, short supply chains, agrifood chains based on quality labels, etc.).

- Promoting the agroecological transition of farms. The transition to agroecology is fraught with uncertainties for farmers who commit to it. Managing transitions well involves identifying their vulnerabilities and equipping the actors involved accordingly. A long-term view is necessary, and scientific knowledge must be combined with the actors' experiences.

- Leveraging ecological and hydro biogeochemical processes in multifunctional landscapes. The landscape dimension, which includes the spatial distribution of landscape elements on and in the soil ("green infrastructure"), the spatio-temporal organization of rotations, and the management of crops and livestock ("landscape of practices") is an essential dimension of agroecology.

- Leveraging genetic diversity in plant and animal selection. Genetic diversity can contribute to the design of agroecological systems. Breeding schemes for plants and animals need to evolve to improve the provision of ecosystem services and resilience of agroecosystems.

- Modelling interactions between living organisms while considering environments and socioeconomic contexts. It is a matter of better equipping researchers and actors in terms of representation, understanding, and prediction of agroecosystem dynamics in order to better identify and manage their strengths and vulnerabilities.

- Identifying agricultural equipment required for agroecology and the possible benefits of digital technology. Examining the potential contributions that technology, sensors, equipment, and services can make to the development of agroecology. 


\section{PRIORITY 2: EXPLORE QUESTIONS OF SCALE, TIME, AND SPACE}

The Contributors emphasized that it is critical to identify both strategic pathways for taking agroecology to scale as well as evidence that circumvents doubts about scalability and demonstrates how it can be done. FAO TAPE, Agroecology Europe, and other Contributors stressed that longitudinal studies are a crucial evidence gap. Agroecological systems are implemented over time, and the collection of data and evidence evolves as the proof of successful transition is demonstrated over longer time periods than most development projects cover. Agroecology Research-Action Collective (ARC) pointed out that the test of time has been applied selectively, and that the Green Revolution was widely accepted and implemented before any rigorous data and evidence existed to support the approach. Agroecological and regenerative approaches have existed over much longer time horizons, and yet some still emphasize there is not enough evidence. The impacts and benefits cited by agroecology researchers (improved rural livelihoods, community health and nutrition, biocultural and biodiversity conservation) are centrally important for food systems resilience. However, important synergies and trade-offs that directly affect these impacts manifest themselves over longer time periods in complex dynamic systems. We must therefore take the time scale into account, frontloading resources to enhance synergies, and anticipate and mitigate trade-offs over the long term.*

\section{The temporal and spatial scales have been critical in the use of TAPE as a measurement tool for agroecological and regenerative approaches. \\ - FOOD AND AGRICULTURE ORGANIZATION, TOOL FOR AGROECOLOGY PERFORMANCE EVALUATION (FAO TAPE)}

Equally important is the spatial analysis of agroecological transition and scaling. For example, ARC observes that the vast majority of North American research on agricultural transition focuses on, and stems from, the mindset of the individualization of farmers' actions (farmers as decision-makers). Yet, the most significant transformative benefits and impacts of agroecology and regenerative approaches manifest themselves beyond the individual or farm level - at the landscape level — in regional food economies and, at times, in sectors other than agriculture (such as public health). ${ }^{152}$ For ARC, FAO TAPE, CAWR-ALC, Agroecology Europe, and others, a true understanding of agroecological transformation requires the lens of "territory": a spatial scale where change is more systemic, a scale in between the whole farm and the food system levels, and an essential domain of agroecological transformation. ${ }^{153}$ Analysis of the territorial level looks beyond the biophysical aspects (landscape and ecosystem), as well as beyond food production, to include territorial markets, local and regional value chains, the role of institutions, and the relationships between growers and eaters. A territorial lens considers ecological, social, political, and economic factors critical to agroecological transition, and includes the political elements of collective rights to lands, waters, and seeds, as well as food sovereignty. This includes scaling up processes (creating enabling policies, markets, and other institutional factors) and scaling out processes (the geographical spread of practices, farmer-to-farmer, across communities, organizations, and regions), ${ }^{154}$ where social movements are key forces for change.

\footnotetext{
*On scaling and amplification typologies, see: David Lam et al., "Scaling the Impact of Sustainability Initiatives: A Typology of Amplification Processes," Urban Transformations 2 (2020).
} 
The Contributors offered the following actions to advance Priority 2:

- Deepen understanding of scale and amplification as it applies to food systems transformation, including scaling up, out, and deep.

- Support research into the territorial domain of agroecological transformation, involving a food systems frame and sociopolitical elements as well as Indigenous foodways frameworks.

- Facilitate longitudinal research on the viability of agroecological transitions over time.

- Support and enable territorial markets and Indigenous foodways as a key strategy for strengthening local and regional food systems.

\section{PRIORITY 3: BUILD CAPACITY FOR TRANSDISCIPLINARY AND PARTICIPATORY RESEARCH AND TRAINING}

Transdisciplinary research combines not only different academic disciplines but also incorporates other ways of knowing, such as farmer, traditional, citizen, and Indigenous knowledges. Participatory action research is a process that involves researchers and other actors as key players in an integrated process of research, reflection, and action for the purpose of social change or the resolution of an identified problem. This approach differs from other research approaches in that it emphasizes the importance and legitimacy of local knowledge and participation in the identification of problems and solutions, and is interactive rather than extractive, involving farmer-scientist teams. Participatory action research can address issues of power, subjectivity, reflexivity, and knowledge that more conventional research approaches do not. The notion of empowering local people through the validation and participatory development of knowledge, as well as through capacity-building and participation in research, are important elements. The Contributors emphasized the importance of this research approach (some referring to it as "knowledge mutualism") that brings together farmers, researchers, policymakers, donors, consumers, and other actors across food systems to leverage food systems transformation. This approach provides contextually relevant evidence and open spaces to discuss and address issues of reciprocity, equality, justice, and power. Implementing this approach can contribute to the democratization and decolonization of research and education systems but will require significant investments to build capacity and advocate for change within universities and research institutes.

EnviroStrat stressed the need for proficient teams with specific and multidimensional skills in agroecology and regenerative approaches, including science and practice, policy, extension, finance, market, and socioeconomic transformation. This is a gap also identified by CCRP, stating that some farmer-research team members possess limited knowledge about experimental design, data-collection tools, and data analysis. At the same time, it was initially difficult for the farmers in the network to find truly participatory-minded researchers who were willing to support them.

For Centro Latinoamericano de Investigaciones Agroecológicas (CELIA), a significant priority — and starting point - is to conduct additional multidisciplinary research, using participatory frameworks involving local actors, and thus address deeply felt needs in food-producer communities. This can open the door for agroecological research to move beyond the farm scale to the territorial scale. Moreover, it considers broader 
forces - such as market and government institutions - that undermine farmers' cultural practices, economic self-sufficiency, and the ecological resource base.

The Contributors offered the following actions to advance Priority 3:

- Reorient research and curriculum development approaches at agricultural research, education, and training programs toward participatory, intercultural, intersectoral, and transdisciplinary approaches and methodologies that include people's knowledge and are rooted in agroecological principles and respectful ways of working.

- Strengthen the capacity of local organizations and groups of farmers and consumer-citizens to carry out their own research and, where appropriate, to identify research needs and engage in the co-construction and co-validation of knowledge and innovations.

- Provide long-term funding to establish and support communities of practice among researchers and practitioners that can enable strengthening of skills, knowledge, and relationships for deeply engaged transdisciplinary research.

- Re-establish agricultural extension, oriented toward horizontal, farmer-to-farmer learning, knowledge sharing, and participatory research methodologies and farmer innovation.

- Adopt and implement research and innovation policies and programs that support decentralized processes of self-managed research.

\section{PRIORITY 4: SUPPORT KNOWLEDGE AND EVIDENCE MOBILIZATION AND COMMUNICATION}

A diversity of evidence that demonstrates the transformative potential of agroecology, regenerative approaches, and Indigenous foodways already exists. The Contributors noted, however, that it is not always available or accessible to the audiences who are asking for evidence, nor in the format that they require. Much of the evidence in support of these approaches reside on farms and in communities across the globe. The mobilization of this grassroots evidence can take many forms depending on who is asking for evidence. For example, farmers are often most convinced when they see another farmer have success. That is why farmer-to-farmer methodologies are such successful mobilization strategies for the scaling out of these approaches. This is what some of the Contributors called "intrinsic evidence mobilization."

This grassroots evidence may not be accessible to other key actors, however, and may require an extrinsic evidence mobilization strategy. Policymakers, funders, and researchers often prefer peer-reviewed meta analyses, which often, but not always, draw from research that uses transdisciplinary and participatory methods. Long-term partnerships between farmers and scientists are important to the process of building the case for transformation. Mobilizing evidence for consumers and civil society in general often requires engaging with local, national, and international media. A mobilization and communication strategy is contextspecific and should be developed by multiple actors so that evidence reaches the right audiences in the most accessible formats and can have the most impact. Implementing diverse strategies for the mobilization of evidence is essential for the scaling and transformation of food systems. Mobilization and communication strategies that couple evidence with ascendant narratives that emphasize the positive social, economic, and ecological impacts of these approaches can be a powerful force for change. 
Below are key action points to help support the amplification and accessibility of knowledge and evidence about agroecology, regenerative approaches, and Indigenous foodways to more diverse audiences.

The Contributors offered the following actions to advance Priority 4:

- Support processes, platforms, and networks that encourage peer-to-peer research and learning alliances and community-based evidence mobilization.

- Provide funding to farmers' organizations to coordinate farmer caravans, seed fairs and exchanges, agroecology schools, and other innovative peer-to-peer exchange to deepen and widen the impact of their work.

- Fund training, development, and implementation of communication strategies that use diverse forms of media (videos, community radio, local news stories, etc.) to make knowledge and evidence accessible to a diversity of audiences.

- Develop and maintain local repositories of knowledge on agroecology, regenerative approaches, and Indigenous foodways and provide support to local organizations for the development and implementation of effective communications and evidence mobilization strategies to stimulate conversations about food systems transformation with key audiences.

\section{PRIORITY 5: ACCELERATE TRANSFORMATIONAL PATHWAYS}

Today we have to conduct very visible experiments to go to scale. We have to prove that what we are doing with a handful of producers can be a lever to move toward changes at the level of the territories. We must demonstrate that agroecology is reliable enough to feed the world, to ensure food and nutrition security. At this level, we lack the funding that allows us to make our experiments more visible and to go to scale.

- ENDA PRONAT

For the Committee on World Food Security (CFS) High Level Panel of Experts, a key question is how to effectively link agroecology and regenerative approaches on the ground, in local communities, to public policies for enhancing food security and nutrition. ${ }^{155}$ Many of the Contributors agreed that governance at all levels plays a critical role in accelerating or hindering agroecological transitions. Several of the Contributors referred to IPES-Food's analysis of structural "lock-ins" that create path dependency on the industrial paradigm. These lock-ins include: short-term thinking, cheap food, export orientation, indebtedness, and false solutions and metrics - all entrenched by corporate power and persistent false narratives. The Contributors noted the need for more case studies, narratives, and evidence on what policies, regulations, and programs are needed to address these structural barriers and systematically unlock the potential for agroecology, regenerative approaches, and Indigenous foodways. IPES-Food proposes virtuous circles of transformation through joined-up policy processes, national and local food policy councils, local procurement of agroecologically produced foods, social solidarity economies, strategic incentives for agroecological transition, system-wide 
metrics to measure sustainability and true costs, and transdisciplinary research. ${ }^{156}$ IPES-Food articulates the need for multiple transition pathways to agroecology and more sustainable food systems.

A strong current in the Contributors' perspectives on how to strengthen and support agroecology and regenerative approaches is what could be described as aspirational agroecology* — that is, an effort to capture the dreams of farmers and communities to change their situation and break out of the current state of farming, and their quest for a different path that brings benefits to them as well as to society. ARC, Agroecology Europe, and others were interested in better understanding how many farmers would like to use more agroecological and regenerative practices, and transition faster toward these farming approaches, if they had access to land, fair prices for their products, and other incentive measures.

How many farmers would choose not to use conventional chemical farming practices, given other alternatives? For ARC, asking this question would allow the larger farming and non-farming community a window for important conversations and help us understand the factors that drive agroecological transitions, such as the role of institutional support, cooperatives, social networks, agricultural extension, and the strength of farmer movements. ${ }^{157}$ Moreover, many less discernible factors influence farming decisions: ENDA Pronat and Lanying Zhang speak of the "immeasurable" value of farming for well-being and joy in the community when farming produces bountiful harvests. FAO TAPE underscores the importance of assessing farmers' level of well-being, including mental health, in a highly unpredictable and stressful farming environment.

When it comes to public support for transition, ARC makes the point that agroecological and regenerative farmers working to relocalize food systems have been very successful in many regions. The large amount of literature (including grey literature, websites, etc.) on farmers' markets, community-supported agriculture, and organic foods provides evidence of the possibility and popularity of this form of consumer support and solidarity with farmers, and grower-eater and rural-urban connections, indicating a flourishing interest in local, healthy, and ecologically grown food. ${ }^{158}$ These transition pathways focus on the importance of territorial markets, regional food systems, and urban-rural connections.

For ARC, broader research is also needed to better understand the regional and international political economy of food, including supply management and supply coordination; to support the calculation and protection of place-based price floors for diverse farmers, fishers, and ranchers; and to prevent overproduction and dumping. This could be situated in a broader analysis of how different countries define, track, and reward outcomes attributable to agroecology, regenerative approaches, and Indigenous foodways and their broader willingness to support a move in that direction at national and territorial levels.

EnviroStrat emphasizes the need for the development of clear transition pathways that are fully supported with training and capacity-building and literacy campaigns in ecological, biological restoration. These strategies should be linked to best practices and policies internationally and nationally (within the context of place) and aligned with international practitioners and resources. Research should be linked to prototyping/

\footnotetext{
*For example, the aspirations of North American farmers and European youth farmers were mentioned by ARC and Agroecology Europe.
} 
experimentation at farm, landscape, and watershed levels through sharing and open-source knowledgebuilding. Developing and implementing harmonized metrics that measure changes and help redefine narratives is an important part of the transformational research agenda. ${ }^{159}$

Many case studies have been produced on the transition to improve or deepen agroecology, regenerative approaches, and Indigenous foodways. Most of the Contributors have themselves been involved in this form of research and agree on the importance of documenting the journeys of agroecological transition — whether for young farmers, large or small farmers, or those farmers who are further into their transition as well as food enterprises and initiatives. In particular, those pathways that have had transformative impacts are critical for learning and to inform theories of change.

Without a focus on political justice, we predict that the agroecological narrative will fall victim to the same take-over and hollowing of sustainability's weak and permeable strategy.

- AGROECOLOGY EUROPE

The Contributors offered the following actions to advance Priority 5:

- Centre agriculture and food policies on a strong foundation of human rights, equity, and women's empowerment in national and international policies and programs. This should include the right to food and collective rights to land and territory, water, seeds, and productive resources. *

- Advocate for, establish, and strengthen participatory and inclusive governance mechanisms at municipal, territorial, national, and international levels that enable the full and effective participation of farmers and food providers in decision-making processes. These include food policy councils at all levels for more inclusive, integrated, and coherent food policies.

- Establish whole-of-government approaches that link agroecological transitions to national climate change, biodiversity, environment, health, poverty, and livelihood targets and strategies. Develop national agroecology strategies integrated and coherent with development goals and targets, as well as sub-national, national, and international commitments to these goals and targets.

- Co-develop incentives and programs with youth to attract new and young farmers to participate in agroecology, regenerative approaches, and Indigenous foodways.

- Redirect subsidies and incentives away from unsustainable practices and toward diversified farms and local, resilient food systems rooted in principles of agroecology, regenerative approaches, and Indigenous foodways.

- Reshape food policies to respond to local needs and opportunities to accelerate transitions through supportive policies and investments in the post-production space: agroecological markets, initiatives to shift demand, subsidies to low-income urban households to afford healthy food, and public procurement for programs such as school meals to incorporate agroecological products.

*In accordance with key international human rights instruments, in particular UNDROP, UNDRIP, and CEDAW. 
- Designate agroecological territories and bioregions at the sub-national level to enhance rural and regional economies and food systems.

- Make financial support available for Indigenous foodways research and programming, including Indigenous-organized and-governed trust funds. Establish clear policies and undertake measures for Indigenous land rematriation and reconciliation.

- Support work across movements and issues (climate, biodiversity, human rights, health, youth, Indigenous and racial justice, etc.) to broaden the political engagement of key constituencies (citizens, policymakers, private-sector actors, and others) toward common transformative agendas.

Agroecology isn't just about techniques. For many, it's about a way of life and vision for the future. It's about democratizing and decolonizing the food system - and the societies we live in as a whole. It's about building power with and alongside Black, Indigenous, and people of colour farmers who've long safeguarded (agro) ecological knowledge and been materially invisibilized and/or dispossessed from farming in North America.

- AGROECOLOGY RESEARCH-ACTION COLLECTIVE (ARC) 
TABLE 2: SUMMARY OF EVIDENCE GAPS IDENTIFIED BY THE CONTRIBUTORS

\section{ENVIRONMENT}

AND RESILIENCE

NUTRITION AND

HUMAN HEALTH
- Synergies between systems of animals, crops, and trees enhanced through agroecological and regenerative approaches, including rotational grazing, agroforestry, and silvopastoral and silvofishery practices.

- Link of animal husbandry and livestock to climate change mitigation and carbon sequestration.

- Increased agricultural biodiversity on-farm, and its contribution to biodiversity conservation and ecosystems functions; breeding for diversity.

- Synergies or trade-offs with other simultaneous transitions (energy, carbon neutrality, mitigation, biodiversity, water).

- Degraded land reclamation and transitioning land to multifunctional and multiproductive uses (plant and/or animal production, timber, etc.) that engender a new vision of productive spaces and agricultural production.

- Managing carbon, nutrient, and water cycles beyond fields and farms.

- Sharing the cultivated landscape to promote diversity and multifunctionality.

- Role of agrobiodiversity; ecosystem functions; approaches to agricultural intensification; tropical agroecosystems (particularly coffee); approaches to pest and weed management; organic agriculture; cropping systems; system transitions, modelling, and design; climate change adaptation; and education.

- Aggregate impacts on food security and nutrition. Nutrition and health outcomes associated with biodiverse, agroecological, regenerative, and Indigenous foodways.

- Connections between diets and malnutrition, obesity, and related non-communicable diseases such as diabetes and hypertension.

- Relationship between agrobiodiversity and nutrition.

- Role of agroecological and regenerative design in the reduction of zoonotic diseases; reductions in antibiotic use.

- Urban agroecology and connections to local food systems, community health, and poverty.

- Connections of agroecology with community engagement, social solidarity, and consumer agency; connections between rural producers and urban consumers.

- Understanding the evidence needs of policymakers to facilitate their support of agroecology, regenerative approaches, and Indigenous foodways and the transition toward more socially just food systems. 
SUMMARY OF EVIDENCE GAPS IDENTIFIED BY THE CONTRIBUTORS

\section{ECONOMIC}

CULTURAL
- The nature of labour and employment in agroecological and regenerative approaches.

- Agroecology and markets (including territorial markets).

- Estimating the true costs - and true value - for the environment, health, and society, and of agroecological and regenerative approaches and production systems.

- Consequences for yields, food availability, quality, and quantity.

- Labour impacts due to mechanization and increasing technology access and approaches.

- Agroecological transition and impacts on food costs.

- Shifts occurring in the locations of production, or reorganization of, national industrial agrifood structures.

- Scalable complexity (for example, with multispecies systems and service crops).

- How traditional, Indigenous knowledge can be strengthened to improve yields in Indigenous foodways. 


\section{CONCLUDING REFLECTIONS}

The Contributors proposed an agenda for research and action that is transdisciplinary, with a focus on political justice, that challenges entrenched power for transformative change. Indeed, many expressed doubts that much will change without a bold political agenda that lifts up the calls to action coming from civil society, social movements, farmers, and Indigenous Peoples' organizations. Agroecology dovetailed with food sovereignty has the power to mobilize intertwined narratives and drive change. In addition, feminist agroecology offers the methodologies and the political platform that are most congruent with agroecology's transformational imperative.

There is significant evidence, and growing consensus, that the industrial food system is failing people, the planet, and the very climatic systems that support life on Earth. The discourse and case studies on evidence mobilization offered here illustrate the argument that industrial agriculture has been able to succeed, to a large extent, because it has created "thick legitimacy" in society. ${ }^{160}$ This thick legitimacy is built on narrow evidence and associated narratives that reveal only part of the picture. Through a diversity of strategies - in policy, science, legal, civic, and practical spaces - the Contributors are building the counter-narratives that expand the legitimacy of agroecology, regenerative approaches, and Indigenous foodways that lies in the confluence of all of these domains.

"The agroecological transition will most likely be chaotic, and certainly not linear," suggests Agroecology Europe. While new evidence, narratives, and epistemological approaches are critical, the growing global efforts to advance agroecology, regenerative approaches, and Indigenous foodways will require political change in this moment of crisis and offer solutions that capture the imagination of a wider concerned public. This involves countering dominant narratives, and strengthening alternative ones, beyond those defined by the forces that shape public discourse. It involves finding the common platforms and the power of stories to overturn prevailing narratives and offering wellreasoned and compelling paths forward that can mobilize public concern to leverage political action.

Further, it involves reawakening the senses and rekindling our relationships with our communities, with nature, and with ourselves. It involves channelling the everyday acts of courage, imagination, ingenuity, and perseverance of farmers, food providers, women, youth, and Indigenous Peoples and turning them into forces for change.

We know from the evidence that it can be done. 


\section{APPENDIX: GUIDING QUESTIONS FOR THE CONTRIBUTORS}

The Contributors shared their perspectives on evidence guided by the following questions:

\section{How do you understand and document evidence?}

- How do you define evidence? What is at the root of the perennial question about whether or not there is evidence in support of agroecology, regenerative approaches, and Indigenous foodways?

- Where do you see documented evidence for these approaches?

- What organizations and communities contribute to your understanding of the knowledge base and evidence, and how?

- What fields of knowledge, approaches, processes, and methodologies do you use or do you think are best suited to produce, collect, document, synthesize, and share the evidence?

- What are the evidence gaps that must be addressed? What is the best approach to address them?

- What has convinced you that these approaches hold solutions to our multiple crises? How could this be more effectively communicated to a broader audience?

\section{What narratives, evidence, audiences are the most important and compelling to you?}

- What narratives supportive of agroecology, regenerative approaches, and/or Indigenous foodways are the most compelling? Why are they compelling? What specific evidence do you use to support these narratives? Address how this may vary depending on the audience.

- What are the common questions/narratives/arguments you encounter against agroecology, regenerative approaches, and/or Indigenous foodways (or in support of industrial production systems)?

- What are the counter-narratives/counter-arguments for each of these?

- What kinds of specific evidence are the most effective in shifting mindsets and shifting the narrative?

- Address how this may vary depending on the audience.

\section{How do you communicate and mobilize evidence?}

- In your experience, who are the audiences that are seeking evidence and why?

- How do you mobilize, communicate, or use evidence? What formats/platforms/channels are the most effective?

- If possible, please share a story or explanation of how you have communicated evidence effectively. 


\section{ENDNOTES}

1 IPES-Food, "From Uniformity to Diversity: A Paradigm Shift From Industrial Agriculture to Diversified Agroecological Systems" (2016). Website.

2 Contributed by CELIA.

3 FAO, "The White/Wiphala Paper on Indigenous Peoples' Food Systems" (Rome: FAO, 2021). Website.

4 Miguel A. Altieri, Agroecology: The Science of Sustainable Agriculture, 2nd ed. (Boulder: Westview Press, 1995).

5 Charles A. Francis et al., "Agroecology: The Ecology of Food Systems," Journal of Sustainable Agriculture 22, no. 3 (2003): $99-118$.

6 Steve Gliessman, "The Framework for Conversion," in Steve Gliessman and Martha E. Rosemeyer (eds.), The Conversion to Sustainable Agriculture: Principles, Processes, and Practices (Boca Raton: CRC Press, 2010): 3-14; and V. Ernesto Méndez et al., Agroecology: A Transdisciplinary, Participatory and Action-oriented Approach, 1st ed. (Boca Raton: CRC Press, 2016).

7 Alexander Wezel et al., "Agroecology as a Science, A Movement and a Practice: A Review," Agronomy for Sustainable Development 29, no. 4 (2009): 503-515; and Francis et al., "Agroecology," 99-118.

8 FAO, "International Symposium on Agroecology for Food Security and Nutrition" (Rome, February 2-3, 2015); IAASTD, Agriculture at the Crossroads: International Assessment of Agricultural Knowledge, Science and Technology for Development: Global Report (Washington: Island Press, 2009); Olivier De Schutter, report submitted by the Special Rapporteur on the Right to Food, UN General Assembly, "Human Rights Council Sixteenth Session, Agenda item 3 A/HRC/16/49" (December 17, 2010).

9 HLPE, "Agroecological and Other Innovative Approaches for Sustainable Agriculture and Food Systems that Enhance Food Security and Nutrition” (Rome, 2019). Website.

10 IPES-Food et al., "A Unifying Framework for Food Systems Transformation" (2021). Website.

11 FAO, "Agroecology Definitions" n.d. Website; and FAO, "The 10 Elements of Agroecology," 2018. Website.

12 FAO, "Sustainable Development Goals" and "Sustainable Agriculture and Rural Development," n.d. Website.

13 Peter Newton et al., "What Is Regenerative Agriculture? A Review of Scholar and Practitioner Definitions Based on Processes and Outcomes," Frontiers in Sustainable Food Systems (2020): 194.

Regenerative Agriculture Initiative (RAI) and The Carbon Underground (TCU), "What Is Regenerative Agriculture?" (2017). Website. Ibid.

Joe Fassier, "Regenerative Agriecuture Needs a Reckoning," The Counter (May 3, 2021). Website.

Samantha Sutton, "The History of Regenerative Agriculture" (reNature, 2021). Website; and Rodale Institute, "7 Tendencies Towards Regeneration" (1983). Website.

Ibid.

IFOAM, "Organic 3.0 for Truly Sustainable Farming and Consumption” (2017). Website.

HLPE, "Agroecological and Other Innovative Approaches for Sustainable Agriculture and Food Systems That Enhance Food Security and Nutrition: A Report." (Rome): Figure 2, 35. Website. IPES-Food, "Unravelling the Food-Health Nexus" (Global Alliance for the Future of Food and IPES Food, 2017). Website. Paper; and IPES-Food, "Too Big to Feed: Exploring the Impacts of Mega-mergers, Consolidation, and Concentration of Power in the Agri-food Sector" (2017). Website.

Contributed by CELIA.

See, for example, Wise, "Failing Africa's Farmers...," 2020; IAASTD, "Agriculture at the Crossroads: International Assessment of Agricultural Knowledge, Science and Technology for Development," n.d. Website; Eric Holt-Gimenez and Miguel A. Altieri, "Agroecology, Food Sovereignty, and the New Green Revolution," Agroecology and Sustainable Food Systems 37, no. 1 (2012): 90-102; Raj Patel, "The Long Green Revolution," Journal of Peasant Studies 40, no. 1 (2013): 1-63; and A. Mkindi et al., "False Promises: The Alliance for a Green Revolution in Africa" (AGRA and INKOTA-netzwerk and Rosa Luxemburg Stiftung, 2020). Website. Contributed by LAC.

Contributed by ARC. 
Contributed by CAWR-ALC.

Francisco J. Rosado-May, "The Intercultural Origin of Agroecology: Contributions from Mexico," in V.E. Méndez et al. (eds.), Agroecology, A Transdisciplinary, Participatory and Action-Oriented Approach (Boca Raton: CRC Press, 2020): 123-138.

Ibid.

Michael Bell et al., "The Productivity of Variability: An Agroecological Hypothesis," in International Journal of Agricultural Sustainability 6, no. 4 (2008): 233-235.

FAO, State of the World's Biodiversity for Food and Agriculture (Rome, 2019). Website; and International Planning Committee for Food Sovereignty, "Peasants Give Life to Biodiversity," March 31, 2016. Website.

Contributed by Agroecology Europe.

Contributed by Agroecology Europe, citing Agence Nationale de Recherche (ANR), "Emérgence de l'agroécologie et perspectives pour le futur: Les programmes ADD Systerra Agrobiosphere," Cahiers de l'ANR nº 08 (2015).

Contributed by ARC and CAWR-ALC.

Contributed by ARC.

Contributed by CAWR-ALC.

Contributed by CAWR-ALC.

Contributed by SFHC.

Erika N. Speelman et al., "Ten Years of Sustainability Evaluation Using the MESMIS Frameworks: Lessons Learned from Its Application in 28 Latin American Case Studies," International Journal of Sustainable Development and World Ecology 14 (2007): 345-361; Clara I. Nicholls and Miguel A. Altieri, “Agroecología y Cambio Climático: Metodologías para evaluar la resiliencia socio-ecológica en comunidades rurales” (CYTED, 2013). Website; Laurent Levard and Bertrand Mathieu, Handbook for the Evaluation of Agroecology: A Method to Evaluate Its Effects and the Conditions for Its Development (Paris: GTAE-AgroParisTech-CIRAD-IRD, 2019).

Contributed by CELIA.

Eric Holt-Gimenez, Campesino a Campesino: Voices from Latin America's Farmer to Farmer Movement for Sustainable Agriculture (Oakland: Food First Books, 2006).

Rucha Chitnis, "Learning Together: The Agroecology Movement Shares Strategies for Impact," Agroecology Fund (2020). Online photo essay.

Contributed by CAWR-ALC.

Contributed by CAWR-ALC and ARC.

Contributed by CCRP.

Contributed by CELIA.

M. Rivera-Ferre, "The Resignification Process of Agroecology: Competing Narratives from Governments, Civil Society and Intergovernmental Organizations," Agroecology and Sustainable Food Systems 42 (6): 666-685.

Contributed by CAWR-ALC.

Contributed by ARC.

Ibid.

Contributed by CAWR-ALC.

Contributed by CAWR-ALC, citing Andy Stirling, "Opening Up and Closing Down Power, Participation, and Pluralism in the Social Appraisal of Technology," Human Values 33, no. 2 (2008): 262-294.

Contributed by CAWR-ALC.

Citations for evidence on farm viability, income, and productivity include: Claire Aubron, L. Noël, and Jacques Lasseur, "Labor as a Driver of Changes in Herd Feeding Patterns: Evidence From a Diachronic Approach in Mediterranean France and Lessons for Agroecology," Ecological Economics 127 (2016): 68-79; Raffele D’Annolfo et al., "A Review of Social and Economic Performance of Agroecology," International Journal of Agricultural Sustainability 15, no. 6 (2017): 632-644; Jan Douwe van der Ploeg et al., "The Economic Potential of Agroecology: Empirical Evidence from Europe," Journal of Rural Studies 71 (2019): 46-61. For crop-protection mobilizing trophic networks and biodiversity: Ivette Perfecto, John Vandermeer, and Stacy M. Philpott, "Complex Ecological Interactions in the Coffee Agroecosystem," Annual Review of Ecology, Evolution, and Systematics 45 (2014): 137-158. For carbon cycle and climate change: R. Munroe et al. "Review of the Evidence Base for Ecosystem-based 
Approaches for Adaptation to Climate Change," Environmental Evidence 1 (2012). For ecosystem services: Sara Palomo-Campesino, José A. González, and Marina Garcia-Llorente, "Exploring the Connections Between Agroecological Practices and Ecosystem Services: A Systematic Literature Review," Sustainability 10, no. 12 (2018): 4339. For food security and nutrition: Rachel Benzer Kerr et al., "Can Agroecology Improve Food Security and Nutrition?: A Review," Global Food Security 29 (2021).

Contributed by Agroecology Europe, citing D’Annolfo et al., "A review of social and economic...," 632-644.

Contributed by SFHC, citing Bezner Kerr et al., "Can Agroecology Improve...?"

Contributed by CELIA.

sobel Tomlinson, "Doubling Food Production to Feed the 9 Billion: A Critical Perspective on a Key Discourse of Food Security in the UK," Journal of Rural Studies 29 (2011): 81-90.

60 A. Sen, Resources, Values, and Development (Cambridge: Harvard University Press, 1997); IAASTD, Agriculture at the Crossroads: International Assessment of Agricultural Knowledge, Science and Technology for Development: Global Report (Washington: Island Press, 2009).

61 Contributed by CAWR-ALC, citing IPES-Food, "Uniformity to Diversity" (2016). Website; Eve Fouilleux, Nicolas Bricas, and Arlène Alpha, "Feeding 9 Billion People: Global Food Security Debates and the Productionist Trap,” Journal of European Public Policy 24, no. 11 (2017): 1658-1677; and Tomlinson, "Doubling Food Production" (2011). Dario Lucantoni et al., "Evidence on the Multidimensional Performance of Agroecology in Mali by using TAPE" (2021).

63 A. Loconto, A. Jiminez, and E. Vandecandelaere, Constructing Markets for Agroecology: An Analysis of Diverse Options for Marketing Products from Agroecology (Rome: FAO and INRA, 2018).

Ponisio et al., "Diversification Practices Reduce Organic to Conventional Yield Gap," Proceedings of the Royal Society B: Biological Sciences 282, no. 1799 (2015); and John P. Reganold and Jonathan M. Watcher, "Organic Agriculture in the Twenty-First Century," Nature Plants 2 (2016). Catherine Badgley et al., "Organic Agriculture and the Global Food Supply," Cambridge University Press 22, no. 2 (2007): 86-108. Adrian Muller et al., "Strategies for Feeding the World More Sustainably with Organic Agriculture," Nature Communications 8 (2017). Benzer Kerr et al., "Can Agroecology Improve...," 100540.

Contributed by Groundswell International.

Contributed by APCNF and ARC.

Hannah Wittman, Dana James, and Zia Mehrabi, “Advancing Food Sovereignty Through Farmer-Driven Digital Agroecology," Ciencia e investigación agraria: Revista Latinoamericana de ciencias de la agricultura 47, no. 3 (2020): 235-248.

71 Michael P. Pimbert and Nina Isabella Moeller, "Absent Agroecology Aid: On UK Agricultural Development Assistance Since 2010," Sustainability 10, no. 2 (2018): 505; CIDSE, Finance for Agroecology: More Than Just a Dream? (2020). Website; Biovision Foundation for Ecological Development and IPES-Food, "Money Flows: What Is Holding Back Investment in Agroecological Research for Africa?", Biovision Foundation for Ecological Development and International Panel of Experts on Sustainable Food Systems (2020). Website; Margot Vermeylen and Olivier De Schutter, "The Share of Agroecology in Belgian Official Development Assistance: An Opportunity Missed” (2020). Website; and Marcia. S. DeLonge, Albie Miles, and Liz Carlisle, "Investing in the Transition to Sustainable Agriculture," Environmental Science and Policy 55, no. 1 (2016): 266-273.

CIDSE, Finance for Agroecology: More Than Just a Dream?

Sidney Madsen et al., "Explaining the Impact of Agroecology on Farm-Level Transitions to Food Security in Malawi," Food Security 13 (2021): 933-954.

V.M. Toledo et al. "Uso multiple y biodiversidad entre los mayas yucatecos." Interciencia (Mexico), 33(5): 345-352.

S. Jeeva, R.C. Laloo and B.P. Mishra, "Traditional Agricultural Practices in Meghalaya, Northeast India," Indian Journal of Traditional Knowledge 5(1): 7-18; K. Upadhaya et al., "Traditional Bun Shifting Cultivation Practice in Meghalaya, Northeast India," Energy, Ecology and Environment 5: 34-46; and S.S. Rathore, K. Karunakaran, and B. Prakash, "Alder-based Farming System: A Traditional Farming Practice in Nagaland for Amelioration of Jhum Land," Indian Journal of Traditional Knowledge 9(4): 677-680.

76 F.J. Rosado-May et al., "Innovation as Key Feature of Indigenous Ways of Learning: Individuals and Communities Generating Knowledge," in N. Suad Nasiret al. (eds.), Handbook of the Cultural Foundations of Learning (New York: Routledge): 79-95.

77 Clara I. Nicholls and Miguel A. Altieri, "Pathways for the Amplification of Agroecology," Agroecology and Sustainable Food Systems 42 , no. 10 (2018): 1170-1193; Mateo Mier y Terán Giménez Cacho et al., "Bringing Agroecology to Scale: Key Drivers and Emblematic Cases," Agroecology and Sustainable Food Systems 42, no. 6 (2018): 637-665; Steven Brescia, Fertile Ground: Scaling Agroecology from the Ground Up (Oakland: Food First Books, 2017); Stéphane Parmentier, "Scaling-up Agroecological Approaches: What, Why and How?," Oxfam Solidarité. Website; Miguel A. Altieri and Clara I. Nicholls, "Agroecology Scaling Up for Food Sovereignty and Resiliency," in E. Lichtfouse (ed.), Sustainable Agriculture Reviews (Springer, Dordrecht, 2012): 1-29. 

"Bringing Agroecology to Scale," 637-665; Steven Brescia, Fertile Ground (2017); Stéphane Parmentier, "Scaling-up Agroecological Approaches," Website; Miguel A. Altieri and Clara I. Nicholls, "Agroecology Scaling Up for Food Sovereignty and Resiliency," 1-29.

Pablo Tittonel et al., "Agroecology in Large Scale Farming: A Research Agenda," Frontiers in Sustainable Food Systems (2020).

IPES-Food, "From Uniformity to Diversity," 2016.

Contributed by CELIA.

FAO, "Tool for Agroecology Performance Evaluation (TAPE)." Website.

FAO, "Tool for Agroecology Performance Evaluation (TAPE)." Website.

Mier y Terán Giménez Cacho et al. "Bringing Agroecology to Scale: Key Drivers and Emblematic Cases," Agroecology and Sustainable Food Systems 42(6): 637-665; and M. Fernandez et al. "New Opportunities, New Challenges: Harnessing Cuba's Advances in Agroecology and Sustainable Agriculture in the Context of Changing Relations with the United States," Elementa: Science of the Anthropocene 6 (2018).

P.M. Rosset et al. "The Campesino-to-Campesino Agroecology Movement of ANAP in Cuba: Social Process Methodology in the Construction of Sustainable Peasant Agriculture and Food Sovereignty," Journal of Peasant Studies 38(1): 161-191; and Clara I. Nicholls and Miguel A. Altieri. "Pathways for the Amplification of Agroecology," Agroecology and Sustainable Food Systems 42(10): 1-24.

N. Companioni, R. Rodríguez-Nodals, and J. Sardiñas, "Capítulo 14: Agricultura urbana, suburbana y familiar," in F. Funes Aguiar and L.V. Vázquez Moreno (eds.), Avances de la Agroecología en Cuba. Matanzas, Cuba: Estación Experimental de Pastos y Forrajes Indio Hatue (Mexico: San Cristóbal, 2016), 233-246.

L. Vazquez, Tansformación Agroecologica Hacia la Sostenibilidad Alimentaria (RedAr, Cuba, 2010).

Contributed by SFHC.

Contributed by CAWR-ALC.

Lucas A. Garibaldi and Néstor Pérez-Méndez, "Positive Outcomes Between Crop Diversity and Agricultural Employment Worldwide," Ecological Economics 164, no. C (2019).

Contributed by SFHC, citing Bezner Kerr et al. (2019); Madsen et al. (2021); Joseph Kangmennaang et al., "Impact of a Participatory Agroecological Development Project on Household Wealth and Food Security in Malawi," Food Security 9, no. 3 (2017): 561-576; Marianne V. Santoso et al., "A Nutrition-Sensitive Agroecology Intervention in Rural Tanzania Increases Children's Dietary Diversity and Household Food Security But Does Not Change Child Anthropometry: Results from a Cluster-Randomized Trial," Journal of Nutrition 151, no. 7 (2021): 2010-2021; and Garibaldi and Pérez-Méndez, "Positive Outcomes Between," 2019.

Contributed by IRR-China and EnviroStrat.

Contributed by Groundswell International.

Jennifer Blesh and Steven Wolf, "Transitions to Agroecological Farming Systems in the Mississippi River Basin: Toward an Integrated SocioEcological Analysis," Agriculture and Human Values 31, no. 4 (2014): 621-635.

Contributed by Mad Agriculture.

J.D. van der Ploeg et al., "The Economic Potential of Agroecology: Empirical Evidence from Europe," Journal of Rural Studies 71: 46-61.

Contributed by ENDA Pronat.

Comités de investigación agrícola local (local agricultural research committees).

Contributed by Groundswell. Also see their video, “Urban Agroecology," YouTube (January 8, 2016).

Contributed by Agroecology Europe: Agroecology Initiatives in European Countries: Key Findings and Recommendations (Brussels, 2020). Website.

03 See Alliance for Food Sovereignty in Africa, "Shaping the Future of Food Markets in Africa: What Kind of Markets Do We Need for the Transition to Agroecology?” AFSA Food Systems Conference Report (October 2020).

104 Ibid.

J.D. van der Ploeg et al., "The Economic Potential of Agroecology," 46-61.

6 Contributed by Agroecology Europe, citing van der Ploeg et al., "The Economic Potential..." (2019): 46-61.

Contributed by FAO-TAPE, citing FAO's TAPE research in Mali: Lucantoni et al., "Evidence on the Multidimensional," (2021). 
108 Contributed by CAWR-ALC, citing research from IPES-Food, "From Uniformity to Diversity" (2016); and E. van Walsum et al., "Unlocking the Potential of Family Farmers with Agroecology," Deep Roots (FAO and Tudor Rose, 2014).

109 Mali Nyéléni, “Declaration of the International Forum for Agroecology," Development 58, 163-168 (2015).

110 Contributed by CAWR-ALC, citing A.A. Desmarais, "The Power of Peasants: Reflections on the Meanings of La Vía Campesina," Journal of Rural Studies 24 (2): 138-149; and P.M. Rosset and M.E. Martinez-Torres, "Rural Social Movements and Agroecology: Context, Theory, and Process," Ecology and Society 17 (3).

111 Contributed by TIP.

112 Ibid.

113 Ashish Kothari, Federico Demaria, and Alberto Acosta, "Buen Vivir, Degrowth and Ecological Swaraj: Alternatives to Sustainable Development and the Green Economy," Development 57, no. 3-4 (2015): 362-375.

114 Ella Houzer and Ian Scoones, Are Livestock Always Bad for the Planet? Rethinking the Protein Transition and Climate Change Debate (Brighton: PASTRES, 2021).

115 Daniel Kpienbaareh et al., "Spatial and Ecological Farmer Knowledge and Decision-Making about Ecosystem Services and Biodiversity," Land 9, no. 10 (2020): 356.

116 Contributed by APCNF.

117 Miguel A. Altieri et al., "Agroecology and the Design of Climate Change Resilient Farming Systems," Agronomy for Sustainable Development 35 , no. 3 (2015): 869-890.

118 Clara I. Nicholls and Miguel A. Altieri, Agroecología y cambio climático: Metodología para evaluar la resilencia socio-ecológica en comunidades rurales (Lima: Redagres, 2013).

119 Sieglinde Snapp et al., Agroecology and Climate Change Rapid Evidence Review: Performance of Agroecological Approaches In Low-and Middle-Income Countries (Wageningen: CGIAR Research Program on Climate Change, Agriculture and Food Security, 2021).

120 Ibid., 8 .

121 Contributed by SFHC, citing Hanson Nyantakyi-Frimpong, "Agricultural Diversification and Dietary Diversity: A Feminist Political Ecology of the Everyday Experiences of Landless and Smallholder Households in Northern Ghana," Geoforum 86 (2017): 63-75; Laura V. Rasmussen et al., "Social-ecological Outcomes of Agricultural Intensification," Nature Sustainability 1, no. 6 (2018): 275-282.

122 Contributed by SFHC, citing research published by Daniel Kpienbaareh et al., "Livelihoods, Deforestation and the Challenge of Forest Restoration in Smallholder Contexts: Insights From Northern Malawi"(forthcoming).

123 Contributed by PHSL; see also their website.

124 Contributed by SFHC and Groundswell International.

125 Contributed by SFHC, citing Cäcilia von Arb et al., "Soil Quality and Phosphorus Status After Nine Years of Organic and Conventional Farming at Two Input Levels in the Central Highlands of Kenya," Geoderma 362 (2020); Wanjiku Kamau et al., "Soil Fertility and Biodiversity on Organic and Conventional Smallholder Farms in Kenya," Applied Soil Ecology 134 (2019): 85-97; Ludovic Temple and Hubert de Bon, "L'agriculture biologique: Controverses et enjeux globaux de développement en Afrique," Cahiers Agricultures 29, no. 3 (2020).

126 Contributed by CAWR-ALC.

127 Contributed by CAWR-ALC.

128 Contributed by CAWR-ALC.

129 Jessica Hutchings et al., "Enhancing Māori Agribusiness Through Kaitiakitanga Tools," (2017).

130 Contributed by EnviroStrat.

131 Contributed by APCNF, SFHC, and ENDA Pronat.

132 Jessica Milgroom, "Linking Food and Feminisims: Learning from Decolonial Movements," Agroecology in Motion (March 7, 2021). Website. On feminist agroecology, see Farming Matters: Agroecology and Feminism 36, no. 1 (CIDSE: October 7, 2020).

133 Contributed by CAWR-ALC, citing HLPE, Agroecological and Other Innovative Approaches for Sustainable Agriculture and Food Systems That Enhance Food Security and Nutrition, (Rome: HLPE, 2019); IPES-Food, Towards a Common Food Policy for the European Union (IPES-Food panel, February 2019); and Claire Lamine, Danièle Magda, and Marie-Josèphe Amiot, "Crossing Sociological, Ecological, and Nutritional Perspectives on Agrifood Systems Transitions: Towards a Transdisciplinary Territorial Approach,” Sustainability 11, no. 5 (2019).

134 Nyéléni, "Declaration of the International Forum for Agroecology," 163-168. 
135 M.P. Pimbert, "Democratizing Knowledge and Ways of Knowing for Food Sovereignty, Agroecology and Biocultural Diversity," in M.P. Pimbert (ed.), Food Sovereignty, Agroecology and Biocultural Diversity (London: Routledge): 259-321

136 Contributed by FAO-TAPE, ARC, Agroecology Europe, and CAWR-ALC.

137 Contributed by CAWR-ALC.

138 Contributed by CELIA and Agroecology Europe.

139 Michael Pollan, "The Sickness in Our Food Supply," The New York Review, June 11, 2020. See also, for example, WBCSD, "Vital Supply Chains." Website.

140 Contributed by CELIA.

141 Contributed by APCNF.

142 Contributed by Groundswell International.

143 Contributed by SFHC.

144 Tom Wakeford, "Citizens Juries: A Radical Alternative for Social Research," Social Research Update (37), 37.

145 Contributed by ARC.

146 K. Davis et al. "Impact of Farmer Field Schools on Agricultural Productivity and Poverty in East Africa," World Development 40 (2): $402-413$.

147 Contributed by AgroEcology Fund.

148 Contributed by Groundswell International.

149 Contributed by CCRP.

150 Intergovernmental Panel on Climate Change, Climate Change 2021: The Physical Science Basis: Contribution of Working Group I to the Sixth Assessment Report of the Intergovernmental Panel on Climate Change (London: Cambridge University Press, forthcoming).

151 Contributed by Agroecology Europe, citing T. Caquet, C. Gascuel, and M. Tixier-Boichard, Agroecology: Research for the Transitions of Agri Food Systems and Territories (Versailles: Quae Ed., 2020).

152 Contributed by ARC.

153 Colin Anderson et al., "From Transition to Domains of Transformation: Getting to Sustainable and Just Food Systems through Agroecology," Sustainability 11, no. 19 (2019); and Alexander Wezel et al., "Agroecology Territories: Places for Sustainable Agricultural and Food Systems and Biodiversity Conservation," Agroecology and Sustainable Food Systems 40, no. 2 (2016): 132-144.

154 Brescia, "Fertile Ground," 2016; Mateo Mier y Terán Giménez Cacho et al., "Bringing Agroecology to Scale” (2108): $637-665$.

155 HLPE, Food Security and Nutrition: Building a Global Narrative Towards 2030 (Rome: High Level Panel of Experts on Food Security and Nutrition of the Committee on World Food Security, 2020): 48.

156 IPES-Food, "From Uniformity to Diversity" (2016).

157 Contributed by ARC.

158 Contributed by ARC.

159 Contributed by EnviroStrat.

160 Montenegro de Wit and Iles, "Toward Thick Legitimacy: Creating a Web of Legitimacy for Agroecology," Elementa: Science of the Anthropocene 4. 


\section{ACKNOWLEDGEMENTS}

We are grateful to the numerous individuals and organizations who provided their time and expertise in the planning and development of this work. The Global Alliance's Agroecology Impact Area Committee must be acknowledged for its leadership and vision. Agroecology Impact Area members include representatives from the following foundations: 11 th Hour Project, Agropolis Fondation, David and Lucile Packard Foundation, Fondation Daniel et Nina Carasso, IKEA Foundation, McKnight Foundation, Porticus Foundation, Sall Family Foundation, Thread Fund, Tudor Trust, W.K. Kellogg Foundation. This work was generously funded by the Ikea Foundation.

The creation of this compendium was led by Faris Ahmed, Lauren Baker, Margarita Fernandez, Samara Brock, and Amanda Jekums and is a synthesis of the contributions from organizations and authors listed on page 1. We are deeply thankful to the Contributing teams for their commitment to this project and for their everyday work to advance sustainable agricultural practices. The Global Alliance remains responsible for the content of this compendium and any errors or omissions.

We extend deep gratitude to the Global Alliance secretariat: Ruth Richardson, Executive Director; Lauren Baker, Senior Director of Programs; Kasia Murphy, Director of Communications; Amanda Jekums, Program Coordinator.

Commissioned by the Global Alliance for the Future of Food. 


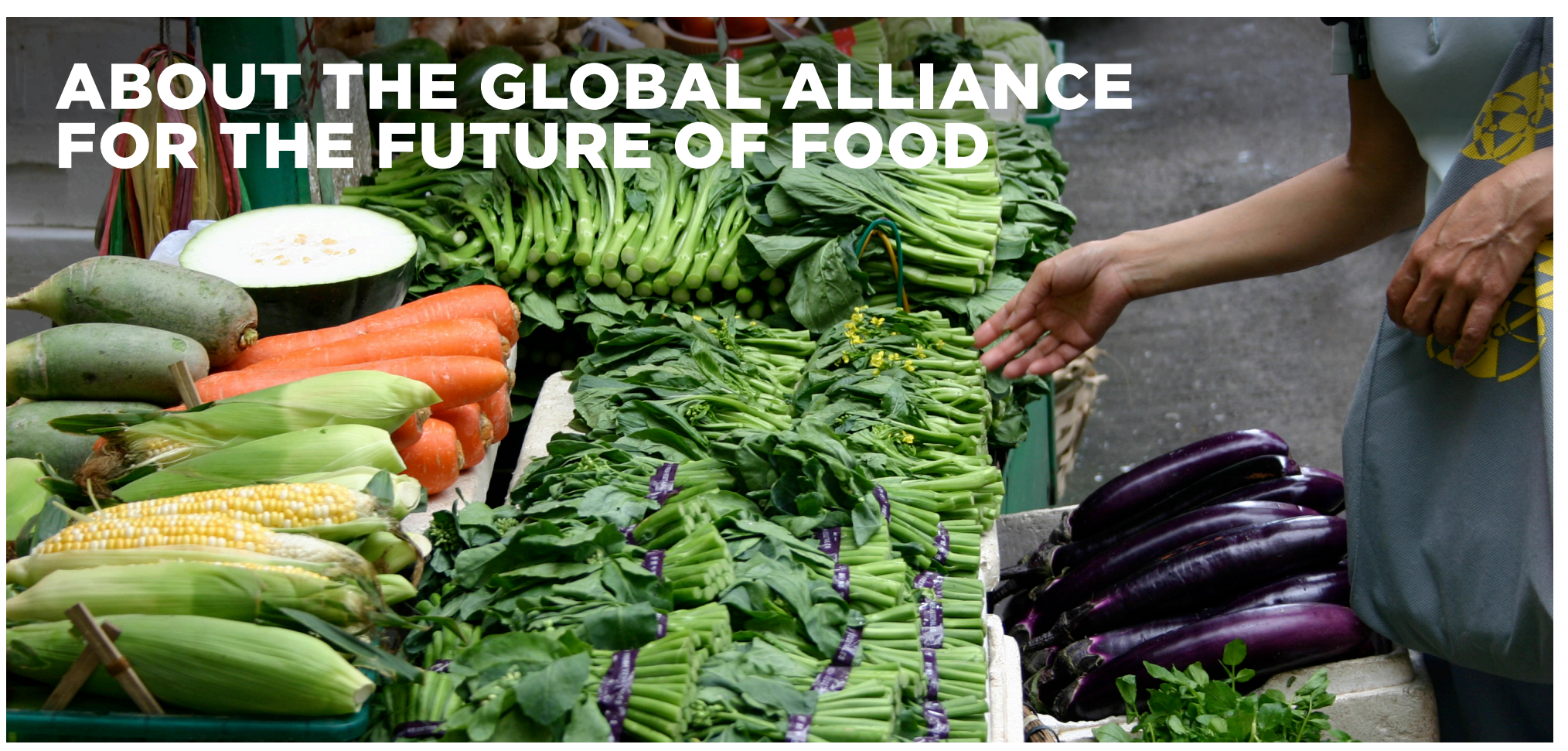

The Global Alliance is a strategic alliance of philanthropic foundations working together and with others to transform global food systems now and for future generations. We believe in the urgency of transforming global food systems and in the power of partnership to effect positive change. Food systems transformation requires new and better solutions at all scales through a systems-level approach and deep collaboration among philanthropy, researchers, grassroots movements, the private sector, farmers and food systems workers, Indigenous Peoples, government, and policymakers.

www.futureoffood.org 


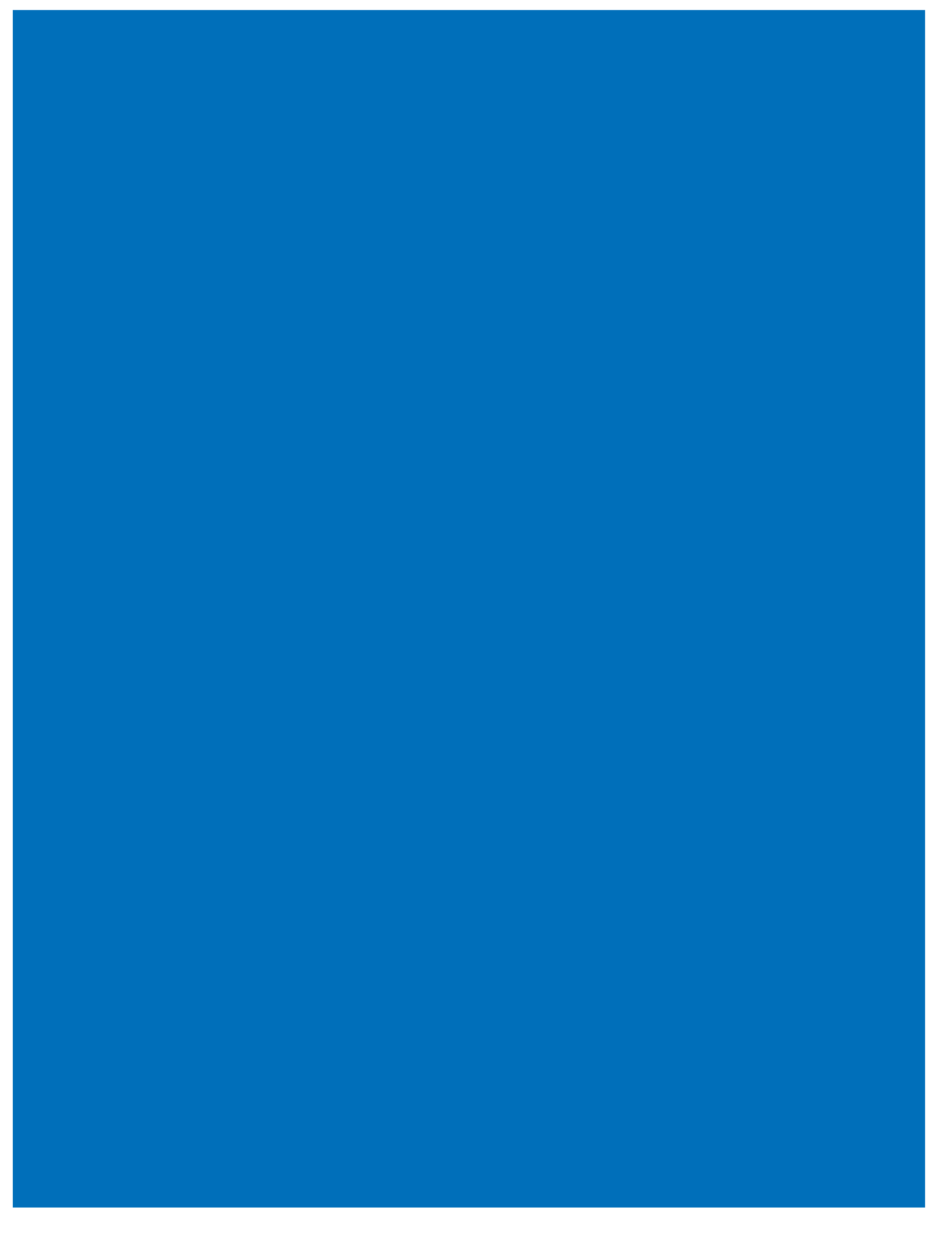

